Supporting information

\title{
Biocatalytic Synthesis of Non-Natural Monoterpene $O$-Glycosides Exhibiting Superior Antibacterial and Antinematodal Properties
}

Puspalata Bashyal ${ }^{\dagger, \|}$, Ramesh Prasad Pandey $y^{\dagger \neq}, \|$, Samir Bahadur Thapa ${ }^{\dagger}$, Min-Kyoung Kang ${ }^{\S}$, Chang-Jin Kim ${ }^{\S}$, Jae Kyung Sohng*,†,

${ }^{\dagger}$ Department of Life Science and Biochemical Engineering, and * Department of Pharmaceutical Engineering and Biotechnology, Sun Moon University, 70 Sunmoon-ro 221, Tangjeong-myeon, Asan-si, Chungnam 31460, Republic of Korea

$\S$ Industrial Biomaterials Research Center Korea Research Institute of Bioscience and Biotechnology 125 Gwahak-ro, Yuseong-gu, Daejon 34141, Korea

*Corresponding author:

Prof. Jae Kyung Sohng

Tel: $+82(41) 530-2246$

Fax: +82(41)544-2919

Email: sohng@,sunmoon.ac.kr 


\section{Table of Contents}

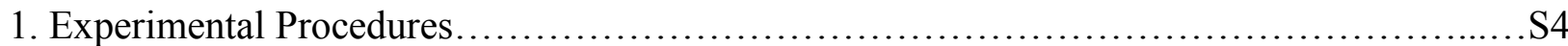

1.1 Chemicals and Reagents

1.2 Plasmids, bacterial strains, and culture conditions

1.3 Protein expression and purification

1.4 Antibacterial activity assay

1.4.1 Disc-diffusion assay

1.4.2 Minimum inhibitory concentration determination

1.4.3 Anti-nematodal activity assay

Results

S8

\section{Supplementary Tables}

Table S1. HPLC-PDA retention time, UV-VIS maxima, chemical formula, calculated and observed mass of 1-7, $\mathbf{1}_{\mathrm{a}-\mathrm{g}} \mathbf{-} \mathbf{7}_{\mathrm{a}-\mathrm{g}}$.

Table S2. Anomeric coupling constants of glucosylated products.

Table S3. Preparative-scale monoterpene $O$-glucoside derivatives with whole cells harboring YjiC.

Table S4. Gram-positive and Gram-negative pathogens used for anti-bacterial activity assays.

Table S5. Bacterial pathogens accessed for their anti-bacterial assay in disc diffusion assay.

Supplementary figures

Figure S1. Chromatographic and spectrometric analysis of eugenol (1) glucosylation reaction.

Figure S2. Chromatographic and spectrometric analysis of thymol (2) glucosylation reaction.

Figure S3. Chromatographic and spectrometric analysis of isoeugenol (3) glucosylation reaction.

Figure S4. Chromatographic and spectrometric analysis of carvacrol (4) glucosylation reaction.

Figure S5. Chromatographic and spectrometric analysis of $\alpha$-terpineol (5) glucosylation reaction.

Figure S6. Spectrometric analysis of $(+)$ menthol (6) glucosylation reaction.

Figure S7. Spectrometric analysis of (-) borneol (7) glucosylation reaction.

Figure S8. Chromatographic analysis of purified glucoside derivatives.

NMR data

Figure S9. ${ }^{1} \mathrm{H}-\mathrm{NMR}$ and ${ }^{13} \mathrm{C}-\mathrm{NMR}$ of $\mathbf{1}$ and $\mathbf{1 a}$.

Figure S10. ${ }^{1} \mathrm{H}-\mathrm{NMR}$ and ${ }^{13} \mathrm{C}-\mathrm{NMR}$ of $\mathbf{2}$ and $\mathbf{2 a}$.

Figure S11. ${ }^{1} \mathrm{H}-\mathrm{NMR}$ and ${ }^{13} \mathrm{C}-\mathrm{NMR}$ of $\mathbf{3}$ and $\mathbf{3 a}$.

Figure S12. ${ }^{1} \mathrm{H}-\mathrm{NMR}$ and ${ }^{13} \mathrm{C}-\mathrm{NMR}$ of $\mathbf{4}$ and $\mathbf{4 a}$.

Figure S13. ${ }^{1} \mathrm{H}-\mathrm{NMR}$ and ${ }^{13} \mathrm{C}-\mathrm{NMR}$ of $\mathbf{5}$ and $\mathbf{5 a}$.

Figure S14. ${ }^{1} \mathrm{H}-\mathrm{NMR}$ and ${ }^{13} \mathrm{C}-\mathrm{NMR}$ of 6 and $\mathbf{6 a}$. 
Figure S15. ${ }^{1} \mathrm{H}-\mathrm{NMR}$ and ${ }^{13} \mathrm{C}-\mathrm{NMR}$ of 7 and $\mathbf{7 a}$.

Figure S16. Chromatographic and spectrometric analysis of glycosylation reaction of $\mathbf{1}$ with different NDP-sugars.

Figure S17. Chromatographic and spectrometric analysis of glycosylation reaction of 2 with different NDP-sugars.

Figure S18. Chromatographic and spectrometric analysis of glycosylation reaction of 3 with different NDP-sugars.

Figure S19. Chromatographic and spectrometric analysis of glycosylation reaction of 4 with different NDP-sugars.

Figure S20. Chromatographic and spectrometric analysis of glycosylation reaction of 5 with different NDP-sugars.

Figure S21. Spectrometric analysis of glycosylation reaction of 6 with different NDP-sugars.

Figure S22. Spectrometric analysis of glycosylation reaction of 7 with different NDP-sugars.

Figure S23. Co-solvent assay

Figure S24. Stability of YjiC in reaction condition

Figure S25. In vivo conversion percentage of monoterpenes into respective glucosides using whole cells of $E$. coli BL21 (DE3) harboring pET28-YjiC at different time interval.

Figure S26. HPLC-PDA (A-E) and HPLC-ELSD (F-G) analysis of cell lysate extracts of in vivo biotransformed cells.

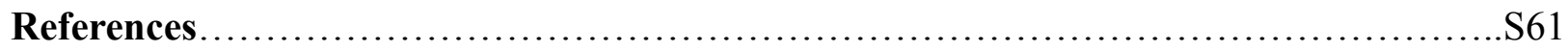




\section{Experimental Procedures}

\subsection{Chemicals and Reagents}

UDP- $\alpha$-D-glucose, UDP- $\alpha$-D-galactose, UDP- $\alpha$-D-glucuronic acid, UDP- $\alpha$-D- $N$-acetyl glucosamine, and UDP- $\alpha-\mathrm{D}-N$-acetyl galactosamine, deuterium oxide $\left(\mathrm{D}_{2} \mathrm{O}\right)$, and DMSO- $d_{6}$ were purchased from Sigma-Aldrich (St. Louis, MO, USA). Nucleotide diphosphates (ADP, TDP, GDP, CDP, and UDP), TDP-L-rhamnose, GDP-L-fucose, and isopropyl- $\beta$-D-thiogalactopyranoside (IPTG) were purchased from GeneChem (Daejeon, Korea). $p$-Nitrophenyl- $\beta$-D-galactoside, $p$ nitrophenyl- $\beta$-D-xyloside, $\alpha$-terpineol, carvacrol, eugenol, isoeugenol, thymol, $(+)$ menthol, and (-) borneol were purchased from Tokyo Chemical Industry Co., Ltd (Japan). HPLC-grade acetonitrile and water were purchased from Mallinckrodt Baker (Phillipsburg, NJ, USA). All other chemicals used were of analytical grade.

\subsection{Plasmids, bacterial strains, and culture conditions}

pET28a-YjiC constructed previously was used. ${ }^{1}$ Escherichia coli BL21(DE3) (Stratagene, USA) was used for the production of enzyme. E. coli strains were grown in Luria-Bertani (LB) broth, supplemented with kanamycin $(50 \mu \mathrm{g} / \mathrm{mL})$.

\subsection{Protein expression and purification}

pET28a-YjiC plasmid was confirmed by restriction enzyme digestion and was transformed to $E$. coli BL21(DE3) using the heat shock transformation method. A colony was picked and transferred to a LB-agar plate containing kanamycin antibiotic. From this culture, $5 \mathrm{~mL}$ of E. coli BL21 (DE3) containing pET28a-YjiC was prepared and kept for growing overnight in shaking incubator at $37^{\circ} \mathrm{C}$. This recombinant strain was cultivated in $1 \mathrm{~L}$ shake flask containing $200 \mathrm{~mL}$ of LB-broth medium with $50 \mu \mathrm{g} / \mathrm{mL}$ of kanamycin and was incubated at $37^{\circ} \mathrm{C}$ until the optical density at 600 
$\mathrm{nm}$ reached $0.5-0.6$. Then the culture was induced by $0.5 \mathrm{mM}$ of IPTG and growth was continued at $20^{\circ} \mathrm{C}$ for $20 \mathrm{~h}$. The cells were harvested by centrifugation at $3000 \mathrm{rpm}(842 \mathrm{xg})$ maintained at $4^{\circ} \mathrm{C}$. The cells were resuspended in $20 \mathrm{~mL}$ of sterile $100 \mathrm{mM}$ tris- $\mathrm{HCl}(\mathrm{pH} 8.0)$ buffer containing $10 \%$ glycerol. The cells were washed twice following the same protocol. Finally, the cells were again resuspended with $1 \mathrm{~mL}$ of the same buffer and lysed by sonication Sonosmasher (Ultrasonic, Inc.) in ice bath. The lysate was centrifuged at $12000 \mathrm{rpm}(13,475 \mathrm{x} \mathrm{g})$ for $30 \mathrm{~min}$ at $4^{\circ} \mathrm{C}$. Soluble and insoluble portion of the sample was separated.

The soluble fraction of the protein was mixed with the Ni-NTA resin (GE, USA) and protein was purified according to the manufactures instruction. The resin bound protein was eluted with the elution buffer containing $100 \mathrm{mM}$ tris- $\mathrm{HCl}(\mathrm{pH} 8.0), 10 \%$ glycerol, $0.5 \mathrm{M} \mathrm{NaCl}$ and different concentrations of imidazole $(10 \mathrm{mM}, 50 \mathrm{mM}, 100 \mathrm{mM}, 150 \mathrm{mM}, 200 \mathrm{mM}, 250 \mathrm{mM})$. Each fraction of the eluted protein was checked by $12 \%$ sodium dodecyl sulfate-polyacrylamide gel electrophoresis (12\% SDS-PAGE) and was confirmed on (100-250 mM) concentration of elution buffer. The fraction containing pure fraction of protein was then collected and concentrated using Amicon Ultra-15 (Millipore, 30 K NMWL centrifugal filters). The purified protein was then stored in buffer containing $100 \mathrm{mM}$ Tris $-\mathrm{HCl}(\mathrm{pH} 8.0)$ with $20 \%(\mathrm{v} / \mathrm{v})$ glycerol until use at $-20^{\circ} \mathrm{C}$. The protein concentration was determined by the Bradford assay using TaKaRa Bradford protein assay kit (Takara, Japan).

\subsection{Antibacterial activity assay}

\subsubsection{Disc-diffusion assay}

To determine antibacterial activity of monoterpene alcohols and their $O$-glucoside derivatives, disc diffusion assay was used for preliminary assay. Disc-diffusion assay was performed using fourteen different Gram-positive and Gram-negative superbugs (Table S4). The Gram-positive pathogens 
include nine different Staphylococcus aureus with either methicillin resistant (MRSA) or methicillin susceptible (MSSA) isolates and Kocuria rhizophila. Gram-negative pathogens used in this study are Proteus hauseri, Klebsilla pneumoniae, Salmonella enterica and Escherichia coli. The paper disc diffusion assay was performed on Muller-Hinton agar (MHA). Inoculum of each pathogen containing $10^{7}$ colony forming units $(\mathrm{CFU}) / \mathrm{mL}$ were spread onto MHA plates. Four microliter of $500 \mathrm{mM}$ of each compound (standard (1-7) and their glucoside derivatives (1a-7a)) was placed on the surface of the pathogen overlaid MHA plate through sterile filter paper discs. The plates were then incubated at $37^{\circ} \mathrm{C}$ plate incubator. The plates were monitored continuously to check zone of inhibition. Once the zone of inhibition was visible, the diameter was measured using ruler.

\subsubsection{Minimum inhibitory concentration determination}

MIC of standard and its glycosylated derivatives were determined using 96-well plate against sixteen different Gram-positive as well as Gram-negative human pathogens. Standard protocol for MIC determination was followed. ${ }^{2}$ The pathogens were incubated for growth at $37^{\circ} \mathrm{C}$ in $\mathrm{LB}$ broth until the O.D.600 reached to 0.6. By diluting with Muller Hinton broth all the bacteria inoculum were prepared to the size of $10^{4}$ to $10^{5} \mathrm{CFU} / \mathrm{mL}$. Desired test compounds (1-7 and 1a-7a) solutions were prepared by dissolving in DMSO and was diluted two times in Muller Hinton broth. For this, $100 \mu \mathrm{L}$ of Muller Hinton broth was dispensed into all wells of the microtiter plate. $100 \mu \mathrm{L}$ of $2 \mathrm{x}$ concentration of each compound was added into the wells of column 1 and was mixed properly. $100 \mu \mathrm{L}$ of mixture from column 1 was added to column 2 . Again after mixing properly in column 2, then was transferred to column 3 and procedure was continued up to column $10.100 \mu \mathrm{L}$ was discarded from the last column 10. $5 \mu \mathrm{L}$ of required bacteria inoculum was mixed into wells in columns 1 to 11 . Plates were incubated at $37^{\circ} \mathrm{C}$ for 12 hours. Reading of results was observed 
using Multiskan spectrum. Only Muller Hilton broth broth was kept as control.

\subsubsection{Anti-nematodal activity assay}

The anti-nematodal activity of monoterpene alcohols and their respective $O$-glucoside derivatives were performed against pine wood nematode Bursaphelenchus xylophilus. Approximately 25-30 B. xylophilus were placed in each 96-well plates and treated with each compound dissolved in DMSO at final concentration of $40 \mu \mathrm{g} / \mathrm{mL}$ to $0.078 \mu \mathrm{g} / \mathrm{mL}$. The treated B. xylophilus were incubated at $25^{\circ} \mathrm{C}$ for $24 \mathrm{~h}$. The following day total number of live and dead B. xylophilus were counted under microscope to determine anti-nematodal activity of each compound. The experiments were carried out in triplicate. The dead nematodes were calculated using following formula:

Dead nematodes $(\%)=($ Dead nematodes $/$ Total nematodes $) \times 100$

$\mathrm{IC}_{50}$ values represent the lowest concentration of compound at which $50 \%$ of nematodes were dead. 


\section{Results}

Table S1. HPLC-PDA retention time, UV-VIS maxima, chemical formula, calculated and observed mass of 1-7, 1 a-g-7a-g. N.D.: Not detected; *: unable to determine.

\begin{tabular}{|c|c|c|c|c|c|}
\hline Compounds & $\begin{array}{c}\text { Retention time } \\
\text { (min) }\end{array}$ & $\begin{array}{c}\text { UV max } \\
(\mathbf{n m})\end{array}$ & Observed mass (Da) & $\begin{array}{c}\text { Calculated mass } \\
\text { (Da) }\end{array}$ & $\begin{array}{c}\text { Chemical } \\
\text { formula }\end{array}$ \\
\hline 1 & 14.8 & 281 & 165.0914 & 165.0915 & $\mathrm{C}_{10} \mathrm{H}_{13} \mathrm{O}_{2}$ \\
\hline $1 \mathrm{a}$ & 10.3 & 276 & 349.1270 & 349.1263 & $\mathrm{C}_{16} \mathrm{H}_{22} \mathrm{NaO}_{7}$ \\
\hline $1 \mathrm{~b}$ & 9.8 & 280 & 390.1518 & 390.1529 & $\mathrm{C}_{18} \mathrm{H}_{25} \mathrm{NNaO}_{7}$ \\
\hline $1 \mathrm{c}$ & 12.09 & 276 & 333.1299 & 333.1314 & $\mathrm{C}_{16} \mathrm{H}_{22} \mathrm{NaO}_{6}$ \\
\hline 1d & 11.9 & 277 & 333.1308 & 333.1314 & $\mathrm{C}_{16} \mathrm{H}_{22} \mathrm{NaO}_{6}$ \\
\hline $1 \mathrm{e}$ & 10.3 & 277 & 349.1268 & 349.1263 & $\mathrm{C}_{16} \mathrm{H}_{22} \mathrm{NaO}_{7}$ \\
\hline 1f & 9.8 & 276 & 363.1050 & 363.1056 & $\mathrm{C}_{16} \mathrm{H}_{20} \mathrm{NaO}_{8}$ \\
\hline $1 \mathrm{~g}$ & 10.4 & 276 & 390.1525 & 390.1529 & $\mathrm{C}_{18} \mathrm{H}_{25} \mathrm{NNaO}_{7}$ \\
\hline 2 & 16.9 & 276 & 151.1121 & 151.1122 & $\mathrm{C}_{10} \mathrm{H}_{15} \mathrm{O}$ \\
\hline $2 a$ & 11.615 & 271 & 335.1464 & 335.1471 & $\mathrm{C}_{16} \mathrm{H}_{24} \mathrm{NaO}_{6}$ \\
\hline $2 b$ & N.D & - & - & - & - \\
\hline $2 c$ & 13.559 & 272 & 319.1513 & 319.1521 & $\mathrm{C}_{16} \mathrm{H}_{24} \mathrm{NaO}_{5}$ \\
\hline 2d & 10.008 & 272 & 319.1506 & 319.1521 & $\mathrm{C}_{16} \mathrm{H}_{24} \mathrm{NaO}_{5}$ \\
\hline $2 \mathrm{e}$ & 11.404 & 271 & 335.1464 & 335.1471 & $\mathrm{C}_{16} \mathrm{H}_{24} \mathrm{NaO}_{6}$ \\
\hline $2 f$ & 11.9 & 271 & 349.1246 & 349.1263 & $\mathrm{C}_{16} \mathrm{H}_{22} \mathrm{NaO}_{7}$ \\
\hline $2 \mathrm{~g}$ & 11.5 & 271 & 376.1726 & 376.1736 & $\mathrm{C}_{18} \mathrm{H}_{27} \mathrm{NNaO}_{6}$ \\
\hline 3 & 15.19 & 255 & 165.0913 & 165.0915 & $\mathrm{C}_{10} \mathrm{H}_{13} \mathrm{O}_{2}$ \\
\hline $3 \mathbf{a}$ & 10.64 & 259 & 349.1264 & 349.1263 & $\mathrm{C}_{16} \mathrm{H}_{22} \mathrm{NaO}_{7}$ \\
\hline $3 \mathbf{b}$ & N.D & - & - & - & - \\
\hline $3 \mathrm{c}$ & 12.2 & 256 & 333.1302 & 333.1314 & $\mathrm{C}_{16} \mathrm{H}_{22} \mathrm{NaO}_{6}$ \\
\hline 3d & 12.1 & 256 & 333.1296 & 333.1314 & $\mathrm{C}_{16} \mathrm{H}_{22} \mathrm{NaO}_{6}$ \\
\hline $3 \mathbf{e}$ & 10.5 & 256 & 349.1255 & 349.1263 & $\mathrm{C}_{16} \mathrm{H}_{22} \mathrm{NaO}_{7}$ \\
\hline $3 f$ & 11.00 & 255 & 363.1056 & 363.1056 & $\mathrm{C}_{16} \mathrm{H}_{20} \mathrm{NaO}_{8}$ \\
\hline $3 g$ & 11.6 & 255 & 390.1518 & 390.1529 & $\mathrm{C}_{18} \mathrm{H}_{25} \mathrm{NNaO}_{7}$ \\
\hline 4 & 16.5 & 275 & 151.1123 & 151.1122 & $\mathrm{C}_{10} \mathrm{H}_{15} \mathrm{O}$ \\
\hline $4 \mathbf{a}$ & 11.57 & 270 & 335.1471 & 335.1471 & $\mathrm{C}_{16} \mathrm{H}_{24} \mathrm{NaO}_{6}$ \\
\hline $4 \mathrm{~b}$ & N.D & - & - & - & - \\
\hline $4 c$ & 13.5 & 271 & 319.1495 & 319.1521 & $\mathrm{C}_{16} \mathrm{H}_{24} \mathrm{NaO}_{5}$ \\
\hline 4d & 13.2 & 271 & 319.1490 & 319.1521 & $\mathrm{C}_{16} \mathrm{H}_{24} \mathrm{NaO}_{5}$ \\
\hline $4 e$ & 11.3 & 270 & 335.1465 & 335.1471 & $\mathrm{C}_{16} \mathrm{H}_{24} \mathrm{NaO}_{6}$ \\
\hline $4 f$ & 11.8 & 277 & 349.1252 & 349.1263 & $\mathrm{C}_{16} \mathrm{H}_{22} \mathrm{NaO}_{7}$ \\
\hline $4 \mathrm{~g}$ & 11.3 & 270 & 376.1728 & 376.1736 & $\mathrm{C}_{18} \mathrm{H}_{27} \mathrm{NNaO}_{6}$ \\
\hline 5 & 15.8 & 201 & 155.1432 & 155.1435 & $\mathrm{C}_{10} \mathrm{H}_{19} \mathrm{O}$ \\
\hline $5 \mathbf{5 a}$ & 11.25 & 200 & 339.1783 & 339.1784 & $\mathrm{C}_{16} \mathrm{H}_{28} \mathrm{NaO}_{6}$ \\
\hline $5 \mathbf{b}$ & N.D & - & - & - & - \\
\hline $5 \mathrm{c}$ & 9.6 & 199 & 323.0639 & 323.1834 & $\mathrm{C}_{16} \mathrm{H}_{28} \mathrm{NaO}_{5}$ \\
\hline $5 d$ & 13.6 & 199 & 323.1816 & 323.1834 & $\mathrm{C}_{16} \mathrm{H}_{28} \mathrm{NaO}_{5}$ \\
\hline $5 e$ & 11.1 & 199 & 339.1776 & 339.1784 & $\mathrm{C}_{16} \mathrm{H}_{28} \mathrm{NaO}_{6}$ \\
\hline $5 f$ & N.D & - & - & - & - \\
\hline $5 \mathrm{~g}$ & N.D & - & - & - & - \\
\hline 6 & $*$ & $*$ & 157.1589 & 157.1592 & $\mathrm{C}_{10} \mathrm{H}_{21} \mathrm{O}$ \\
\hline $6 a$ & 12.2 & $*$ & 341.1931 & 341.1940 & $\mathrm{C}_{16} \mathrm{H}_{30} \mathrm{NaO}_{6}$ \\
\hline $6 \mathbf{b}$ & 9.6 & * & 382.2307 & 382.2206 & $\mathrm{C}_{18} \mathrm{H}_{33} \mathrm{NNaO}_{6}$ \\
\hline $6 c$ & 14.9 & $*$ & 325.1974 & 325.1990 & $\mathrm{C}_{16} \mathrm{H}_{30} \mathrm{NaO}_{5}$ \\
\hline 6d & 9.6 & $*$ & 325.2012 & 325.1991 & $\mathrm{C}_{16} \mathrm{H}_{30} \mathrm{NaO}_{5}$ \\
\hline $6 e$ & 12.1 & $*$ & 341.1937 & 341.1940 & $\mathrm{C}_{16} \mathrm{H}_{30} \mathrm{NaO}_{6}$ \\
\hline $6 f$ & N.D & - & - & - & - \\
\hline $6 g$ & 11.8 & * & 382.2236 & 382.2206 & $\mathrm{C}_{18} \mathrm{H}_{33} \mathrm{NNaO}_{6}$ \\
\hline 7 & $*$ & $*$ & 155.1422 & 155.1435 & $\mathrm{C}_{10} \mathrm{H}_{19} \mathrm{O}$ \\
\hline $7 \mathbf{a}$ & 11.6 & $*$ & 339.1770 & 339.1784 & $\mathrm{C}_{16} \mathrm{H}_{28} \mathrm{NaO}_{6}$ \\
\hline $7 b$ & N.D & - & - & - & - \\
\hline $7 \mathrm{c}$ & 9.6 & $*$ & 323.1841 & 323.1834 & $\mathrm{C}_{16} \mathrm{H}_{28} \mathrm{NaO}_{5}$ \\
\hline $7 d$ & 9.6 & * & 323.1872 & 323.1834 & $\mathrm{C}_{16} \mathrm{H}_{28} \mathrm{NaO}_{5}$ \\
\hline $7 e$ & 11.5 & $*$ & 339.1839 & 339.1784 & $\mathrm{C}_{16} \mathrm{H}_{28} \mathrm{NaO}_{6}$ \\
\hline $7 f$ & 5.4 & $*$ & 338.2318 & 338.1341 & $\mathrm{C}_{15} \mathrm{H}_{23} \mathrm{NaO}_{7}$ \\
\hline $7 g$ & 11.2 & * & 380.2043 & 380.2049 & $\mathrm{C}_{18} \mathrm{H}_{31} \mathrm{NNaO}_{6}$ \\
\hline
\end{tabular}


Table S2. Anomeric coupling constants of glucosylated products.

\begin{tabular}{|c|c|c|}
\hline $\begin{array}{c}\text { Glucosylated } \\
\text { Products }\end{array}$ & $\begin{array}{c}\text { Chemical shift } \\
\text { (ppm) }\end{array}$ & $\begin{array}{c}\text { Anomeric Coupling } \\
\text { Constants }\end{array}$ \\
\hline 1a & 4.84 & $d, J=7.3 \mathrm{~Hz}$ \\
\hline $\mathbf{2 a}$ & 4.75 & $d, J=7.6 \mathrm{~Hz}$ \\
\hline $\mathbf{3 a}$ & 4.87 & $d, J=7.3 \mathrm{~Hz}$ \\
\hline $\mathbf{4 a}$ & 4.77 & $d, J=7.70 \mathrm{~Hz}$ \\
\hline $\mathbf{5 a}$ & 4.28 & $d, J=7.71 \mathrm{~Hz}$ \\
\hline $\mathbf{6 a}$ & 4.14 & $d, J=7.69 \mathrm{~Hz}$ \\
\hline $\mathbf{7 a}$ & 4.07 & $d, J=7.75 \mathrm{~Hz}$ \\
\hline
\end{tabular}


Table S3. Preparative-scale monoterpene $O$-glucoside derivatives with whole cells harboring YjiC.

\begin{tabular}{|c|c|l|}
\hline $\begin{array}{c}\text { Starting } \\
\text { substrate }\end{array}$ & $\begin{array}{c}\text { Glucoside } \\
\text { Product }\end{array}$ & Yield \% \\
\hline $\mathbf{1}$ & 1a & 93.3 \\
\hline $\mathbf{2}$ & $\mathbf{2 a}$ & 47.6 \\
\hline $\mathbf{3}$ & $\mathbf{3 a}$ & 91.3 \\
\hline $\mathbf{4}$ & $\mathbf{4 a}$ & 51.5 \\
\hline $\mathbf{5}$ & $\mathbf{5 a}$ & 75.4 \\
\hline $\mathbf{6}$ & $\mathbf{6 a}$ & 68 \\
\hline $\mathbf{7}$ & $\mathbf{7 a}$ & 43 \\
\hline
\end{tabular}


Table S4. Gram-positive and Gram-negative pathogens used for anti-bacterial activity assays.

\section{Gram-positive Strains}

Staphylococcus aureus 3640 (MRSA)

Staphylococcus aureus CCARM 3089 (MRSA)

Staphylococcus aureus 33591 (MRSA)

Staphylococcus aureus CCARM 0205 (MSSA)

Staphylococcus aureus CCARM 0204 (MSSA)

Staphylococcus aureus CCARM 0027 (MSSA)

Staphylococcus aureus CCARM 3090 (MRSA)

Staphylococcus aureus CCARM 3634 (MRSA)

Staphylococcus aureus CCARM 3635 (MRSA)

Enterococcus faecalis 19433

Bacillus subtillis ATCC 6633

Kocuria rhizophila NBRC 12708

Gram-negative Strains

Salmonella enterica ATCC 14028

Proteus hauseri NBRC 3851

Escherichia coli ATCC 25922

Klebsiella pneumoniae ATCC 10031 
Table S5. Bacterial pathogens accessed for their anti-bacterial assay in disc diffusion assay.

\begin{tabular}{|c|c|c|c|c|c|c|c|c|c|c|c|c|c|c|}
\hline \multirow{2}{*}{ Strains } & \multicolumn{14}{|c|}{ Zone of Inhibition (mm) } \\
\hline & 1 & $\mathbf{1 a}$ & 2 & $2 \mathbf{a}$ & 3 & $3 \mathbf{a}$ & 4 & $4 \mathbf{a}$ & 5 & $5 \mathbf{a}$ & 6 & $\mathbf{6 a}$ & 7 & $7 \mathbf{a}$ \\
\hline S. aureus CCARM 3640 (MRSA) & $8 \pm 0.2$ & $*$ & $11 \pm 0.3$ & $9 \pm 0.45$ & $10 \pm 0.30$ & $8 \pm 0.2$ & $19 \pm 0.3$ & $*$ & $8 \pm 0.2$ & * & $7.5 \pm 0.11$ & $8 \pm 0.11$ & * & $9 \pm 0.13$ \\
\hline S. aureus CCARM 3089 (MRSA) & $8 \pm 0.12$ & $*$ & $19 \pm 0.35$ & $8 \pm 0.21$ & $15 \pm 0.11$ & $10 \pm 0.14$ & $20 \pm 0.26$ & $8 \pm 0.17$ & $8 \pm 0.11$ & $8 \pm 0.21$ & $7.5 \pm 0.2$ & $20 \pm 0.21$ & $*$ & $14 \pm 0.3$ \\
\hline S. aureus ATCC 33591 (MRSA) & $9 \pm 0.10$ & $*$ & $18 \pm 0.2$ & $8 \pm 0.1$ & $9 \pm 0.14$ & $9 \pm 0.21$ & $21 \pm 0.12$ & $8 \pm 0.16$ & $*$ & $*$ & $8 \pm 0.35$ & $9 \pm 0.25$ & $*$ & $9 \pm 0.14$ \\
\hline S. aureus CCARM 0205 (MSSA) & $9 \pm 0.2$ & $*$ & $14 \pm 0.12$ & $8 \pm 0.11$ & $10 \pm 0.22$ & $17 \pm 0.13$ & $16 \pm 0.3$ & $8 \pm 0.2$ & $*$ & $12 \pm 0.3$ & $9 \pm 0.17$ & $8 \pm 0.17$ & * & $8 \pm 0.21$ \\
\hline S. aureus CCARM 0204 (MSSA) & $8 \pm 0.1$ & $*$ & $15 \pm 0.25$ & $9 \pm 0.18$ & $10 \pm 0.17$ & $16 \pm 0.25$ & $12 \pm 0.13$ & $8 \pm 0.22$ & $8 \pm 0.3$ & $12 \pm 0.16$ & $8 \pm 0.16$ & $18 \pm 0.3$ & * & $13 \pm 0.22$ \\
\hline S. aureus CCARM 0027 (MSSA) & $8 \pm 0.3$ & $*$ & $19 \pm 0.21$ & $8 \pm 0.26$ & $12 \pm 0.32$ & $10 \pm 0.15$ & $18 \pm 0.2$ & $*$ & * & $8 \pm 0.18$ & * & $8 \pm 0.16$ & * & $8 \pm 0.14$ \\
\hline S. aureus CCARM 3090 (MRSA) & * & $*$ & $12 \pm 0.15$ & $*$ & $10 \pm 0.22$ & $10 \pm 0.14$ & $12 \pm 0.16$ & $8 \pm 0.18$ & $*$ & $8 \pm 0.25$ & $8 \pm 0.2$ & $13 \pm 0.16$ & * & $8 \pm 0.15$ \\
\hline S. aureus CCARM 3634 (MRSA) & $*$ & $*$ & $12 \pm 0.2$ & $8 \pm 0.16$ & $*$ & $10 \pm 0.35$ & $9 \pm 0.25$ & $8 \pm 0.3$ & * & $8 \pm 0.14$ & $8 \pm 0.24$ & $13 \pm 0.2$ & * & $8 \pm 0.25$ \\
\hline S. aureus CCARM 3635 (MRSA) & * & * & $17 \pm 0.15$ & $8 \pm 0.2$ & $9 \pm 0.3$ & * & $21 \pm 0.28$ & $8 \pm 0.21$ & * & $8 \pm 0.3$ & $8 \pm 0.3$ & $20 \pm 0.11$ & * & $8 \pm 0.20$ \\
\hline Enterococcus faecalis 19433 & NT & NT & NT & NT & NT & NT & NT & NT & NT & NT & NT & NT & NT & NT \\
\hline Bacillus subtilis ATCC 6633 & NT & NT & NT & NT & $14 \pm 0.22$ & $8 \pm 0.2$ & NT & NT & NT & NT & NT & NT & NT & NT \\
\hline Kocuria rhizophila NBRC 12708 & $*$ & $*$ & $10 \pm 0.11$ & $8 \pm 0.3$ & $11 \pm 0.1$ & $10 \pm 0.2$ & $10 \pm 0.3$ & $*$ & $*$ & $8 \pm 0.1$ & $*$ & $15 \pm 0.15$ & * & $8 \pm 0.19$ \\
\hline Salmonella enterica ATCC 14028 & N.D & * & $19 \pm 0.25$ & $8 \pm 0.14$ & $10 \pm 0.2$ & $8 \pm 0.3$ & * & * & $*$ & * & $10 \pm 0.22$ & $19 \pm 0.11$ & $8 \pm 0.22$ & $15 \pm 0.1$ \\
\hline Proteus hauseri NBRC 3851 & $9 \pm 0.11$ & $*$ & $15 \pm 0.35$ & $15 \pm 0.11$ & $11 \pm 0.1$ & $16 \pm 0.18$ & $22 \pm 0.2$ & $15 \pm 0.22$ & $8 \pm 0.16$ & $9 \pm 0.17$ & $*$ & $9 \pm 0.13$ & $10 \pm 0.11$ & * \\
\hline E. coli ATCC 25922 & $8 \pm 0.2$ & * & $13 \pm 0.3$ & * & $10 \pm 0.2$ & $*$ & $18 \pm 0.11$ & $8 \pm 0.21$ & $*$ & $8 \pm 0.15$ & $10 \pm 0.18$ & $*$ & $*$ & $8 \pm 0.22$ \\
\hline $\begin{array}{l}\text { Klebsiella pneumoniae ATCC } \\
10031\end{array}$ & $*$ & $*$ & $20 \pm 0.1$ & $10 \pm 0.2$ & $15 \pm 0.22$ & $15 \pm 0.35$ & $19 \pm 0.25$ & $10 \pm 0.31$ & $8 \pm 0.11$ & $8 \pm 0.22$ & $9 \pm 0.16$ & $8 \pm 0.1$ & * & $8 \pm 0.16$ \\
\hline
\end{tabular}

Asterisk $\left(^{*}\right)$ indicates no activity and NT means not tested. 

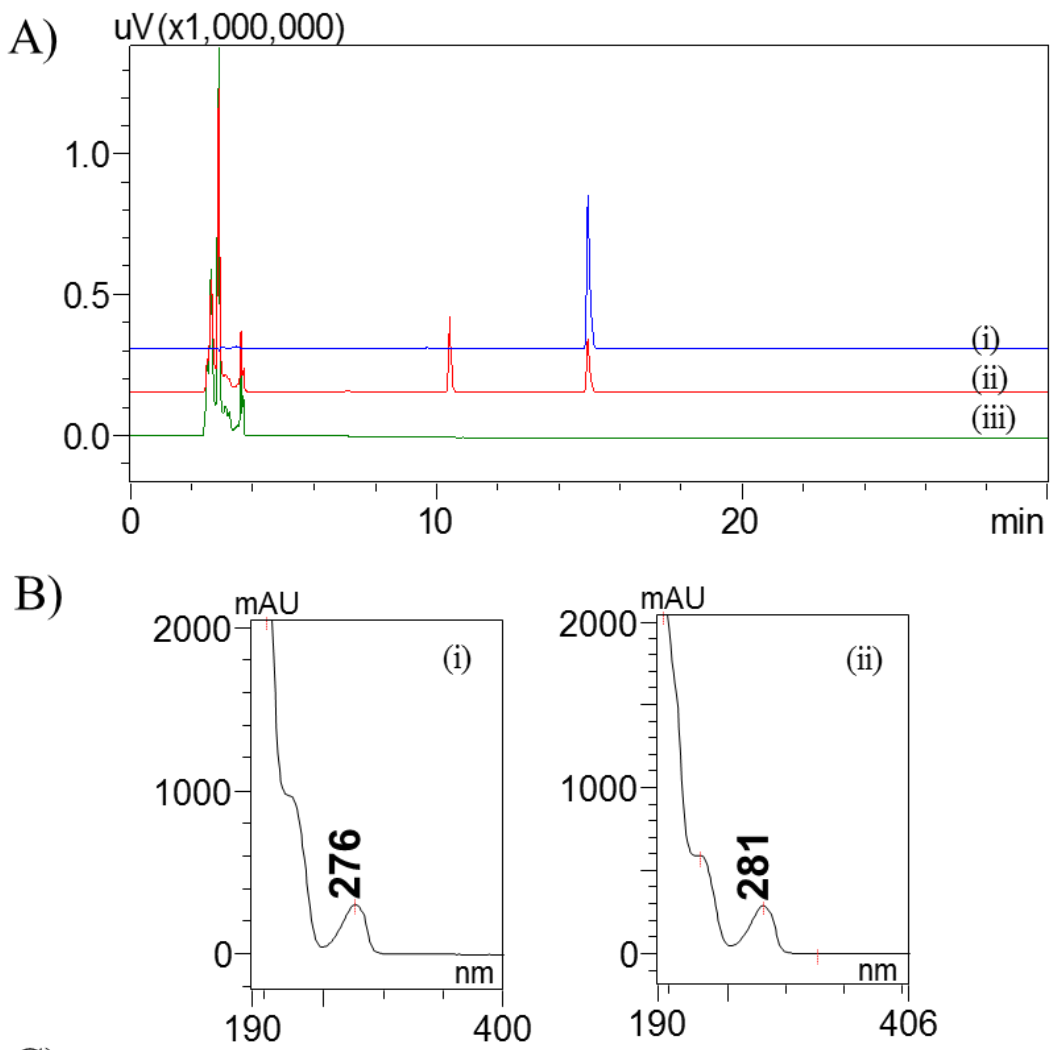

C)
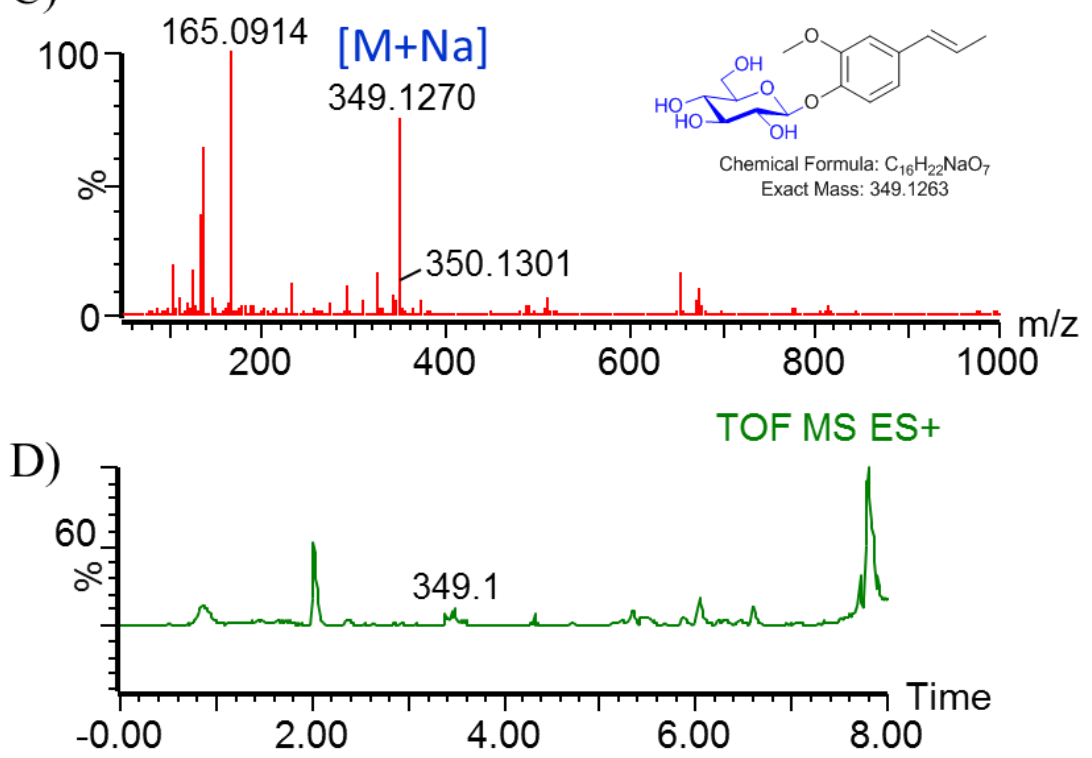

Figure S1. Chromatographic and spectrometric analysis of eugenol (1) glucosylation reaction. A) HPLC-PDA analysis. i) Standard 1, ii) Reaction mixture 1 with UDP-Glc, iii) Control reaction without 1. B) UV-VIS of i) Product and ii) Standard 1. C) HR-QTOF-ESI/MS of product exhibiting exact observed mass of $349.1270 \mathrm{Da}$ for calculated formula $\mathrm{C}_{16} \mathrm{H}_{22} \mathrm{NaO}_{7}$ for which calculated exact mass was $[\mathrm{M}+\mathrm{Na}]^{+} 349.1263$ Da. D) HR-QTOF-ESI/MS total ion chromatogram showing exact mass of glucosylated 1. 


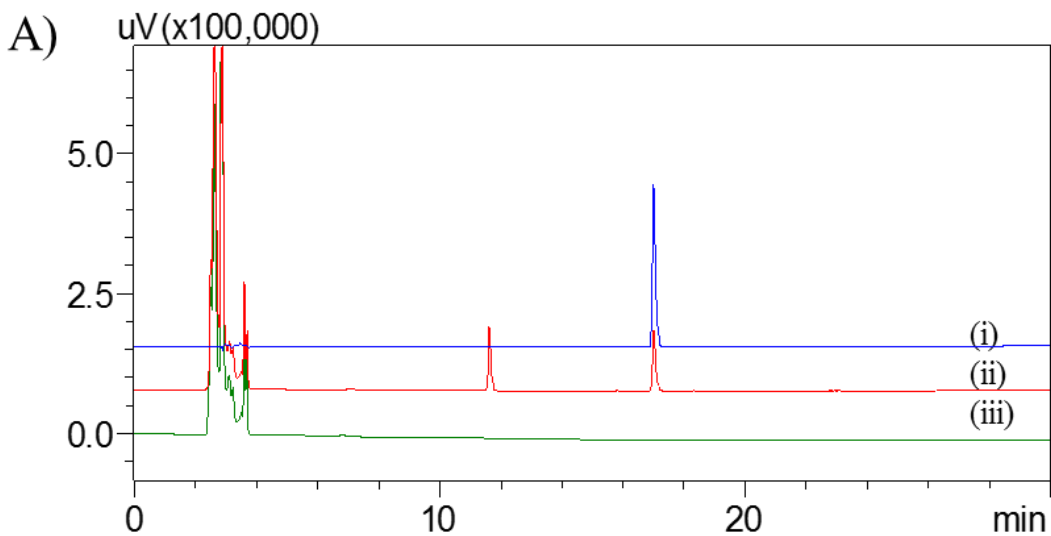

B)
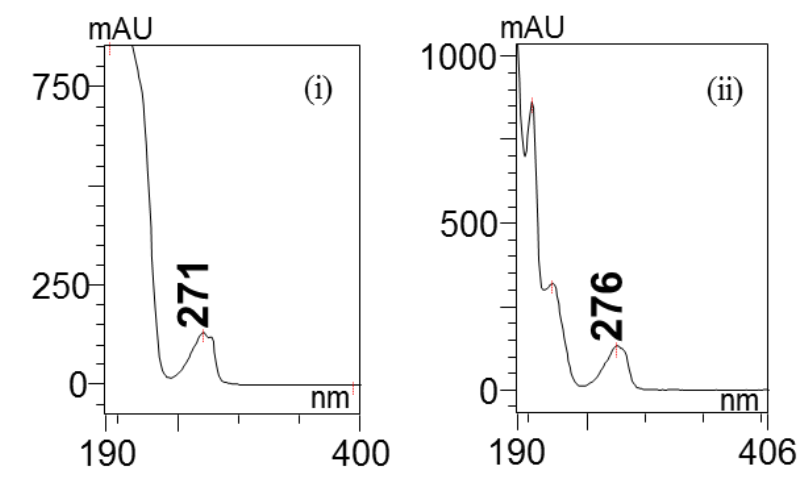

C)

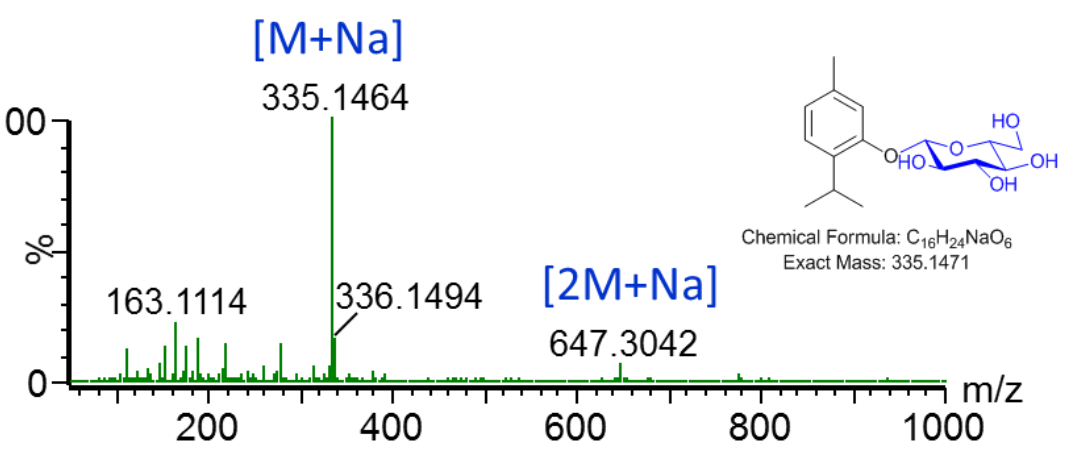

D)

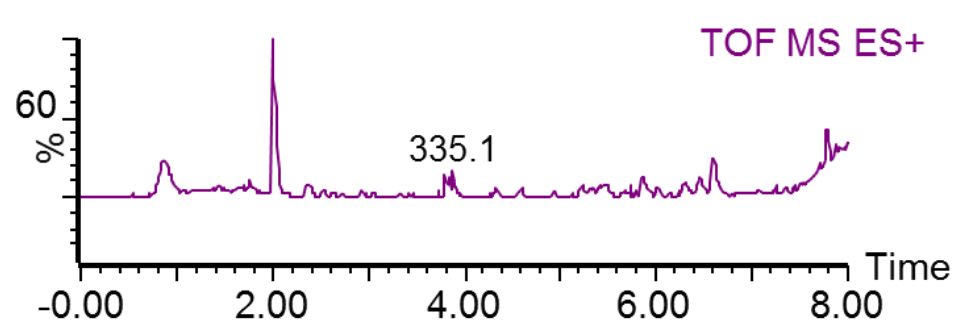

Figure S2. Chromatographic and spectrometric analysis of thymol (2) glucosylation reaction. A) HPLC-PDA analysis. i) Standard 2, ii) Reaction mixture of 2 with UDP-Glc, iii) Control reaction without 2. B) UV-VIS of i) Product and ii) Standard 2. C) HR-QTOF-ESI/MS of product exhibiting exact observed mass of $335.1464 \mathrm{Da}$ for calculated formula $\mathrm{C}_{16} \mathrm{H}_{24} \mathrm{NaO}_{6}$ for which calculated exact mass was $[\mathrm{M}+\mathrm{Na}]^{+} 335.1471 \mathrm{Da}$. D) HR-QTOF-ESI/MS total ion chromatogram showing exact mass of glucosylated $\mathbf{2}$. 


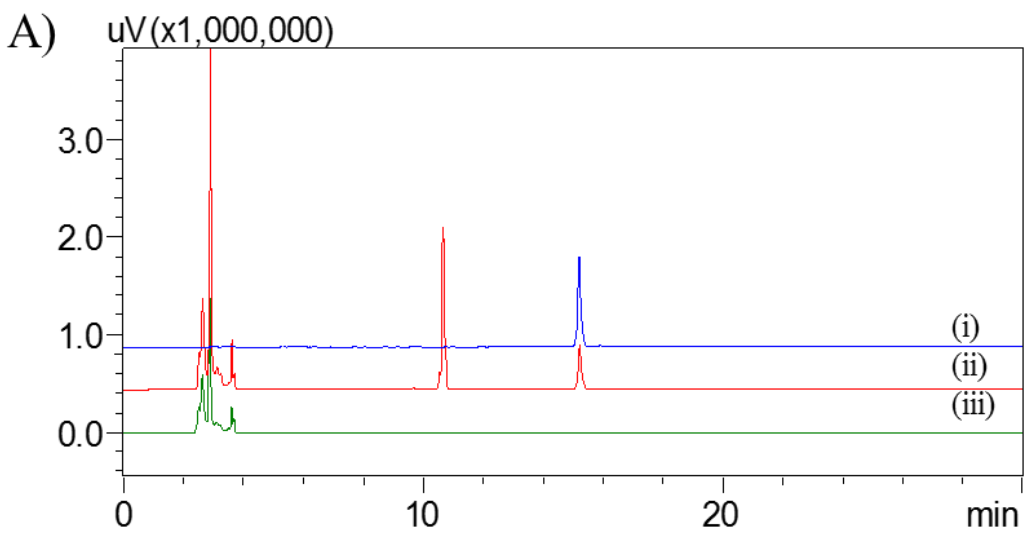

B)

C)
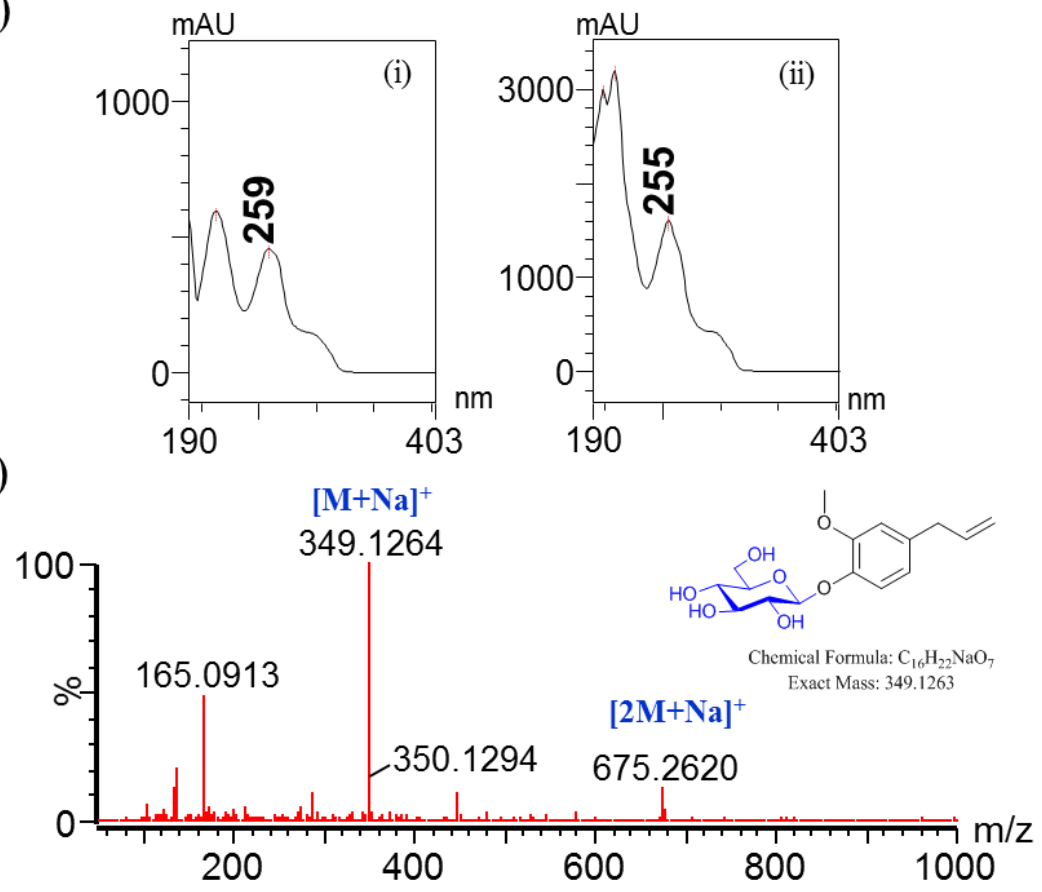

D)

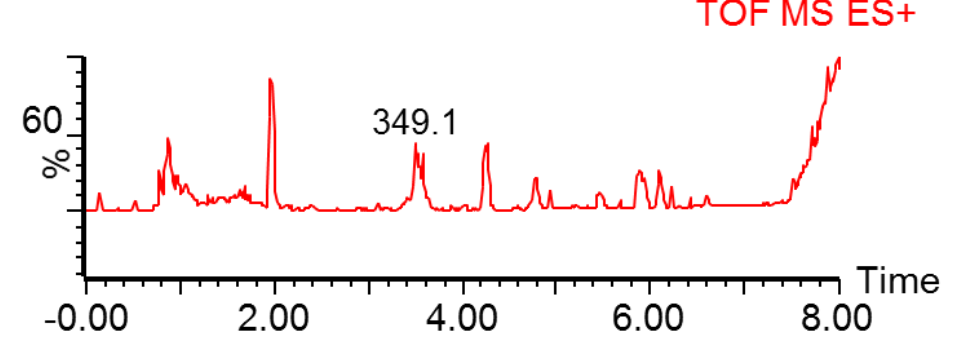

Figure S3. Chromatographic and spectrometric analysis of isoeugenol (3) glucosylation reaction. A) HPLC-PDA analysis. i) Standard 3, ii) Reaction mixture of $\mathbf{3}$ with UDP-Glc, iii) Control reaction without 3. B) UV-VIS of i) Product and ii) Standard 3. C) HR-QTOF-ESI/MS of product exhibiting exact observed mass of $349.1264 \mathrm{Da}$ for calculated formula $\mathrm{C}_{16} \mathrm{H}_{22} \mathrm{NaO}_{7}$ for which calculated exact mass was $[\mathrm{M}+\mathrm{Na}]^{+} 349.1263 \mathrm{Da}$. D) HR-QTOF-ESI/MS total ion chromatogram showing exact mass of glucosylated $\mathbf{3}$. 


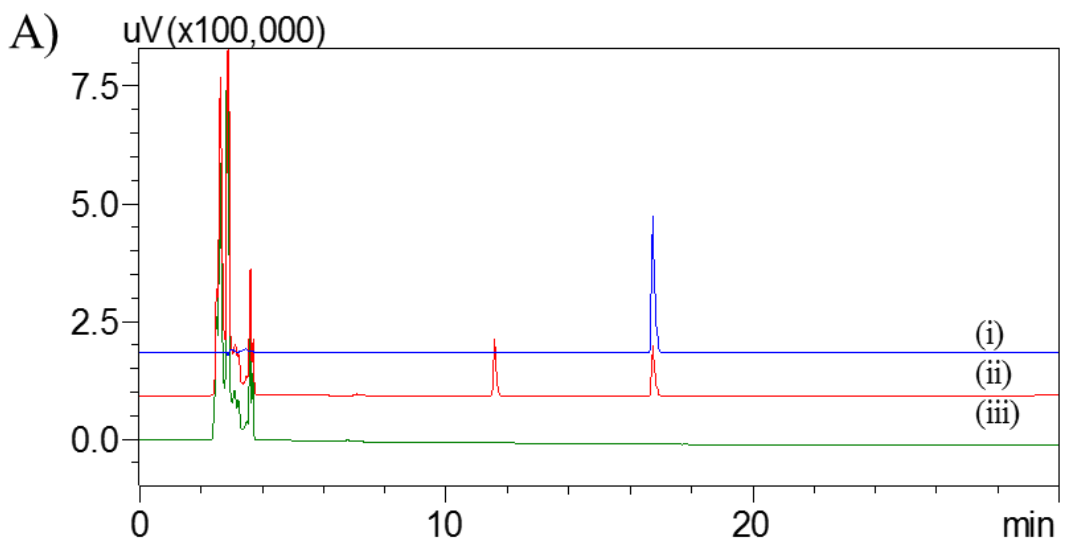

B)
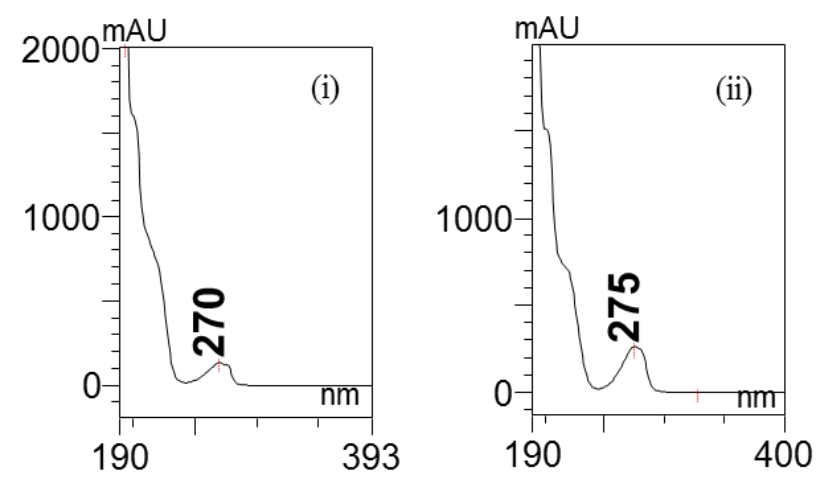

C)

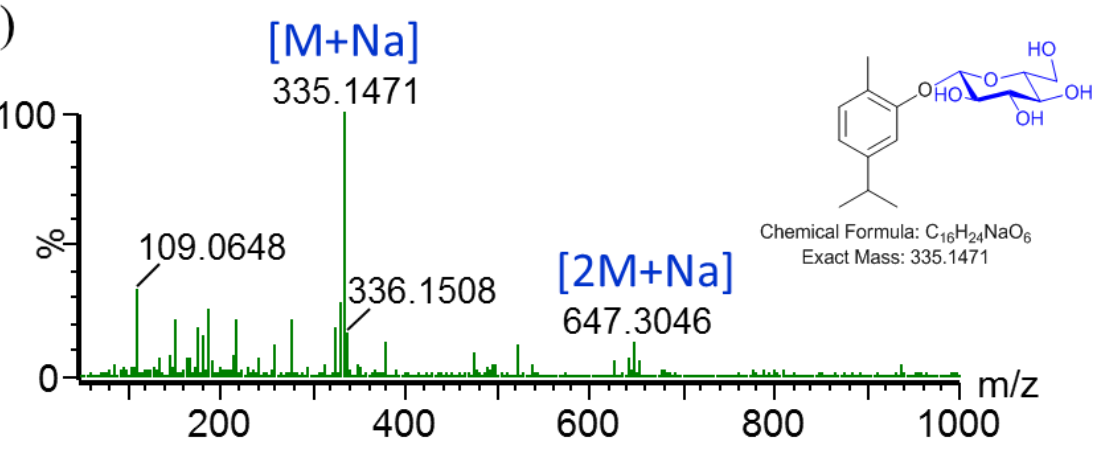

D)

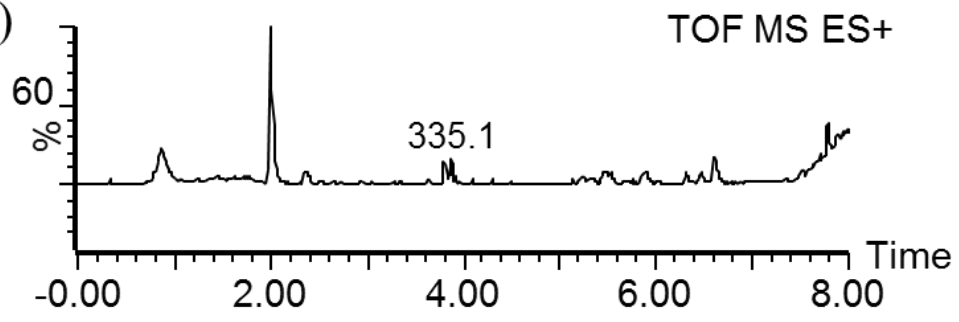

Figure S4. Chromatographic and spectrometric analysis of carvacrol (4) glucosylation reaction. A) HPLC-PDA analysis. i) Standard 4, ii) Reaction mixture of 4, iii) Control reaction without 4. B) UV-VIS of i) Product and ii) Standard 4. C) HR-QTOF-ESI/MS of product exhibiting exact observed mass of $335.1471 \mathrm{Da}$ for calculated formula $\mathrm{C}_{16} \mathrm{H}_{24} \mathrm{NaO}_{6}$ for which calculated exact mass was $[\mathrm{M}+\mathrm{Na}]^{+} 335.1471 \mathrm{Da}$. D) HR-QTOF-ESI/MS total ion chromatogram showing exact mass of glucosylated 4 . 

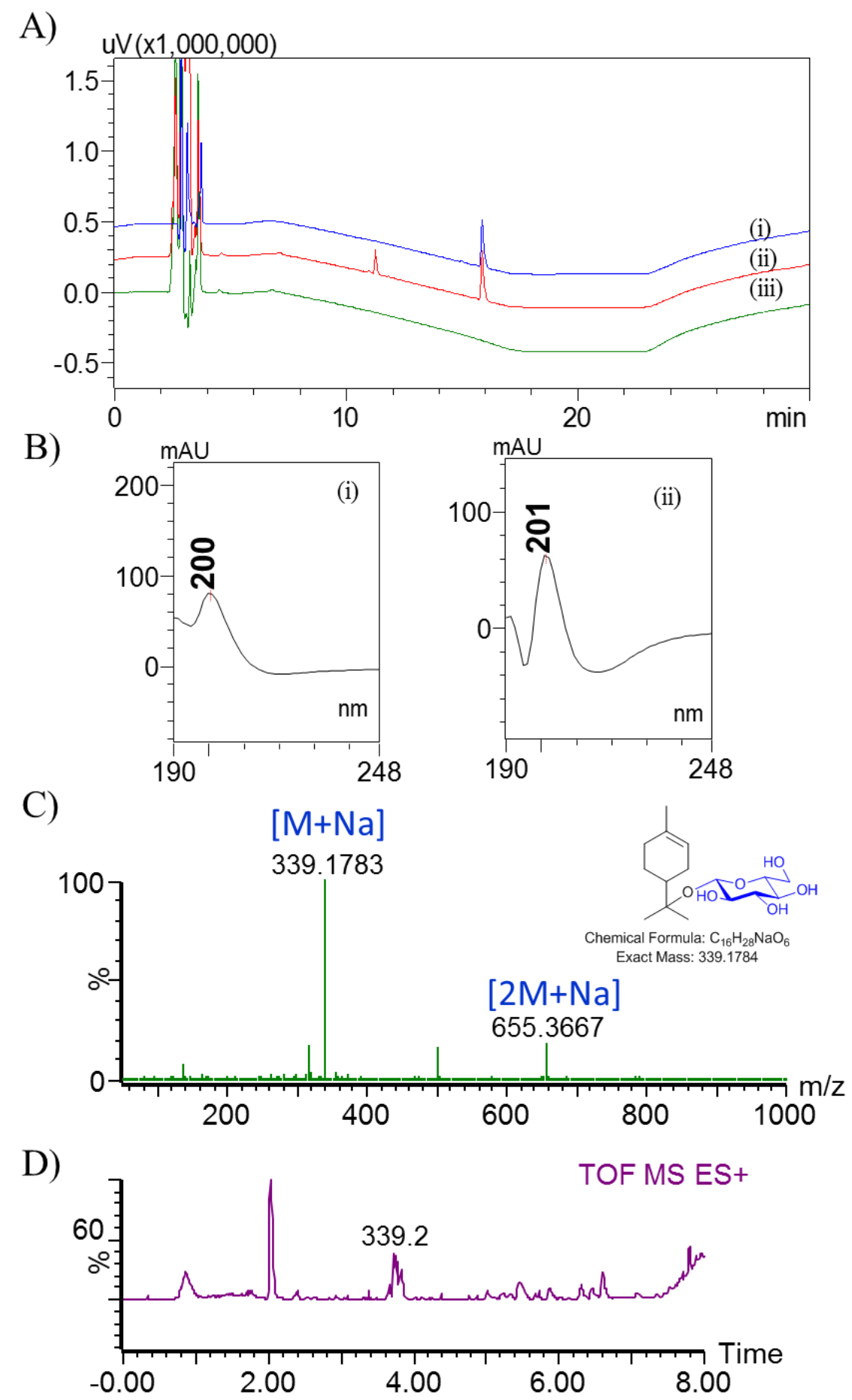

Figure S5. Chromatographic and spectrometric analysis of $\alpha$-terpineol (5) glucosylation reaction. A) HPLC-PDA analysis. i) Standard 5, ii) Reaction mixture of 5 with UDP-Glc, iii) Control reaction without 5. B) UV-VIS of i) Product and ii) standard 5. C) HR-QTOF-ESI/MS of product exhibiting exact observed mass of $339.1783 \mathrm{Da}$ for calculated formula $\mathrm{C}_{16} \mathrm{H}_{28} \mathrm{NaO}_{6}$ for which calculated exact mass was $[\mathrm{M}+\mathrm{Na}]^{+} 339.1784 \mathrm{Da}$. D) HR-QTOF-ESI/MS total ion chromatogram showing exact mass of glucosylated $\mathbf{5}$. 
A)

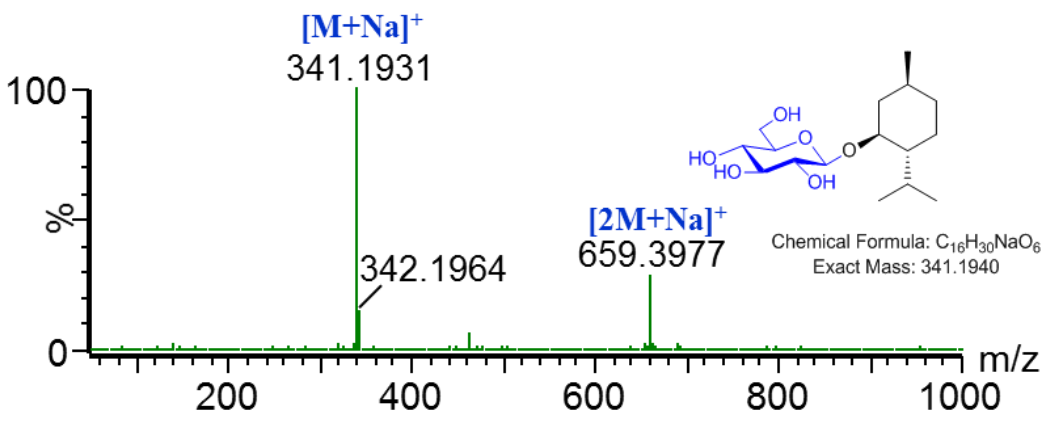

B)

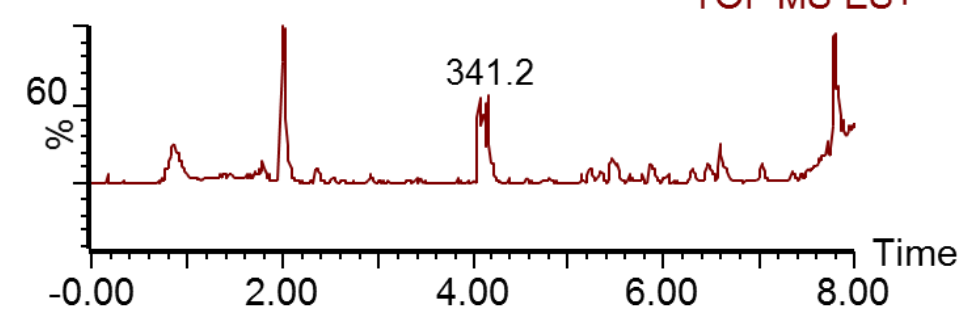

Figure S6. Spectrometric analysis of (+) menthol (6) glucosylation reaction. A) HR-QTOFESI/MS of product exhibiting exact observed mass of $341.1931 \mathrm{Da}$ for calculated formula $\mathrm{C}_{16} \mathrm{H}_{30} \mathrm{NaO}_{6}$ for which calculated exact mass was [M+Na] $]^{+} 341.1940$ Da. B) HR-QTOF-ESI/MS total ion chromatogram showing exact mass of glucosylated $\mathbf{6}$. 
A)

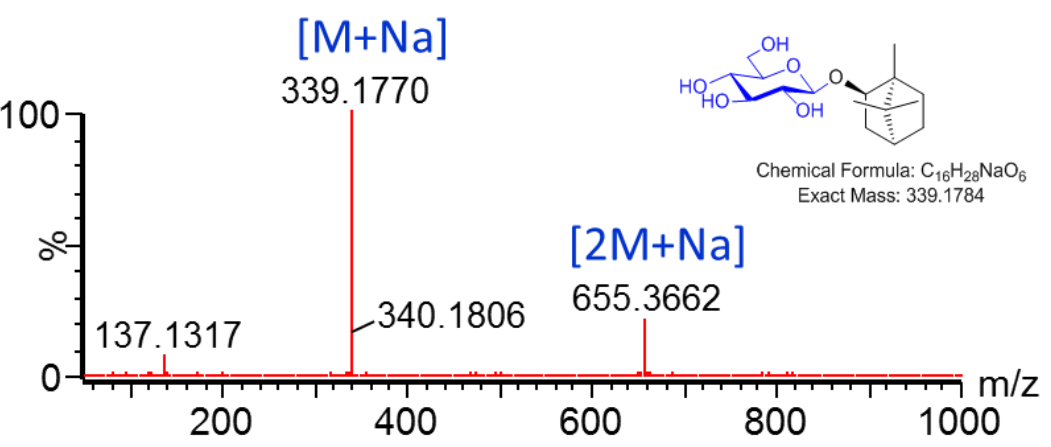

B)

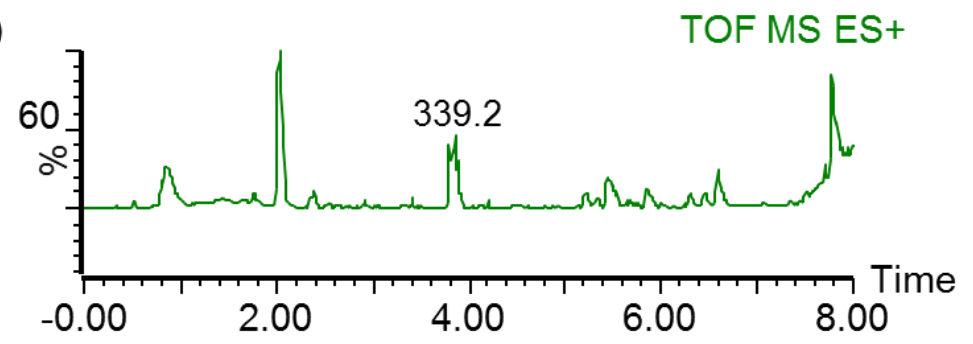

Figure S7. Spectrometric analysis of (-) borneol (7) glucosylation reaction. A) HR-QTOF-ESI/MS of product exhibiting exact observed mass of $339.1770 \mathrm{Da}$ for calculated formula $\mathrm{C}_{16} \mathrm{H}_{2} 8 \mathrm{NaO}_{6}$ for which calculated exact mass was $[\mathrm{M}+\mathrm{Na}]^{+} 339.1784$ Da. B) HR-QTOF-ESI/MS total ion chromatogram showing exact mass of glucosylated 7 . 


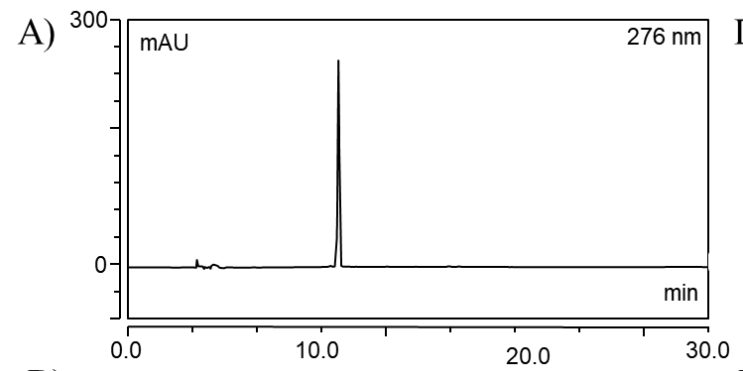

B)

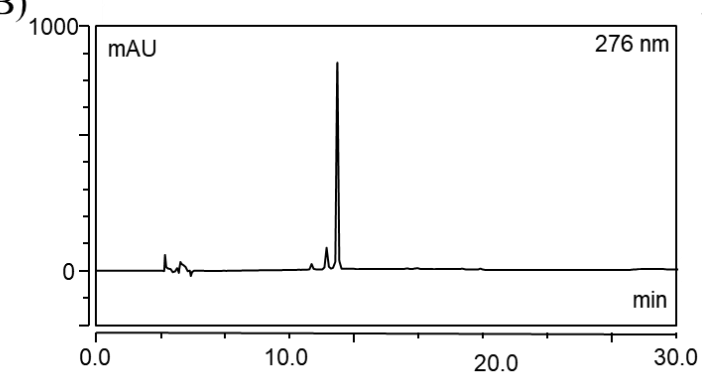

C)

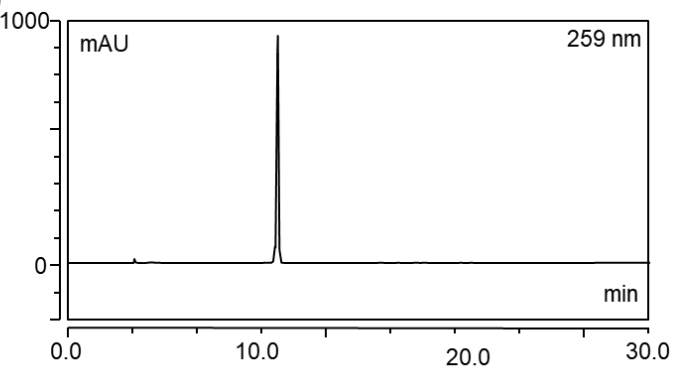

D)

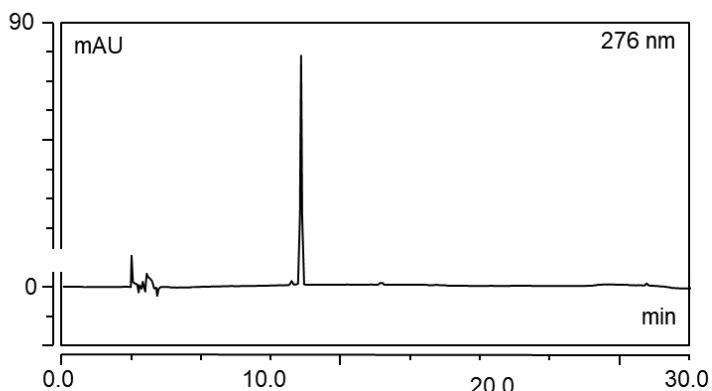

F)

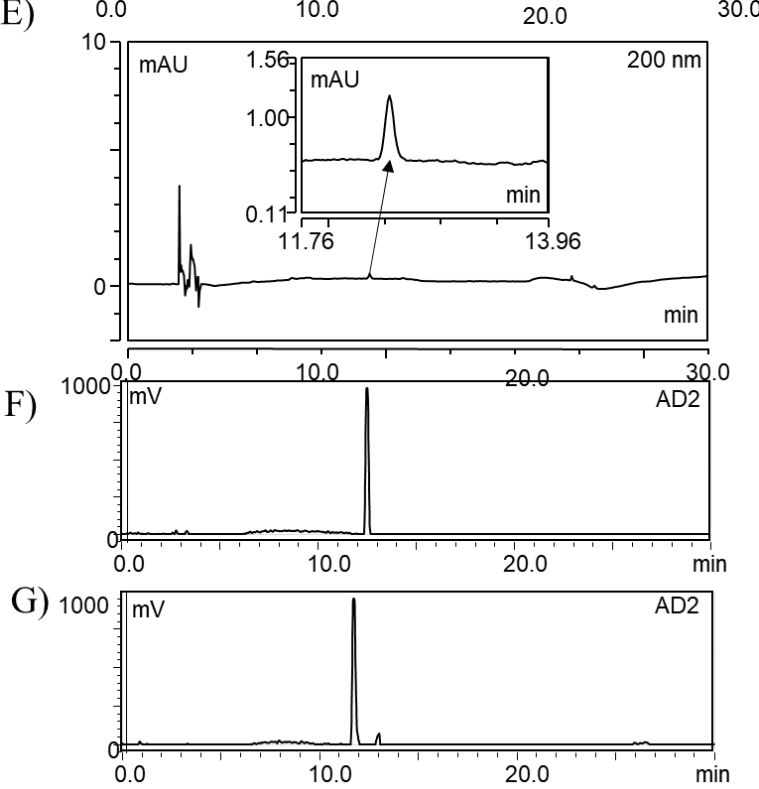

Figure S8. Chromatographic analysis of purified glucoside derivatives. HPLC-PDA chromatograms of A) 1a, B) 2a, C) 3a, D) 4a, and E) 5a. ELSD chromatograms of F) 6a and G) $7 a$. 


\section{NMR data:}

Eugenol (1): White amorphous powder; $\lambda_{\max }: 281 \mathrm{~nm} ;{ }^{1} \mathrm{H}$ NMR $\left(300 \mathrm{MHz}, \mathrm{DMSO}-d_{6}\right): \delta_{\mathrm{H}} 8.73$ (s, $1 \mathrm{H}), 6.78-6.69(\mathrm{~m}, 1 \mathrm{H}), 6.72(\mathrm{~s}, 1 \mathrm{H}), 6.58(\mathrm{ddt}, J=7.9,2.0,0.6 \mathrm{~Hz}, 1 \mathrm{H}), 5.93$ (ddt, $J=16.8$, 10.0, 6.7 Hz, 1H), $5.13-4.95(\mathrm{~m}, 2 \mathrm{H}), 3.74(\mathrm{~s}, 3 \mathrm{H}), 3.26$ (dddd, $J=6.7,2.1,1.3,0.5 \mathrm{~Hz}, 2 \mathrm{H}) .{ }^{13} \mathrm{C}$ NMR (75 MHz, DMSO-d6): $\delta$ 147.98, 145.28, 138.66, 130.96, 121.04, 115.90, 115.63, 113.09, $56.00,39.64$.

Thymol (2): White amorphous powder; $\lambda_{\max }: 271 \mathrm{~nm} ;{ }^{1} \mathrm{H}$ NMR $\left(300 \mathrm{MHz}, \mathrm{DMSO}-d_{6}\right): \delta_{\mathrm{H}} 9.06$ (s, $1 \mathrm{H}), 6.96(\mathrm{~d}, J=7.7 \mathrm{~Hz}, 1 \mathrm{H}), 6.60(\mathrm{dd}, J=1.7,0.8 \mathrm{~Hz}, 1 \mathrm{H}), 6.54(\mathrm{dtd}, J=7.7,1.1,0.5 \mathrm{~Hz}, 1 \mathrm{H})$, 3.17 (hept, $J=6.9 \mathrm{~Hz}, 1 \mathrm{H}), 2.17$ (d, $J=0.6 \mathrm{~Hz}, 3 \mathrm{H}), 1.15$ (s, 3H), 1.12 (s, 3H). ${ }^{13} \mathrm{C} \mathrm{NMR}(75 \mathrm{MHz}$, DMSO- $\left.d_{6}\right): \delta 154.65,135.69,131.66,126.07,120.09,116.04,26.53,23.06,23,21.12$.

Isoeugenol (3): White amorphous powder; $\lambda_{\max }: 255 \mathrm{~nm} ;{ }^{1} \mathrm{H}$ NMR (300 MHz, DMSO- $\left.d_{6}\right): \delta_{\mathrm{H}} 8.94$ $(\mathrm{d}, J=0.7 \mathrm{~Hz}, 1 \mathrm{H}), 6.95(\mathrm{~d}, J=1.7 \mathrm{~Hz}, 1 \mathrm{H}), 6.75(\mathrm{~d}, J=1.6 \mathrm{~Hz}, 1 \mathrm{H}), 6.73(\mathrm{~s}, 1 \mathrm{H}), 6.28(\mathrm{dd}, J=$ 15.7, $1.5 \mathrm{~Hz}, 2 \mathrm{H}), 6.07$ (ddd, $J=15.7,6.5,0.7 \mathrm{~Hz}, 1 \mathrm{H}), 3.78$ (d, $J=0.7 \mathrm{~Hz}, 3 \mathrm{H}), 1.80$ (ddd, $J=$ 6.5, 1.6, $0.7 \mathrm{~Hz}, 3 \mathrm{H}) .{ }^{13} \mathrm{C}$ NMR (75 MHz, DMSO- $\left.d_{6}\right): \delta 148.16,146.31,131.38,129.65,122.52$, $119.29,115.93,109.92,56.00,18.55$.

Carvacrol (4): White amorphous powder; $\lambda_{\max }: 275 \mathrm{~nm} ;{ }^{1} \mathrm{H}$ NMR (300 MHz, DMSO- $\left.d_{6}\right): \delta_{\mathrm{H}} 9.06$ (s, 1H), $6.94(\mathrm{dd}, J=7.6,0.8 \mathrm{~Hz}, 1 \mathrm{H}), 6.68(\mathrm{~d}, J=1.8 \mathrm{~Hz}, 1 \mathrm{H}), 6.56(\mathrm{dd}, J=7.6,1.8 \mathrm{~Hz}, 1 \mathrm{H})$, $2.73(\mathrm{~h}, J=6.9 \mathrm{~Hz}, 1 \mathrm{H}), 2.10(\mathrm{~s}, 3 \mathrm{H}), 1.18(\mathrm{~s}, 0 \mathrm{H}), 1.17(\mathrm{~s}, 3 \mathrm{H}), 1.15(\mathrm{~s}, 3 \mathrm{H}) .{ }^{13} \mathrm{C} \mathrm{NMR}(75 \mathrm{MHz}$, DMSO- $\left.d_{6}\right): \delta 155.70,147.44,130.75,121.45,117.10,113.05,33.59,24.42,24.42,16.03$.

$\boldsymbol{\alpha}$-Terpineol (5): liquid; $\lambda_{\max }: 201 \mathrm{~nm} ;{ }^{1} \mathrm{H}$ NMR (300 MHz, DMSO- $\left.d_{6}\right): \delta_{\mathrm{H}} 5.42-5.27(\mathrm{~m}, 1 \mathrm{H})$, $3.36(\mathrm{~s}, 1 \mathrm{H}), 2.21-1.63(\mathrm{~m}, 4 \mathrm{H}), 1.59(\mathrm{qdd}, J=2.3,1.3,0.6 \mathrm{~Hz}, 4 \mathrm{H}), 1.45-1.25(\mathrm{~m}, 1 \mathrm{H}), 1.20-$ $1.06(\mathrm{~m}, 1 \mathrm{H}), 1.03(\mathrm{~d}, J=4.2 \mathrm{~Hz}, 6 \mathrm{H}) .{ }^{13} \mathrm{C}$ NMR (75 MHz, DMSO-d $): \delta 133.36,121.48,70.86$, $45.03,31.21,27.73,26.97,26.71,24.07,23.62$.

(+) Menthol (6): White transparent crystal; ${ }^{1} \mathrm{H}$ NMR (300 MHz, DMSO- $\left.d_{6}\right): \delta_{\mathrm{H}} 4.31(\mathrm{~d}, J=5.7$ $\mathrm{Hz}, 1 \mathrm{H}), 3.23-3.04(\mathrm{~m}, 2 \mathrm{H}), 2.18(\mathrm{pd}, J=7.0,2.4 \mathrm{~Hz}, 1 \mathrm{H}), 1.82(\mathrm{dtd}, J=12.2,4.1,2.1 \mathrm{~Hz}, 1 \mathrm{H})$, $1.68-1.50(\mathrm{~m}, 2 \mathrm{H}), 1.57-1.44(\mathrm{~m}, 1 \mathrm{H}), 1.33(\mathrm{ttt}, J=12.7,6.3,3.3 \mathrm{~Hz}, 1 \mathrm{H}), 1.08-0.86(\mathrm{~m}, 2 \mathrm{H})$, $0.90-0.80(\mathrm{~m}, 7 \mathrm{H}), 0.85-0.74(\mathrm{~m}, 1 \mathrm{H}), 0.72(\mathrm{~d}, J=6.9 \mathrm{~Hz}, 4 \mathrm{H}) .{ }^{13} \mathrm{C}$ NMR $(75 \mathrm{MHz}, \mathrm{DMSO}-$ $\left.d_{6}\right): \delta 69.95,50.04,45.68,34.84,31.65,25.53,23.27,22.80,21.51,16.54$. 
(-) Borneol (7): White amorphous powder; ${ }^{1} \mathrm{H}$ NMR (300 MHz, DMSO- $\left.d_{6}\right): \delta_{\mathrm{H}} 4.46$ (dd, $J=$ 4.7, $0.8 \mathrm{~Hz}, 1 \mathrm{H}), 3.84-3.72(\mathrm{~m}, 1 \mathrm{H}), 2.09$ (dddd, $J=13.1,10.0,4.9,3.5 \mathrm{~Hz}, 1 \mathrm{H}), 1.93$ (ddd, $J=$ 12.2, 10.0, $4.5 \mathrm{~Hz}, 1 \mathrm{H}), 1.61$ (dddd, $J=13.1,9.2,6.6,3.5 \mathrm{~Hz}, 1 \mathrm{H}), 1.52$ (t, $J=4.6 \mathrm{~Hz}, 1 \mathrm{H}), 1.20$ -1.09 (m, 2H), 1.05 (ddd, $J=11.9,4.4,2.1 \mathrm{~Hz}, 1 \mathrm{H}), 0.80(\mathrm{~s}, 6 \mathrm{H}), 0.75(\mathrm{~s}, 3 \mathrm{H}) .{ }^{13} \mathrm{C}$ NMR $(75$ MHz, DMSO- $\left.d_{6}\right): \delta 75.27,49.49,47.78,45.04,38.96,28.48,26.22,20.60,19.08,13.95$. 
Figure S9a. ${ }^{1} \mathrm{H}-\mathrm{NMR}\left(300 \mathrm{MHz}, \mathrm{DMSO}-d_{6}\right)$ of $\mathbf{1}$.

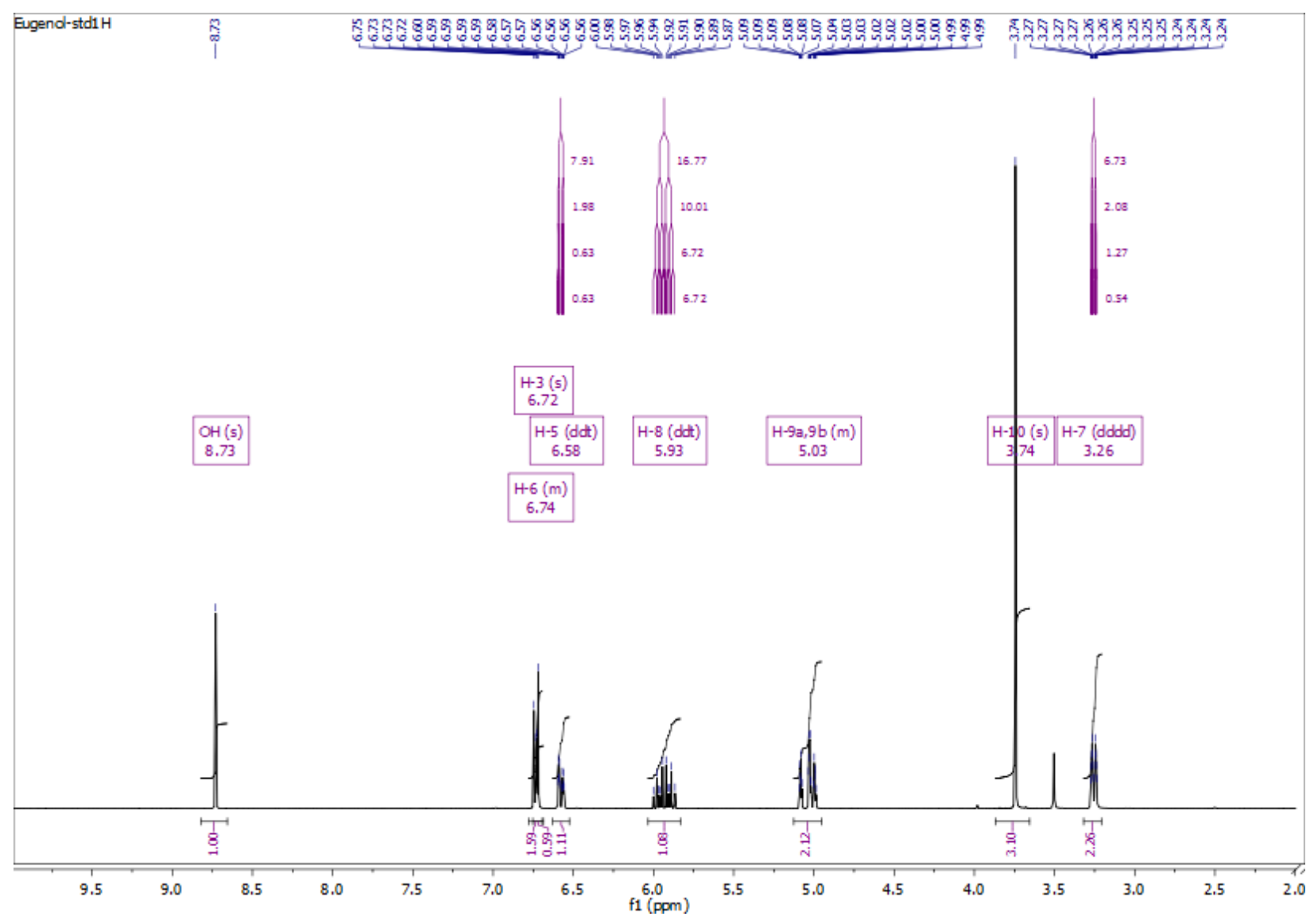


Figure S9b. ${ }^{13} \mathrm{C}-\mathrm{NMR}\left(75 \mathrm{MHz}, \mathrm{DMSO}-d_{6}\right)$ of $\mathbf{1}$.

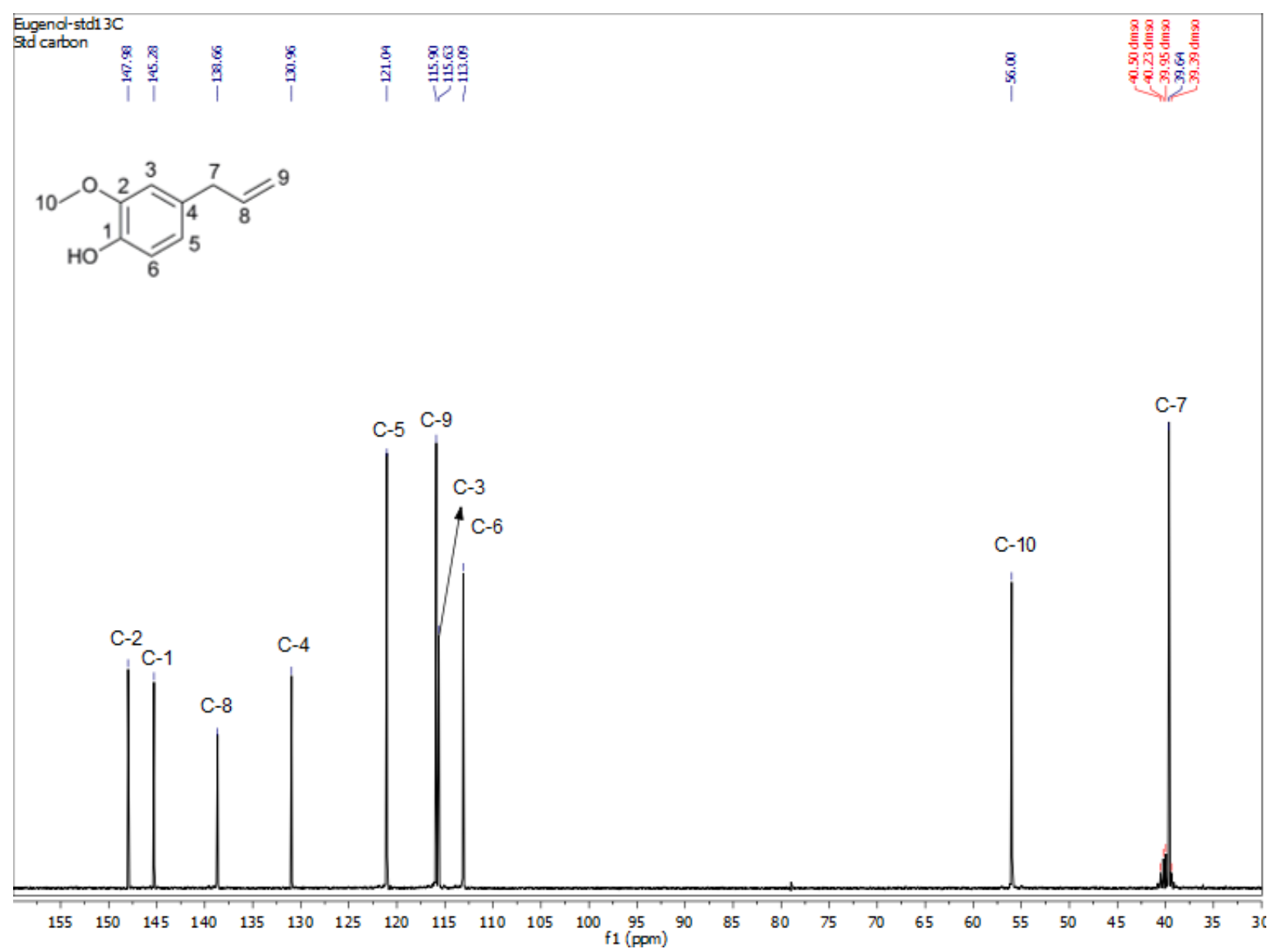


Figure S9c. ${ }^{1} \mathrm{H}-\mathrm{NMR}\left(300 \mathrm{MHz}, \mathrm{DMSO}-d_{6}\right)$ of $\mathbf{1 a}$.

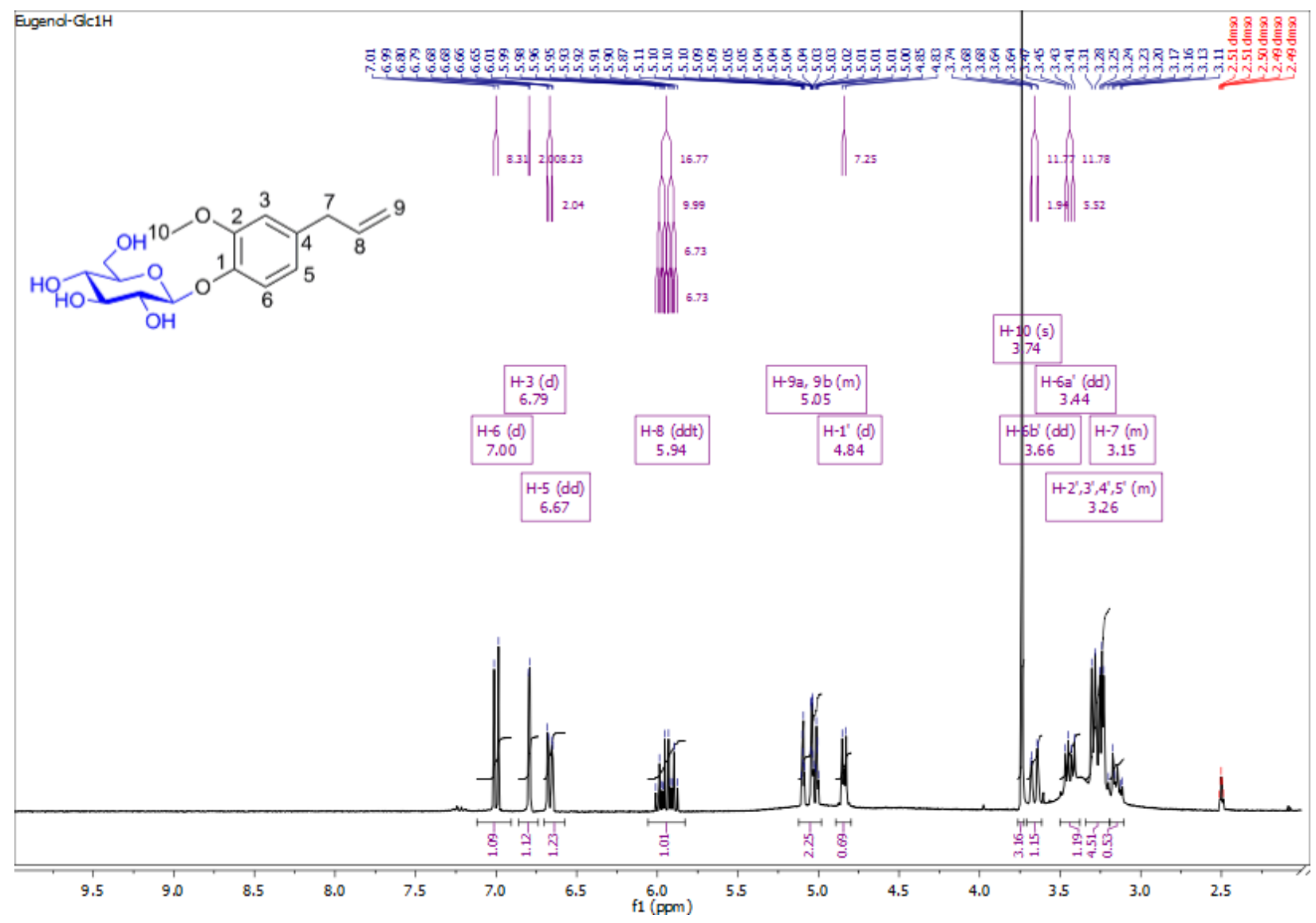


Figure S9d. ${ }^{13} \mathrm{C}-\mathrm{NMR}\left(75 \mathrm{MHz}, \mathrm{DMSO}-d_{6}\right)$ of 1a.

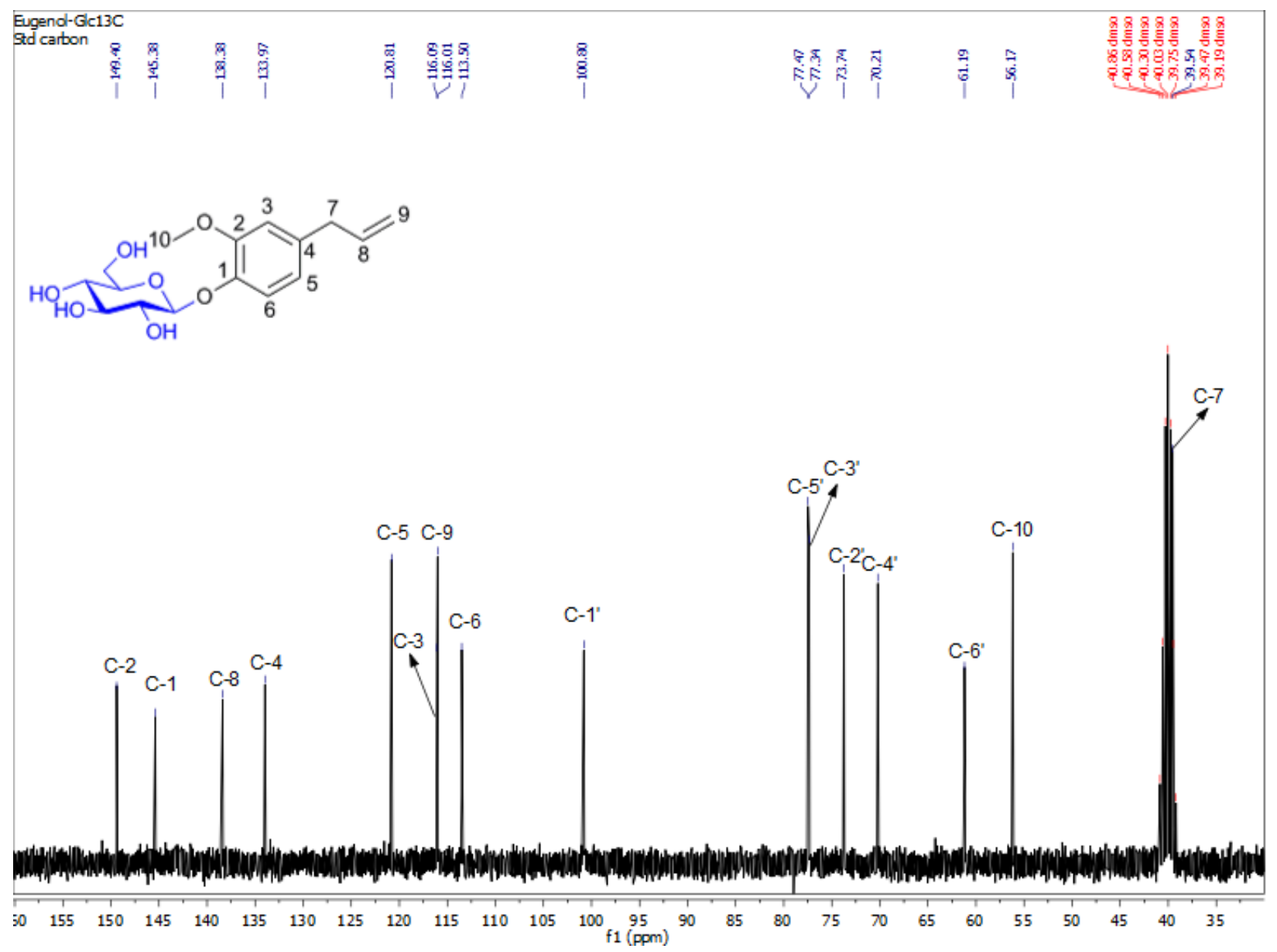


Figure S10a. ${ }^{1} \mathrm{H}-\mathrm{NMR}\left(300 \mathrm{MHz}, \mathrm{DMSO}-d_{6}\right)$ of 2.

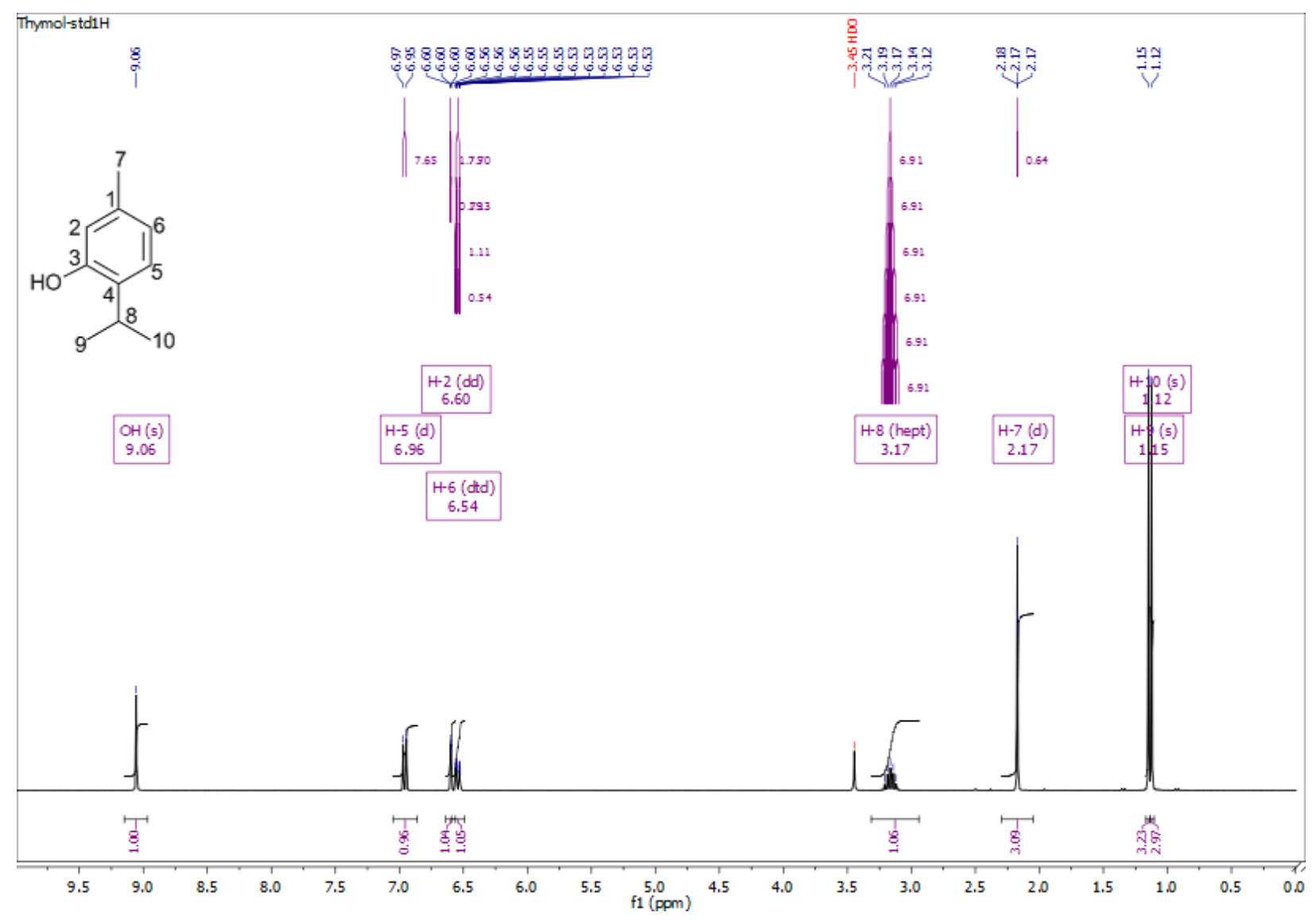


Figure S10b. ${ }^{13} \mathrm{C}-\mathrm{NMR}\left(75 \mathrm{MHz}, \mathrm{DMSO}-d_{6}\right)$ of 2.

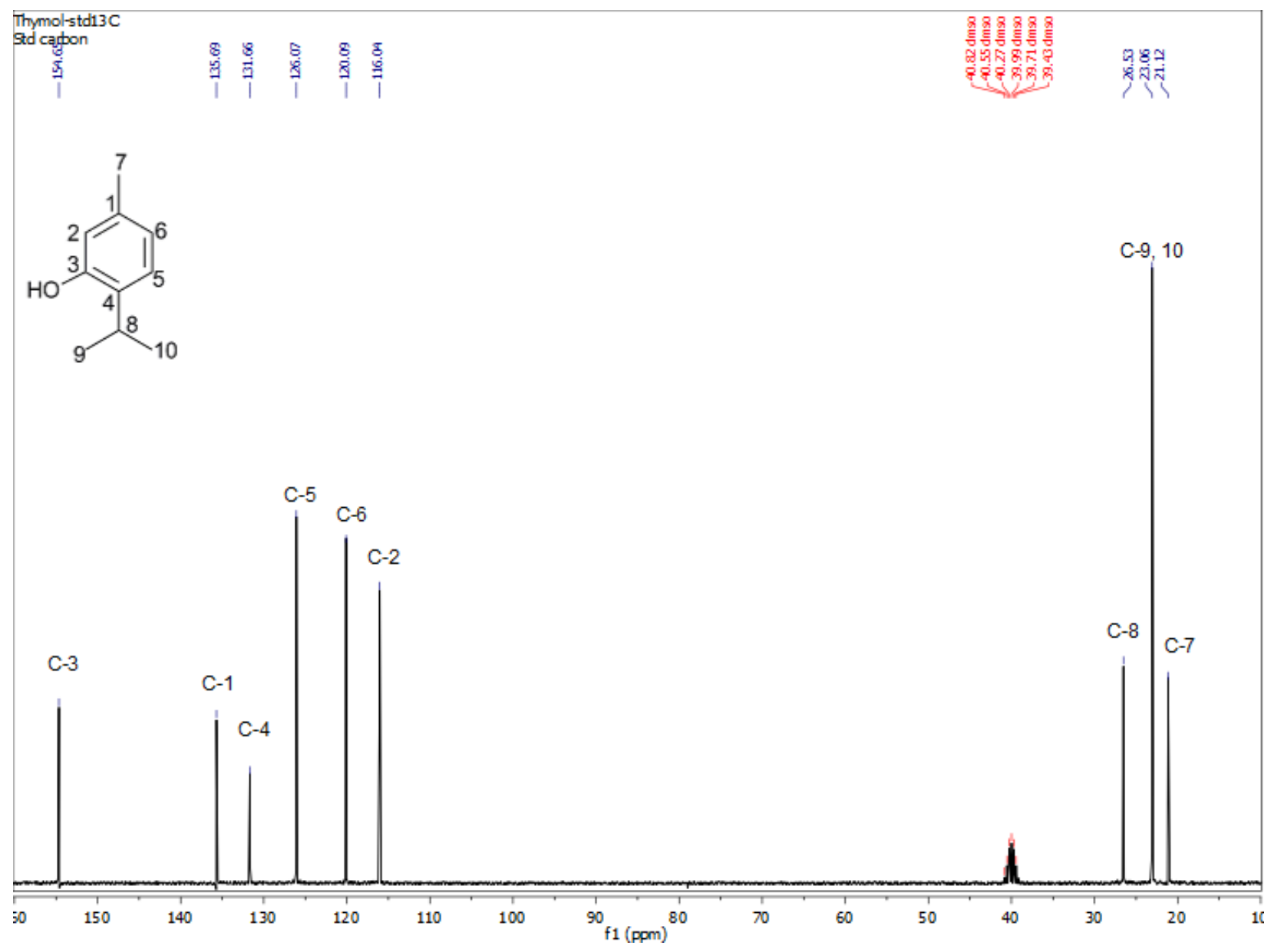


Figure S10c. ${ }^{1} \mathrm{H}-\mathrm{NMR}\left(300 \mathrm{MHz}, \mathrm{DMSO}-d_{6}\right)$ of $\mathbf{2 a}$.

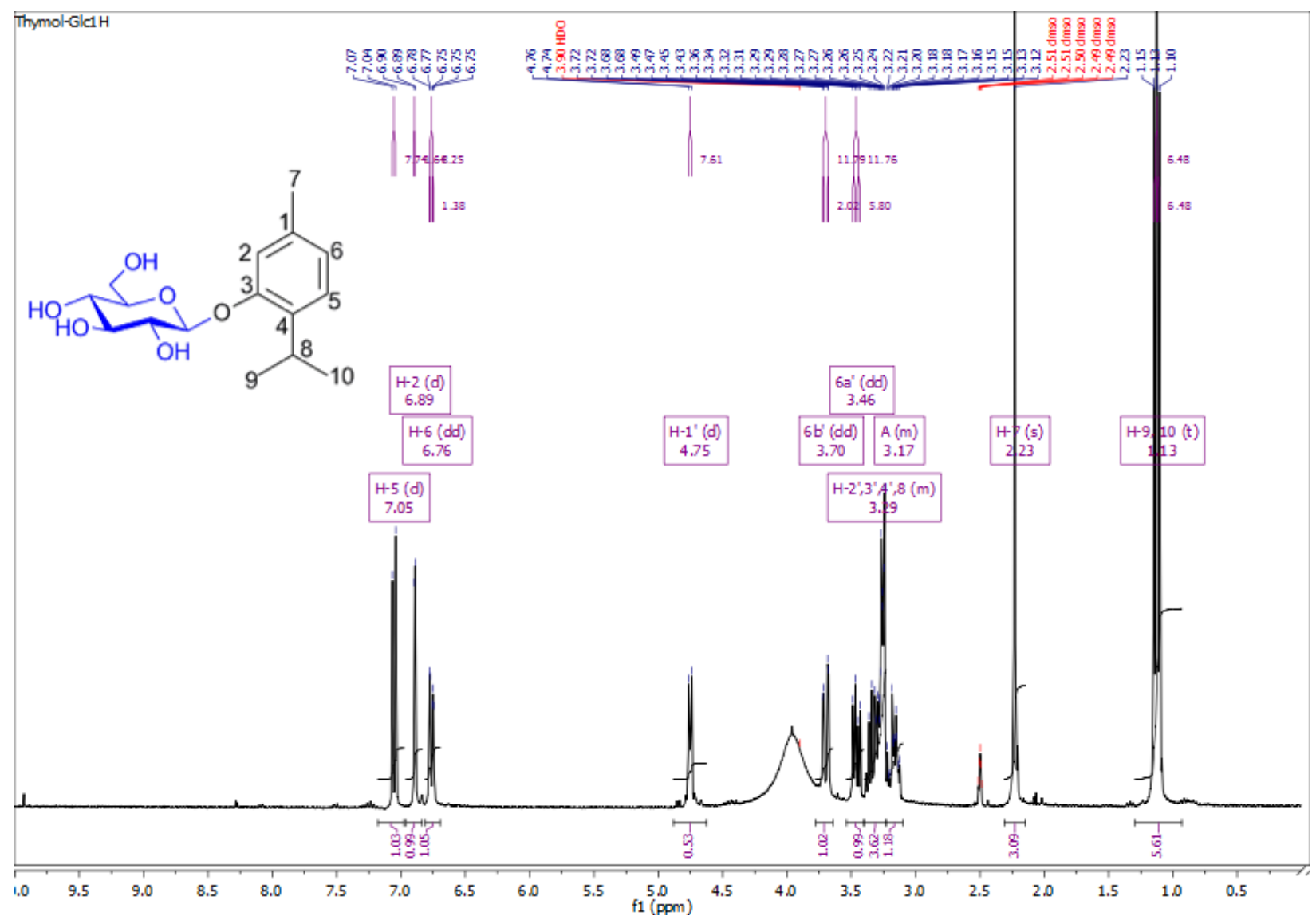


Figure S10d. ${ }^{13} \mathrm{C}-\mathrm{NMR}\left(75 \mathrm{MHz}\right.$, DMSO- $d_{6}$ ) of $\mathbf{2 a}$.

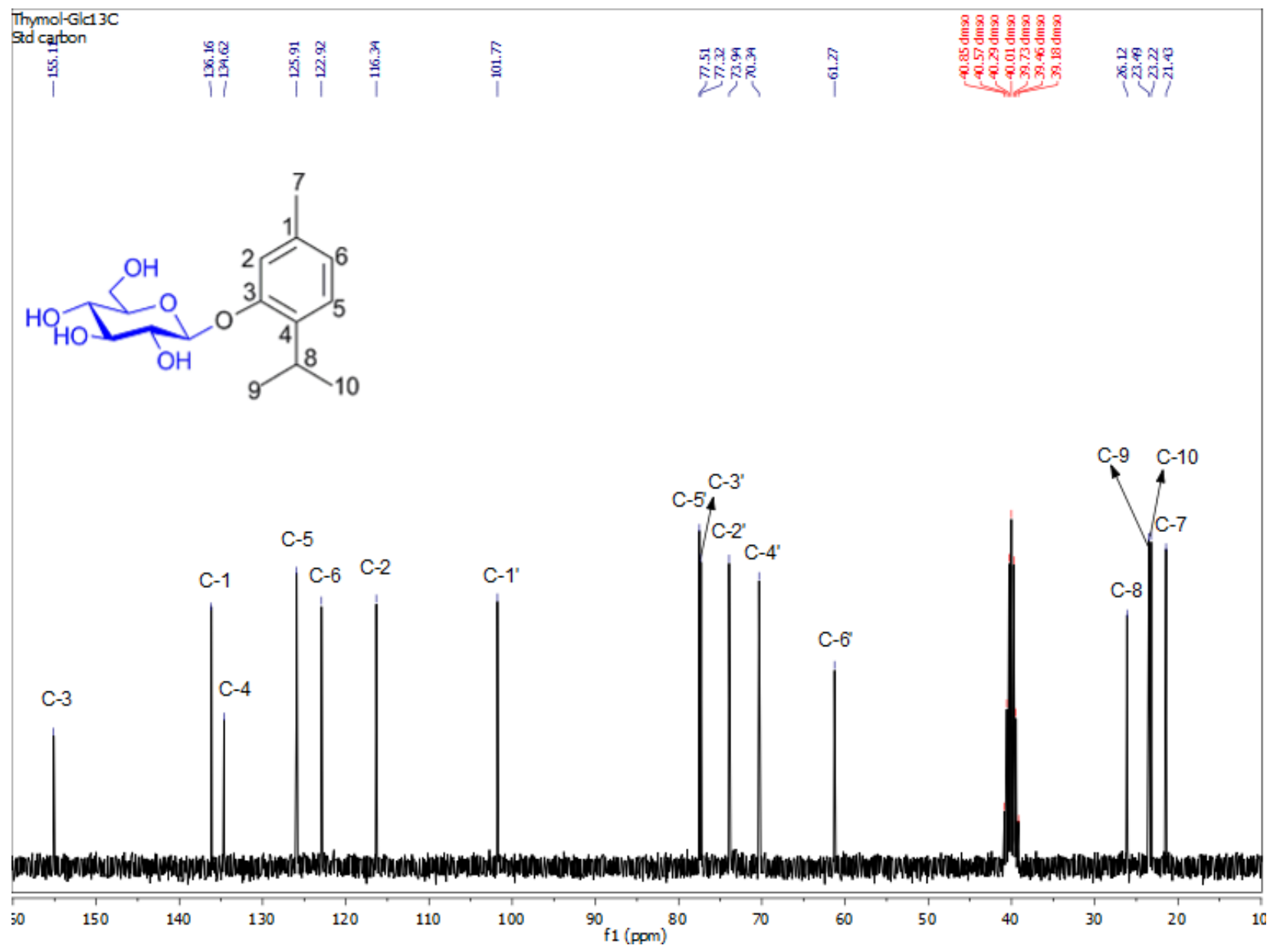


Figure S11a. ${ }^{1} \mathrm{H}-\mathrm{NMR}\left(300 \mathrm{MHz}, \mathrm{DMSO}-d_{6}\right)$ of $\mathbf{3}$.

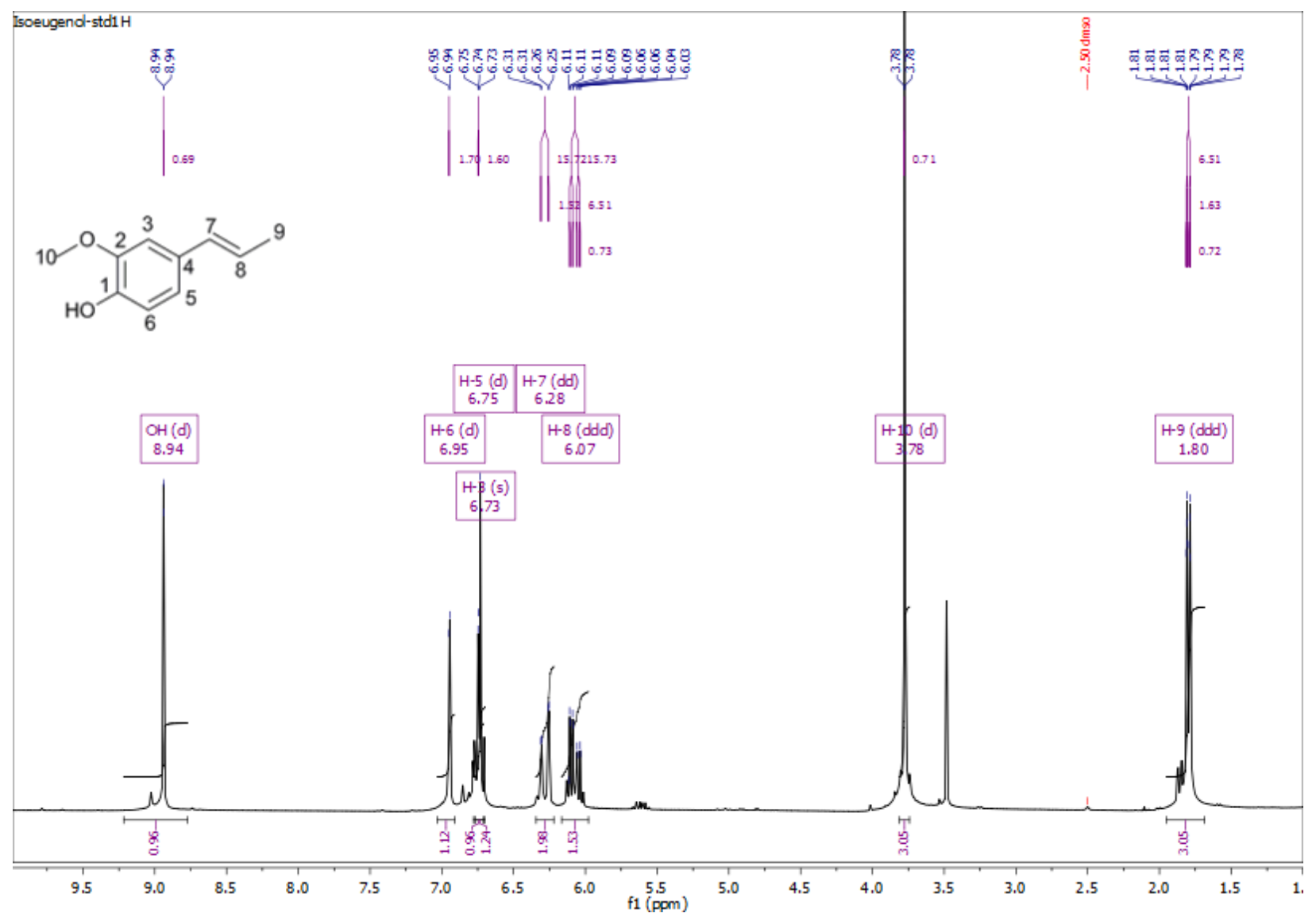


Figure S11b. ${ }^{13} \mathrm{C}-\mathrm{NMR}\left(75 \mathrm{MHz}, \mathrm{DMSO}-d_{6}\right)$ of 3.

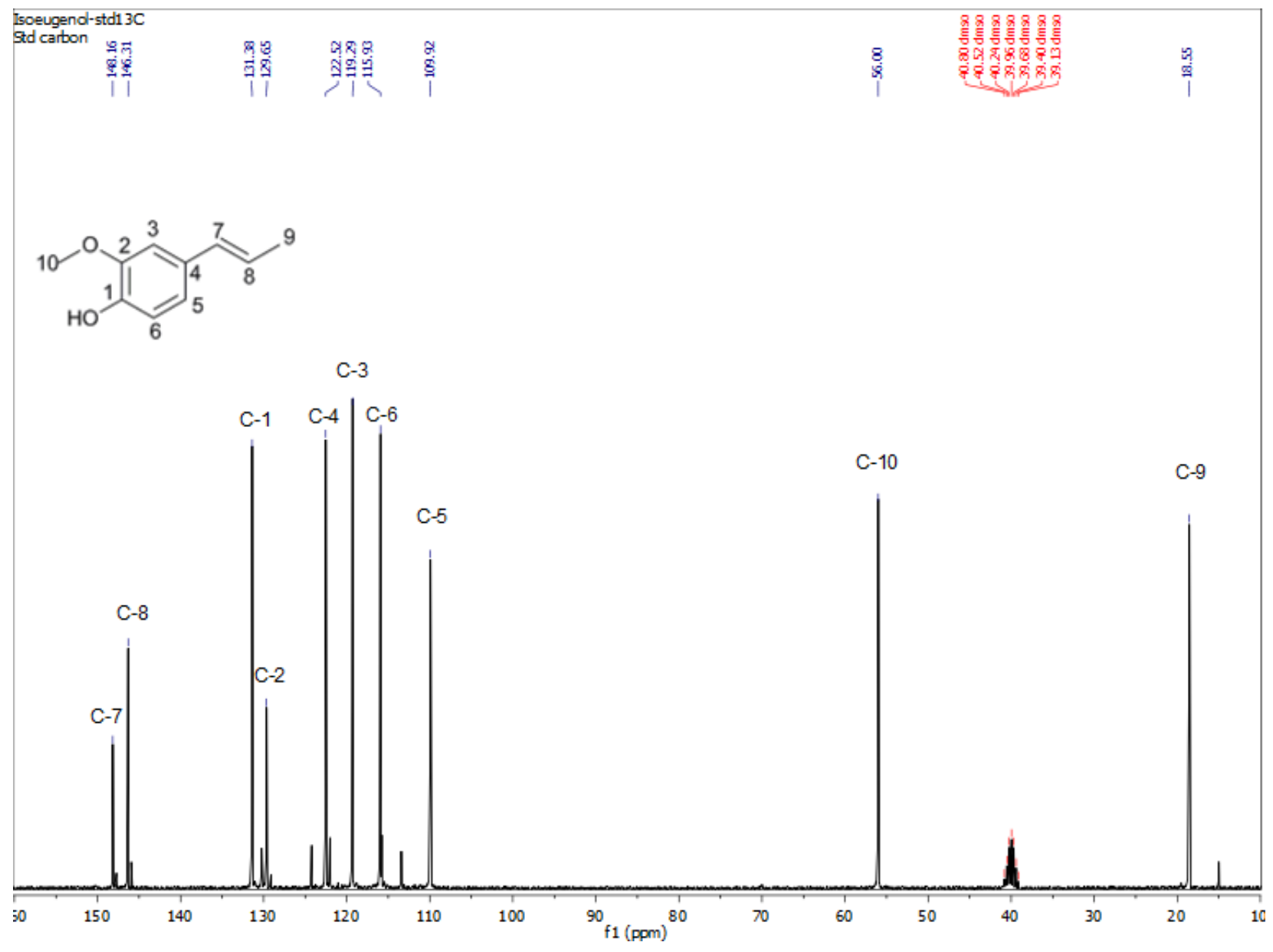


Figure S11c. ${ }^{1} \mathrm{H}-\mathrm{NMR}\left(300 \mathrm{MHz}, \mathrm{DMSO}-d_{6}\right)$ of 3a.

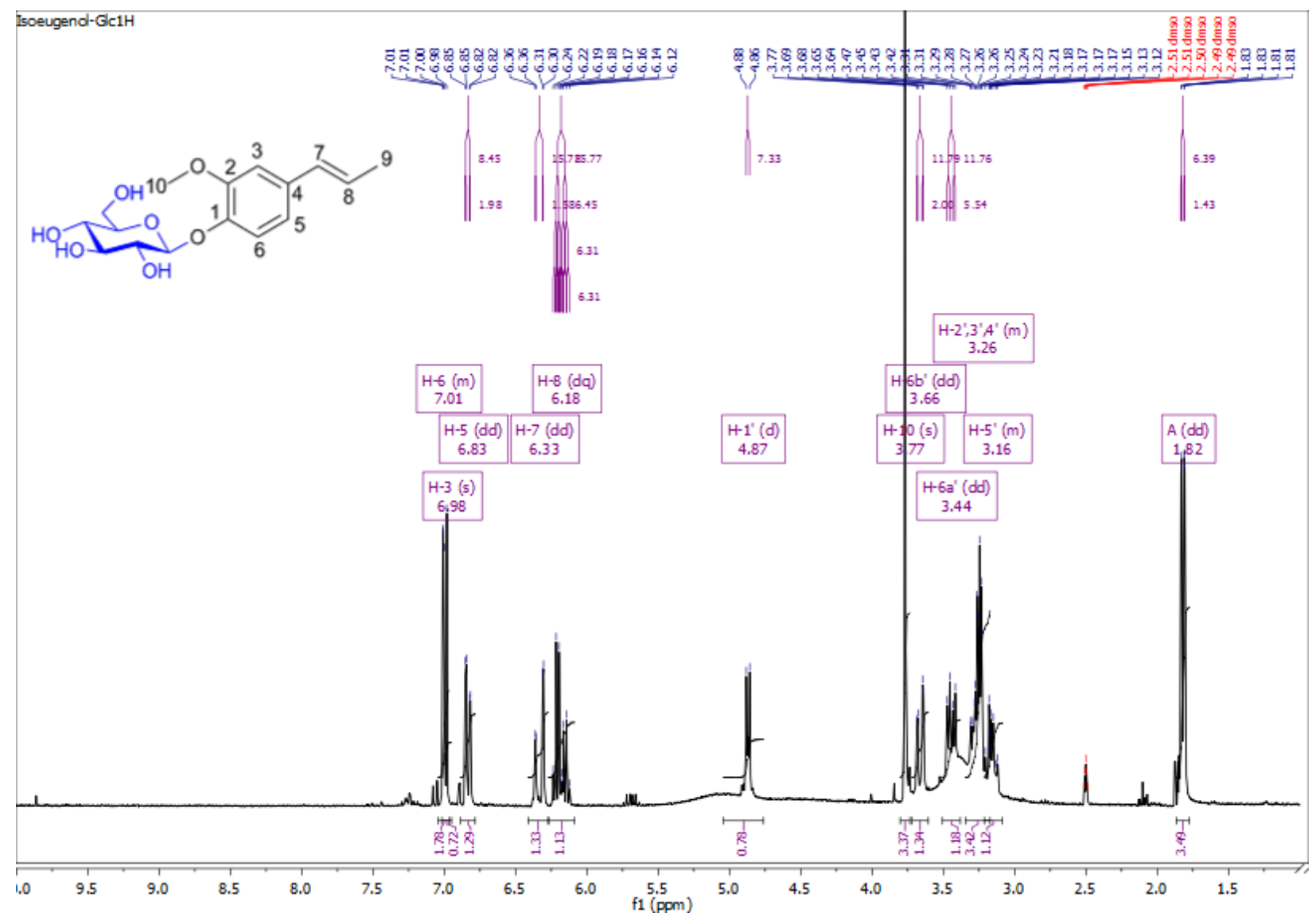


Figure S11d. ${ }^{13} \mathrm{C}-\mathrm{NMR}\left(75 \mathrm{MHz}\right.$, DMSO- $d_{6}$ ) of $\mathbf{3 a}$.

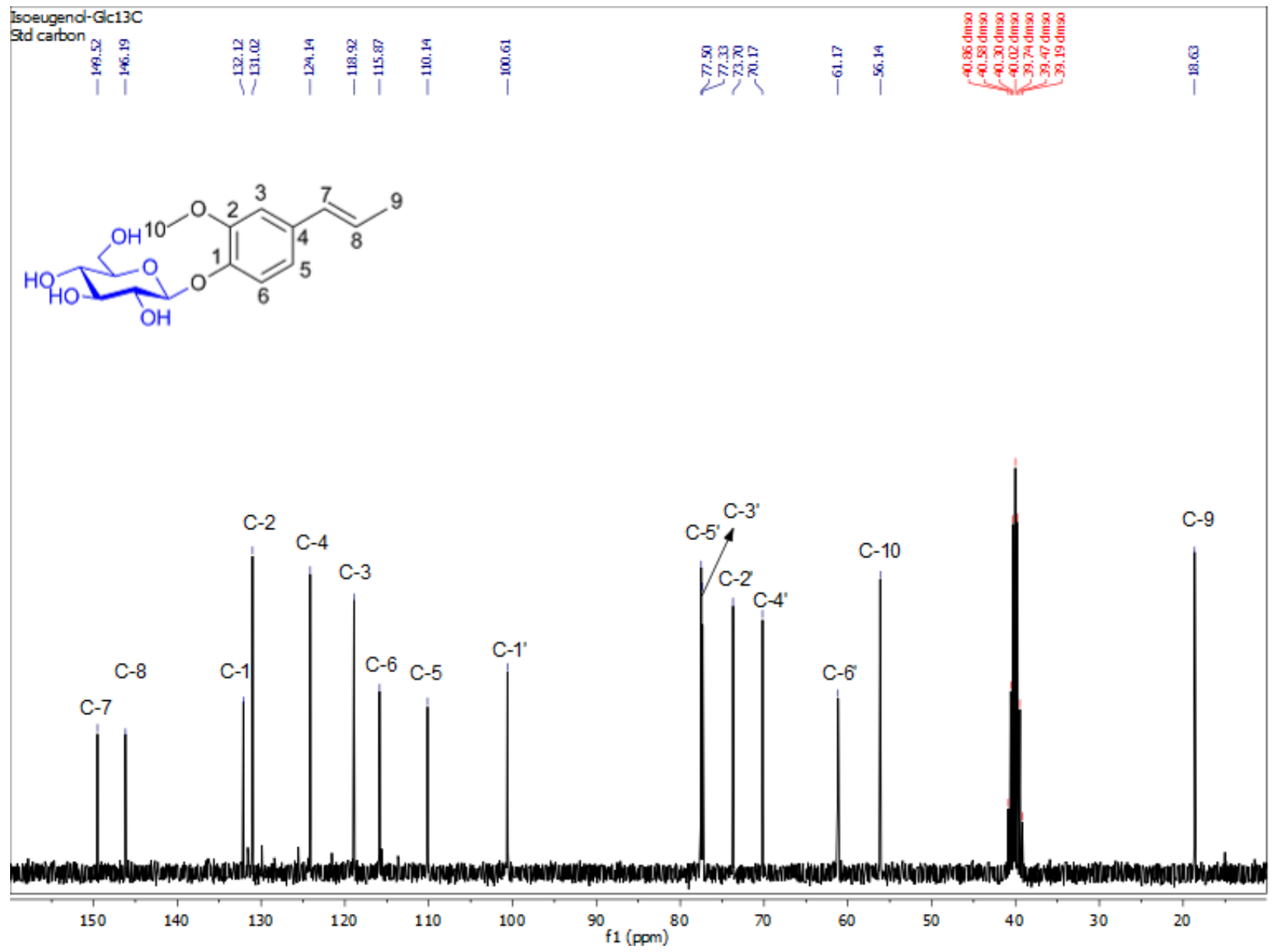


Figure S12a. ${ }^{1} \mathrm{H}-\mathrm{NMR}$ (300 MHz, DMSO- $d_{6}$ ) of 4.

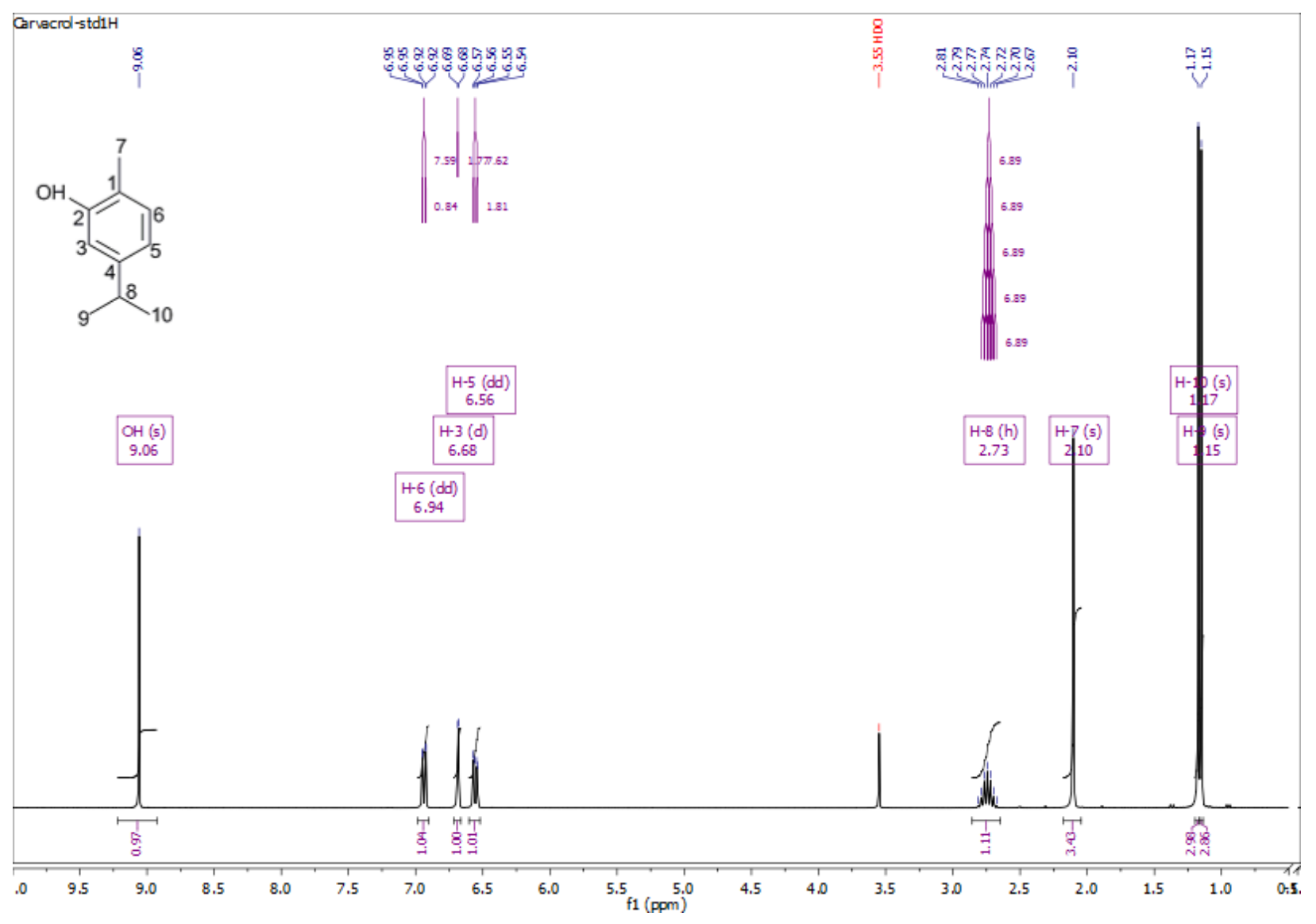


Figure S12b. ${ }^{13} \mathrm{C}-\mathrm{NMR}$ (75 MHz, DMSO- $d_{6}$ ) of 4.

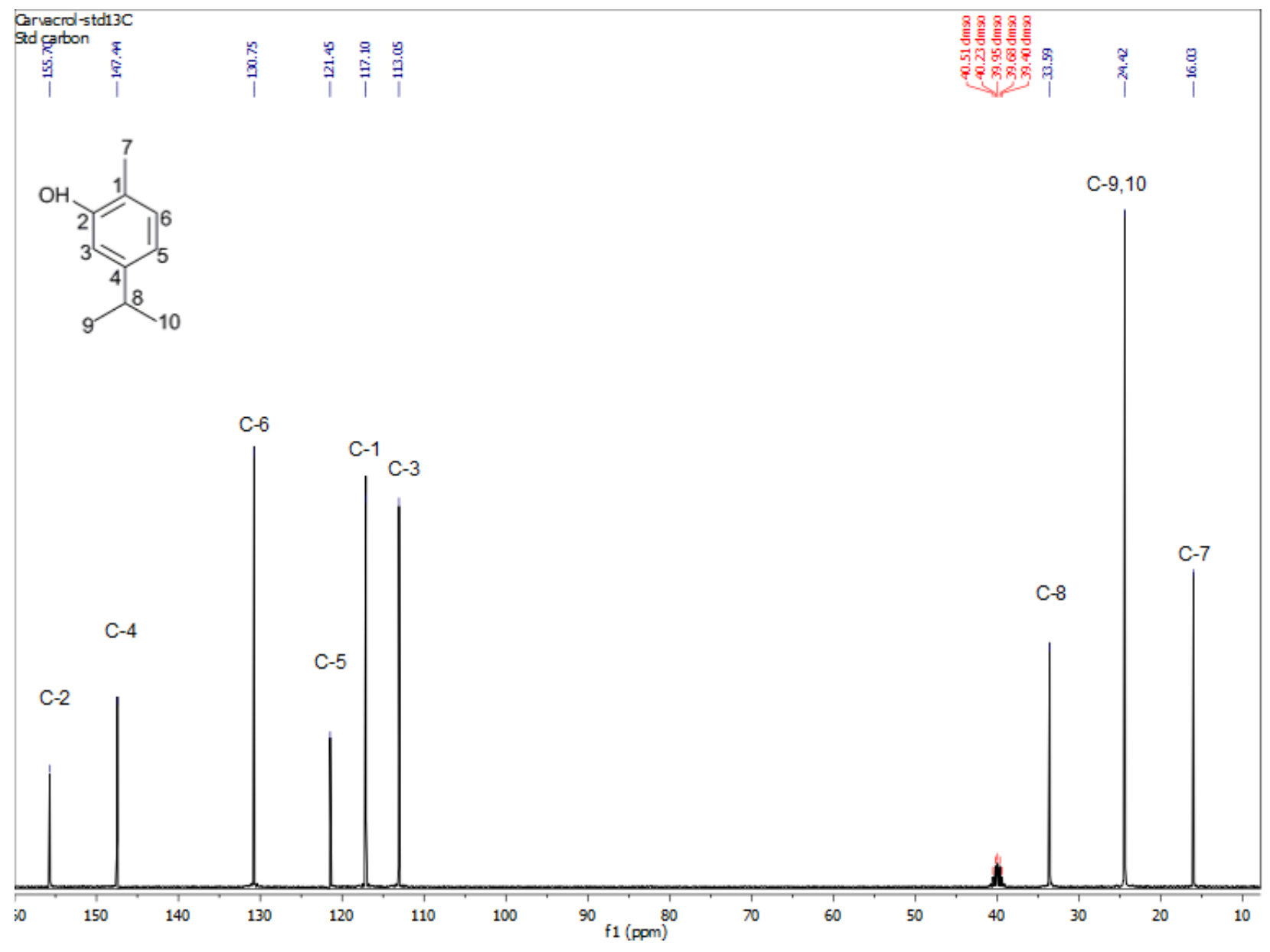


Figure S12c. ${ }^{1} \mathrm{H}-\mathrm{NMR}\left(300 \mathrm{MHz}\right.$, DMSO- $\left.d_{6}\right)$ of $\mathbf{4 a}$.

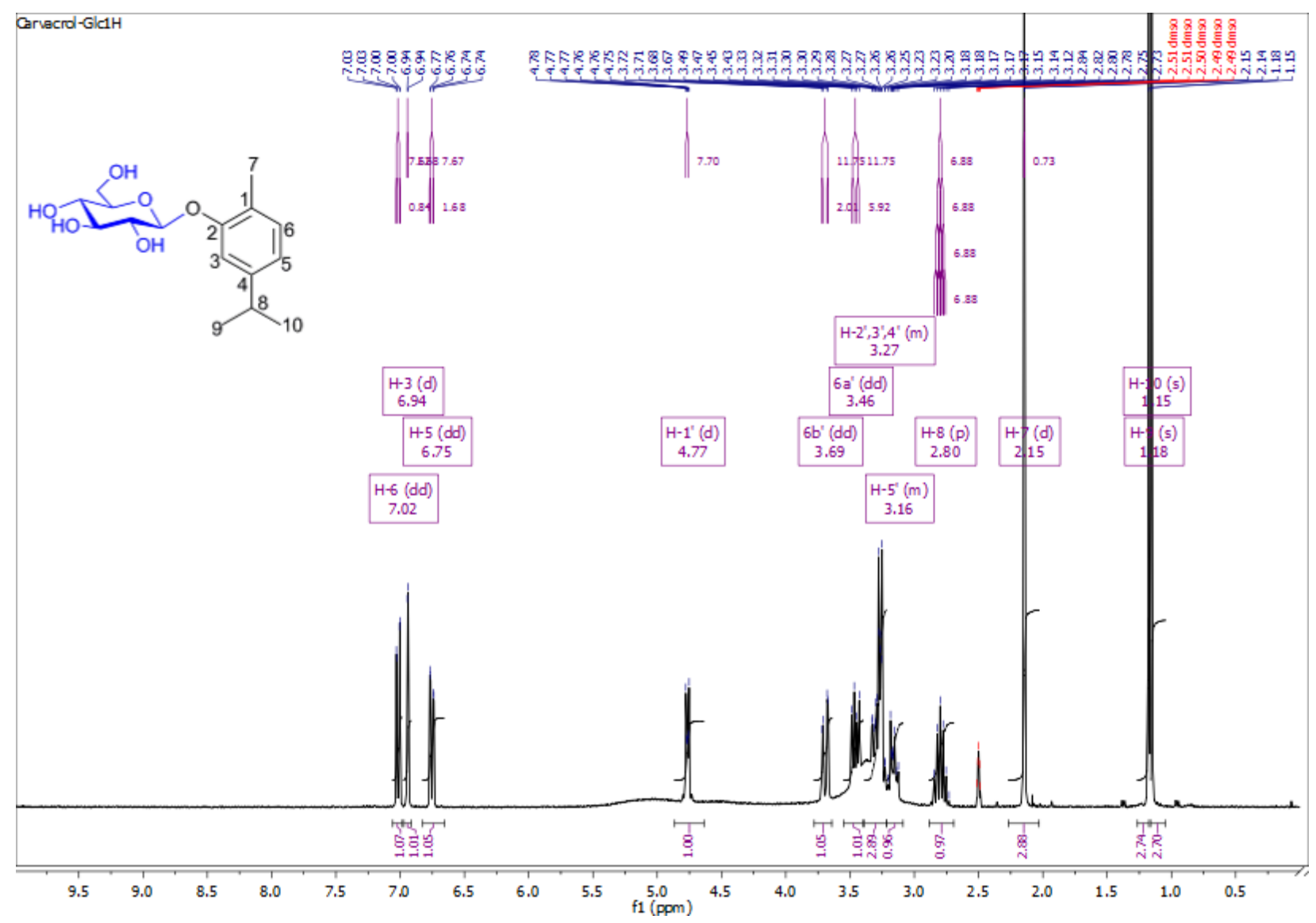


Figure S12d. ${ }^{13} \mathrm{C}-\mathrm{NMR}\left(75 \mathrm{MHz}\right.$, DMSO- $d_{6}$ ) of $\mathbf{4 a}$.

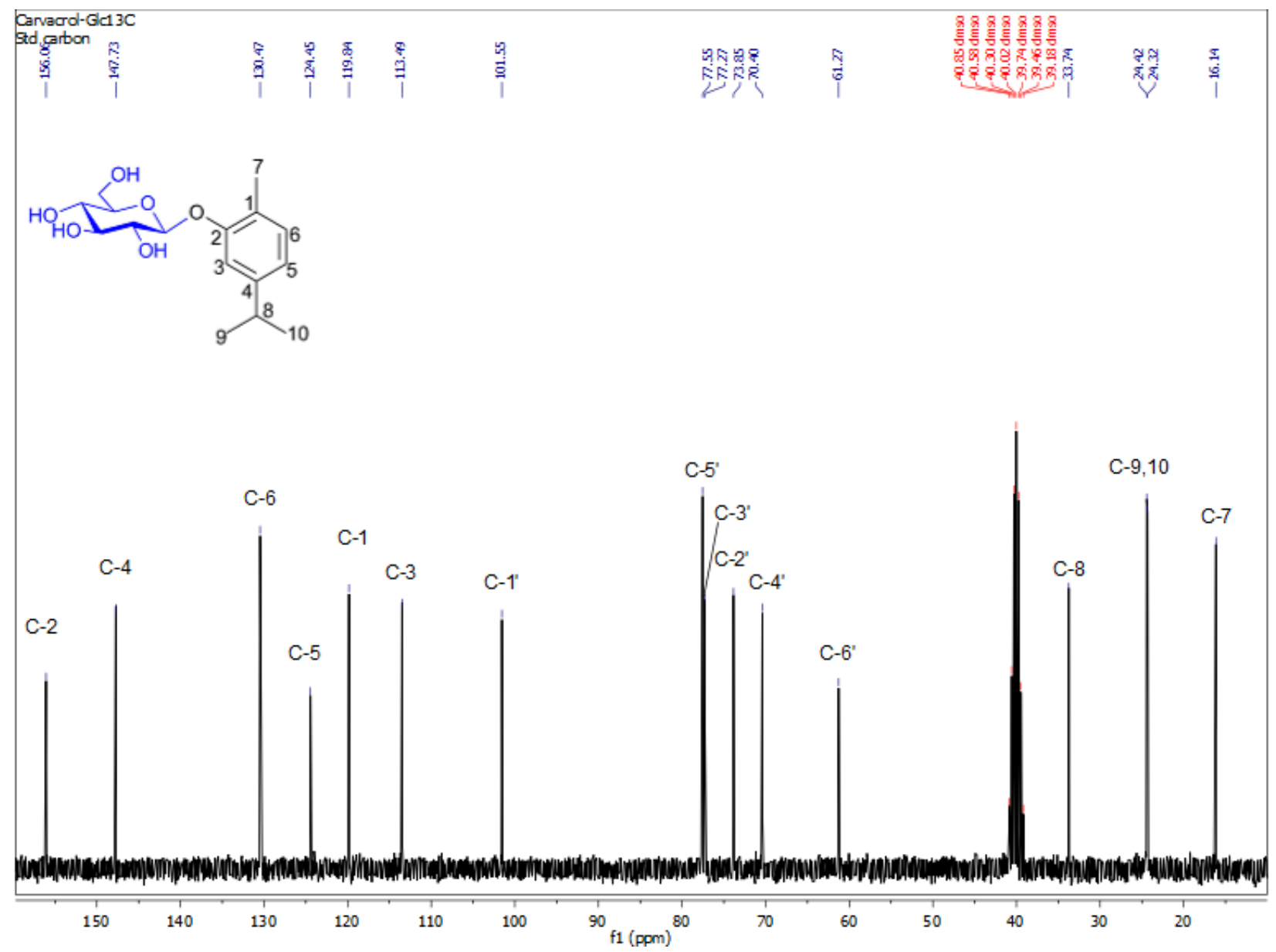


Figure S13a. ${ }^{1} \mathrm{H}-\mathrm{NMR}\left(300 \mathrm{MHz}, \mathrm{DMSO}-d_{6}\right)$ of 5.

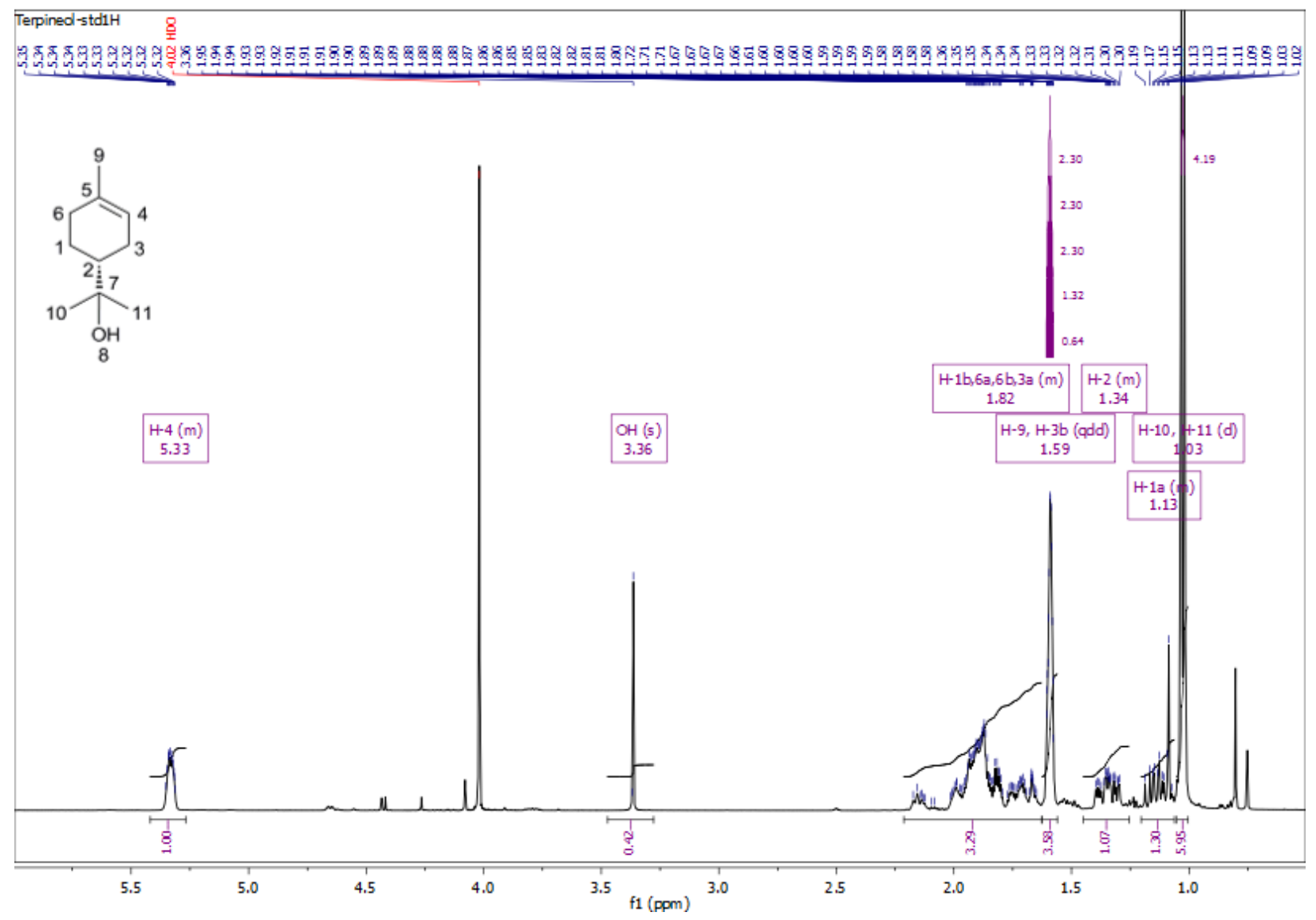


Figure S13b. ${ }^{13} \mathrm{C}-\mathrm{NMR}\left(75 \mathrm{MHz}, \mathrm{DMSO}-d_{6}\right)$ of 5.

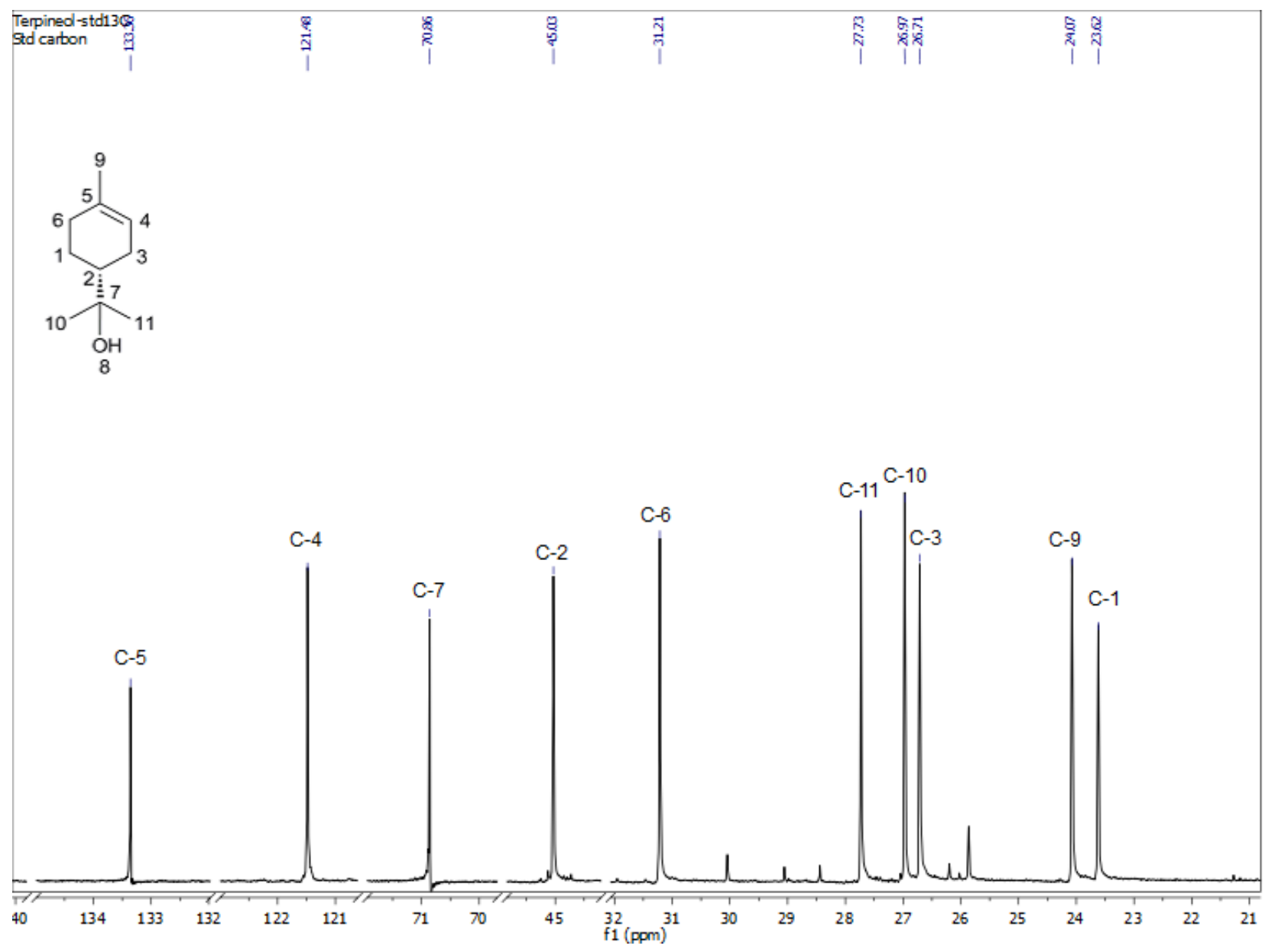


Figure S13c. ${ }^{1} \mathrm{H}-\mathrm{NMR}\left(300 \mathrm{MHz}, \mathrm{DMSO}-d_{6}\right)$ of $\mathbf{5 a}$.

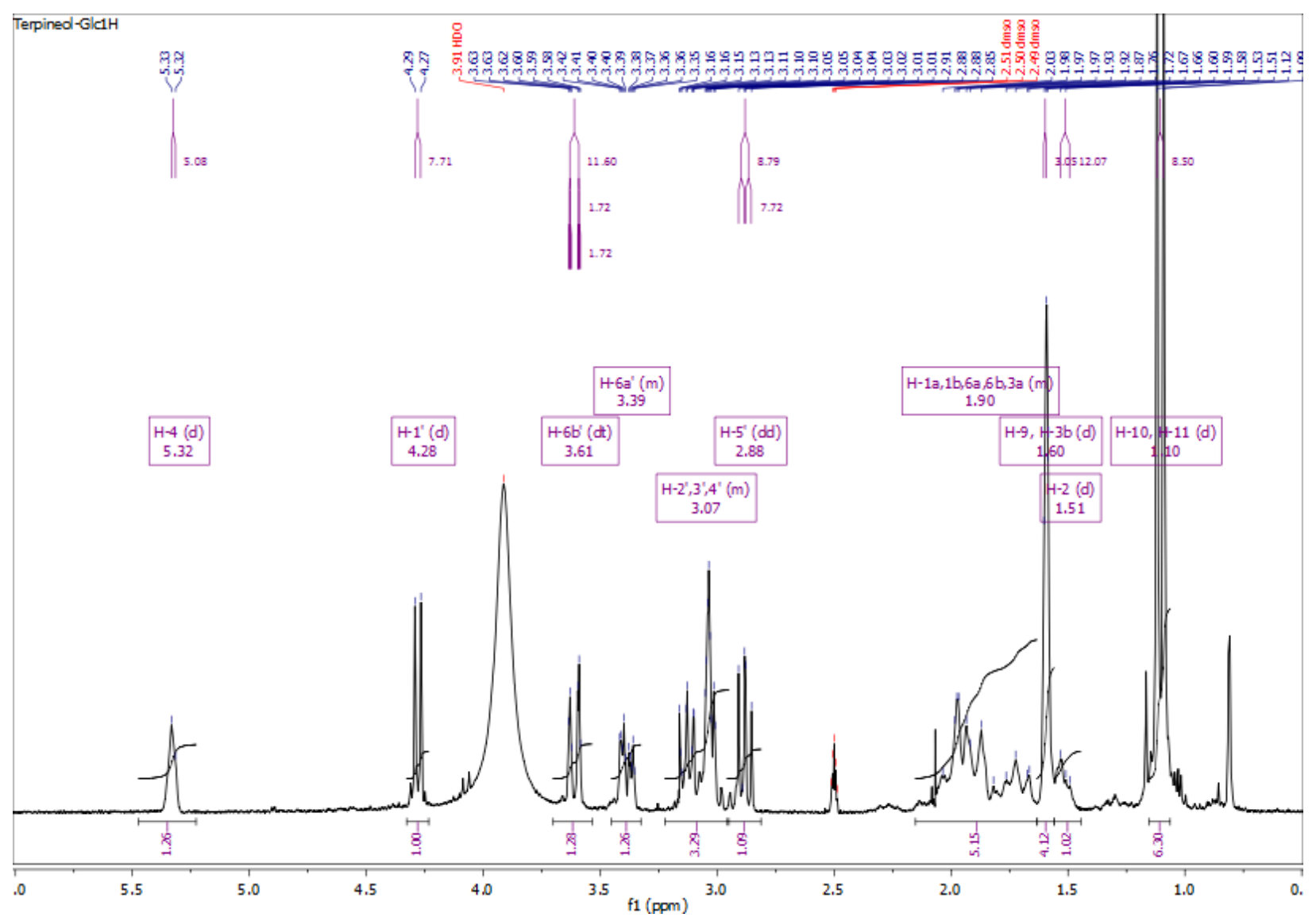


Figure S13d. ${ }^{13} \mathrm{C}-\mathrm{NMR}\left(75 \mathrm{MHz}\right.$, DMSO- $d_{6}$ ) of $\mathbf{5 a}$.

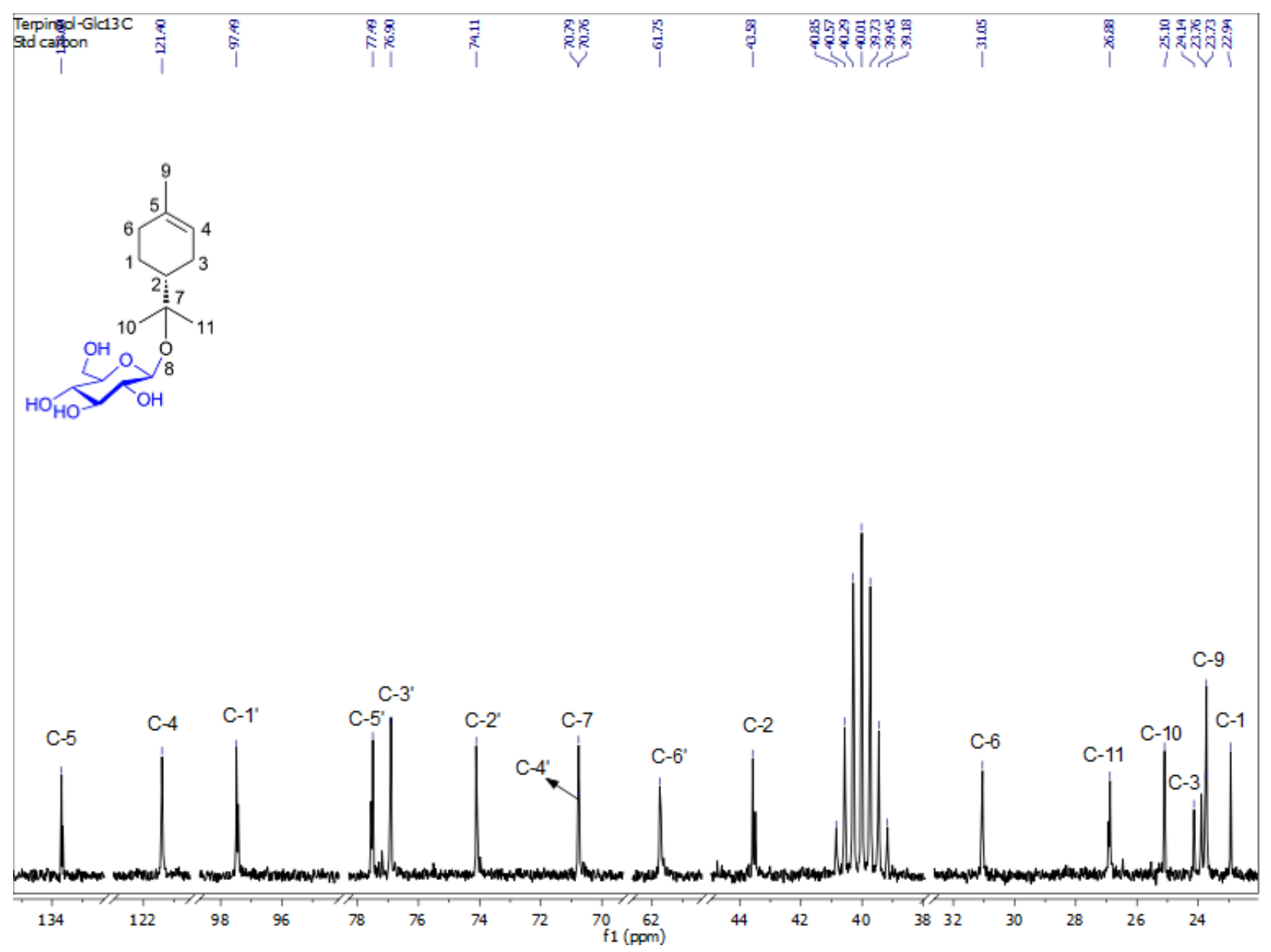


Figure S14a. ${ }^{1} \mathrm{H}-\mathrm{NMR}\left(300 \mathrm{MHz}, \mathrm{DMSO}-d_{6}\right)$ of 6.

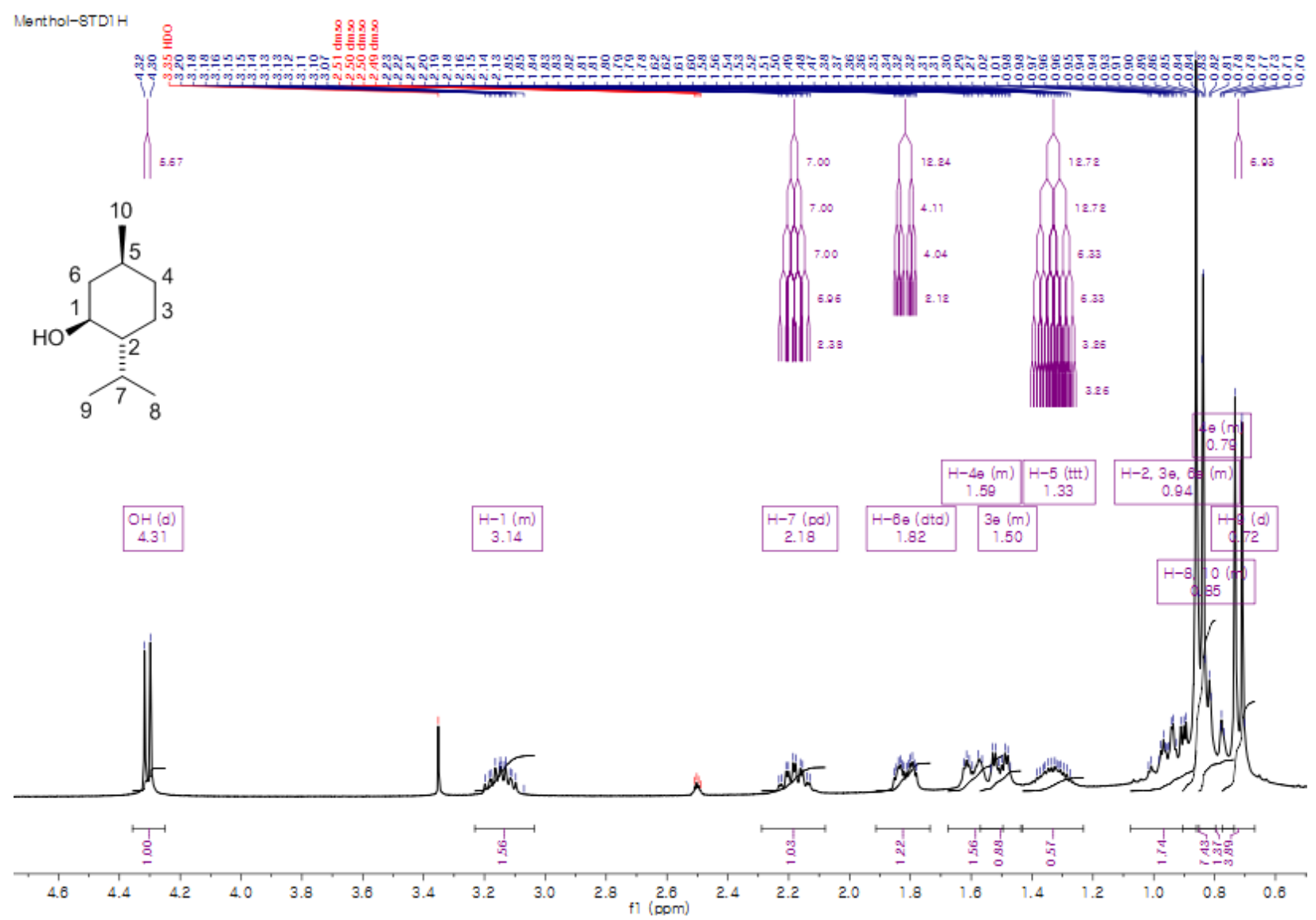


Figure S14b. ${ }^{13} \mathrm{C}-\mathrm{NMR}\left(75 \mathrm{MHz}, \mathrm{DMSO}-d_{6}\right)$ of 6.

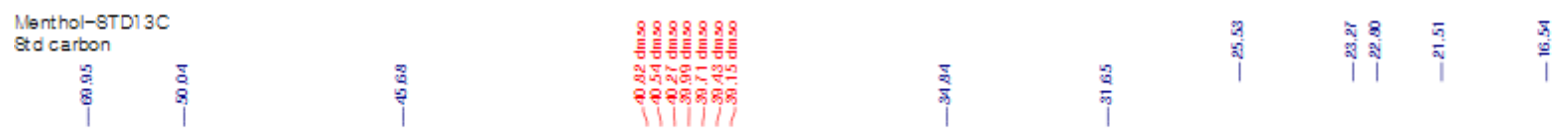

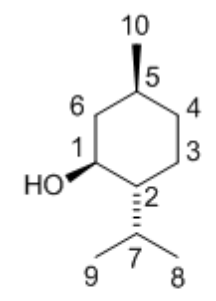

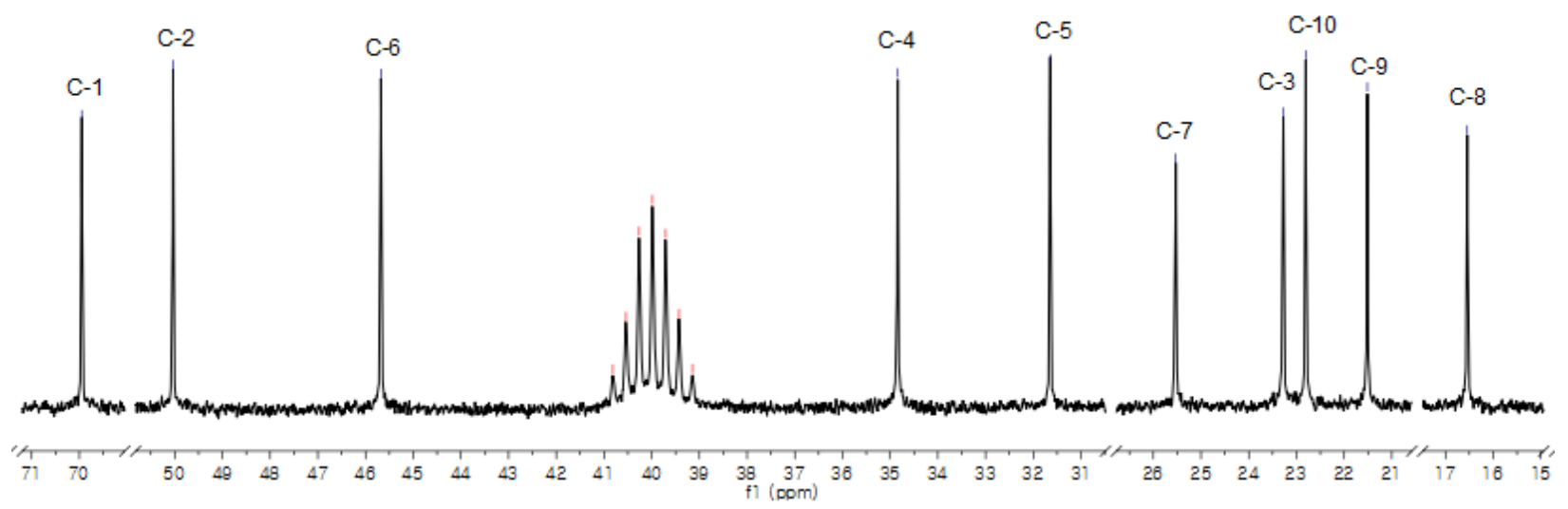


Figure S14c. ${ }^{1} \mathrm{H}-\mathrm{NMR}\left(300 \mathrm{MHz}, \mathrm{DMSO}-d_{6}\right)$ of $\mathbf{6 a}$.

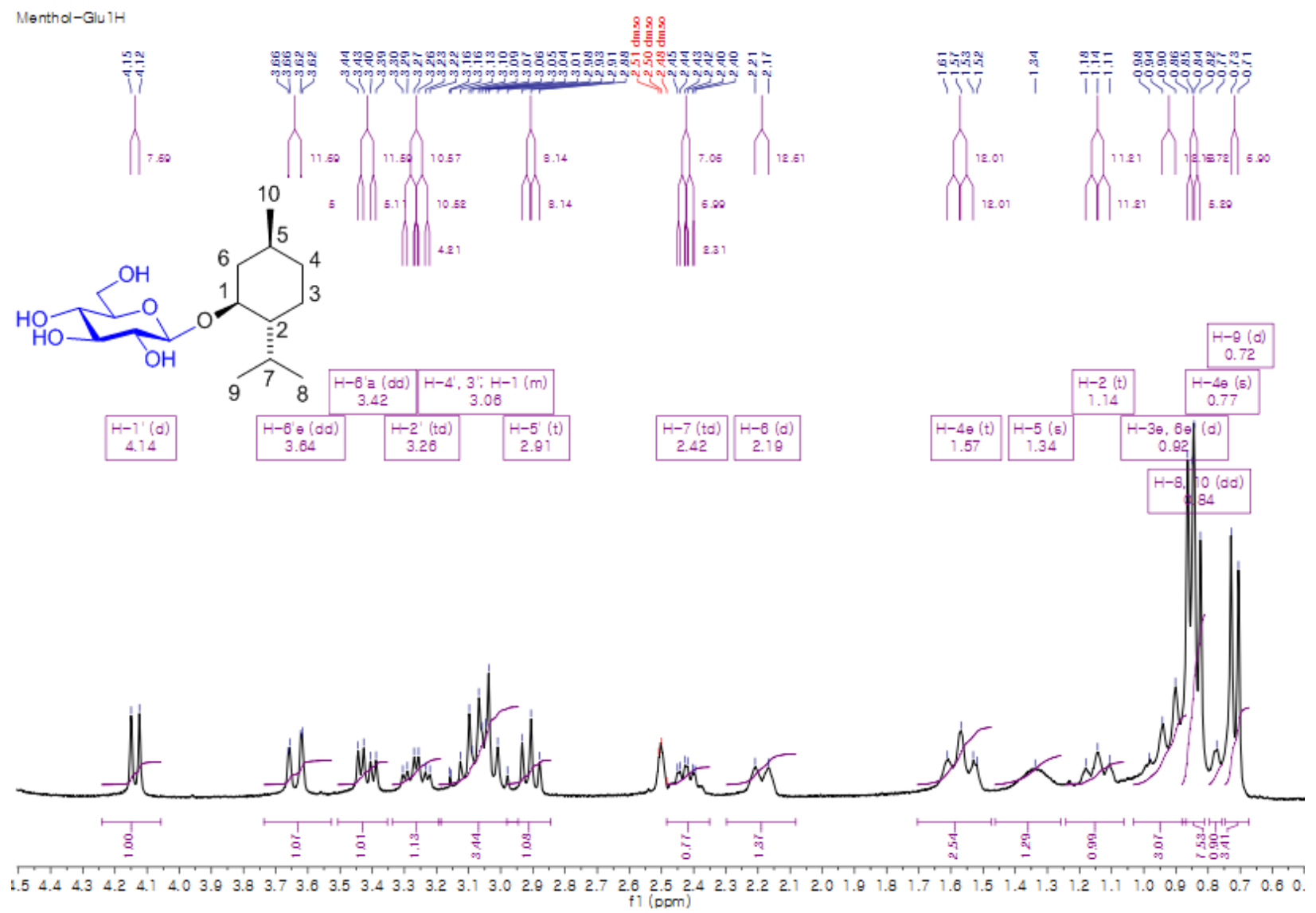


Figure S14d. ${ }^{13} \mathrm{C}-\mathrm{NMR}\left(75 \mathrm{MHz}\right.$, DMSO- $d_{6}$ ) of $\mathbf{6 a}$.

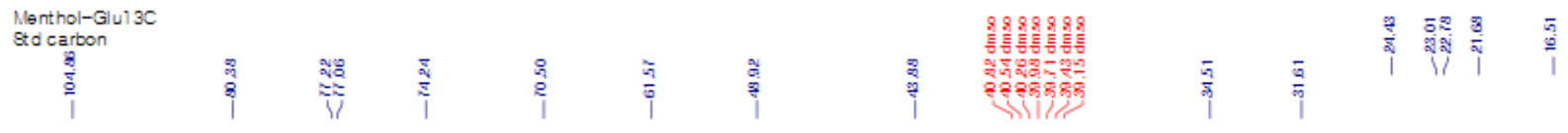

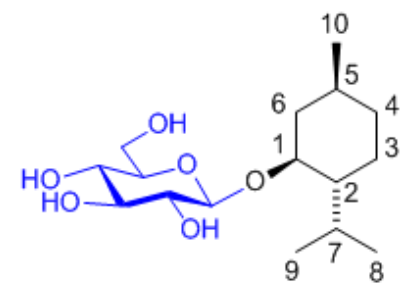

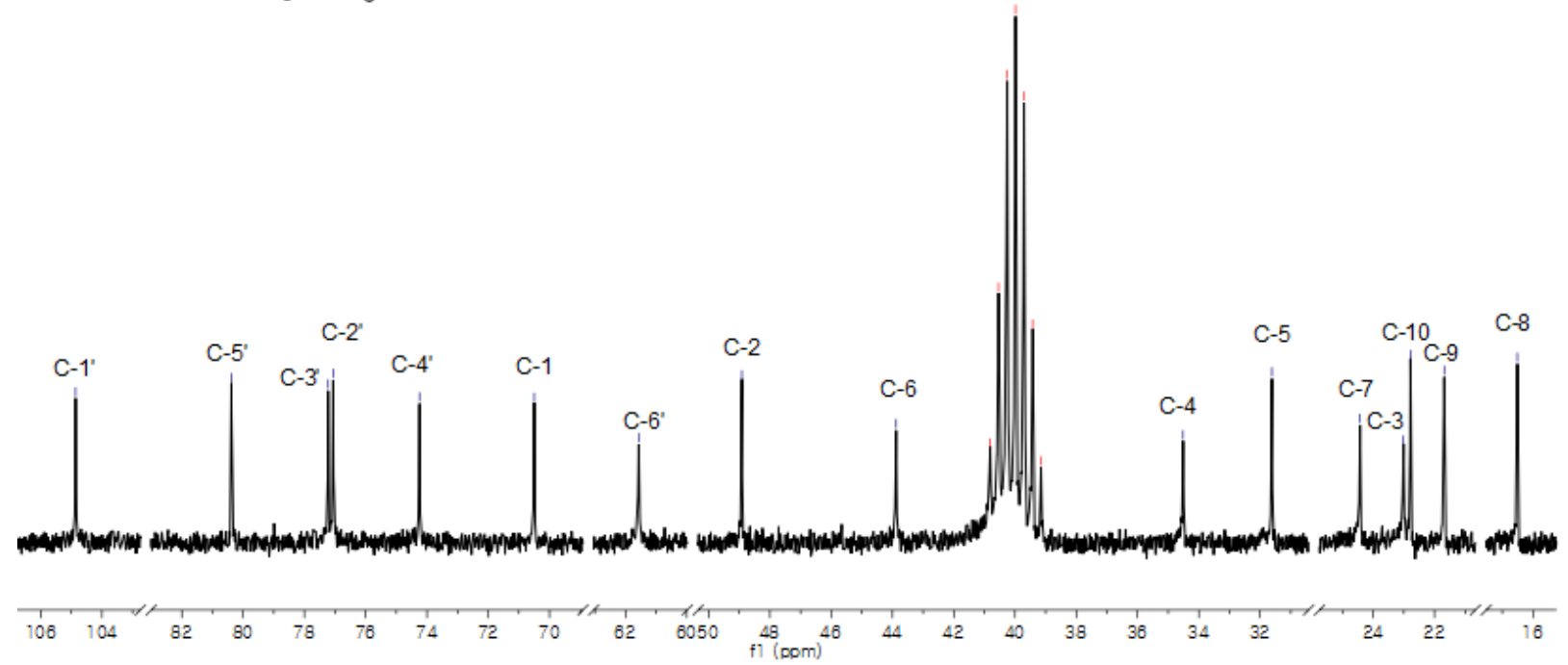


Figure S15a. ${ }^{1} \mathrm{H}-\mathrm{NMR}\left(300 \mathrm{MHz}, \mathrm{DMSO}-d_{6}\right)$ of 7.

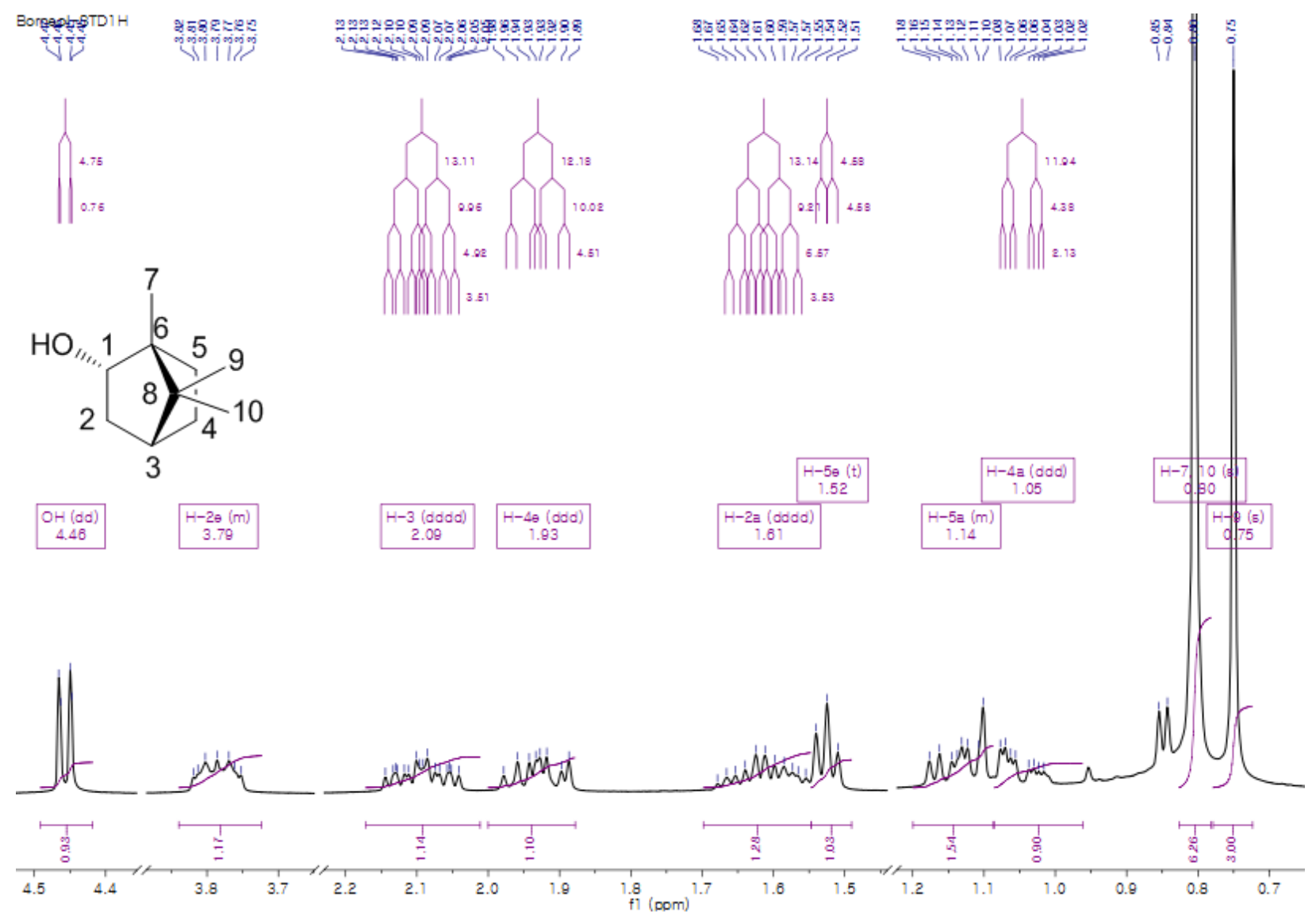


Figure S15b. ${ }^{13} \mathrm{C}-\mathrm{NMR}(75 \mathrm{MHz}$, DMSO-d $)$ of 7.
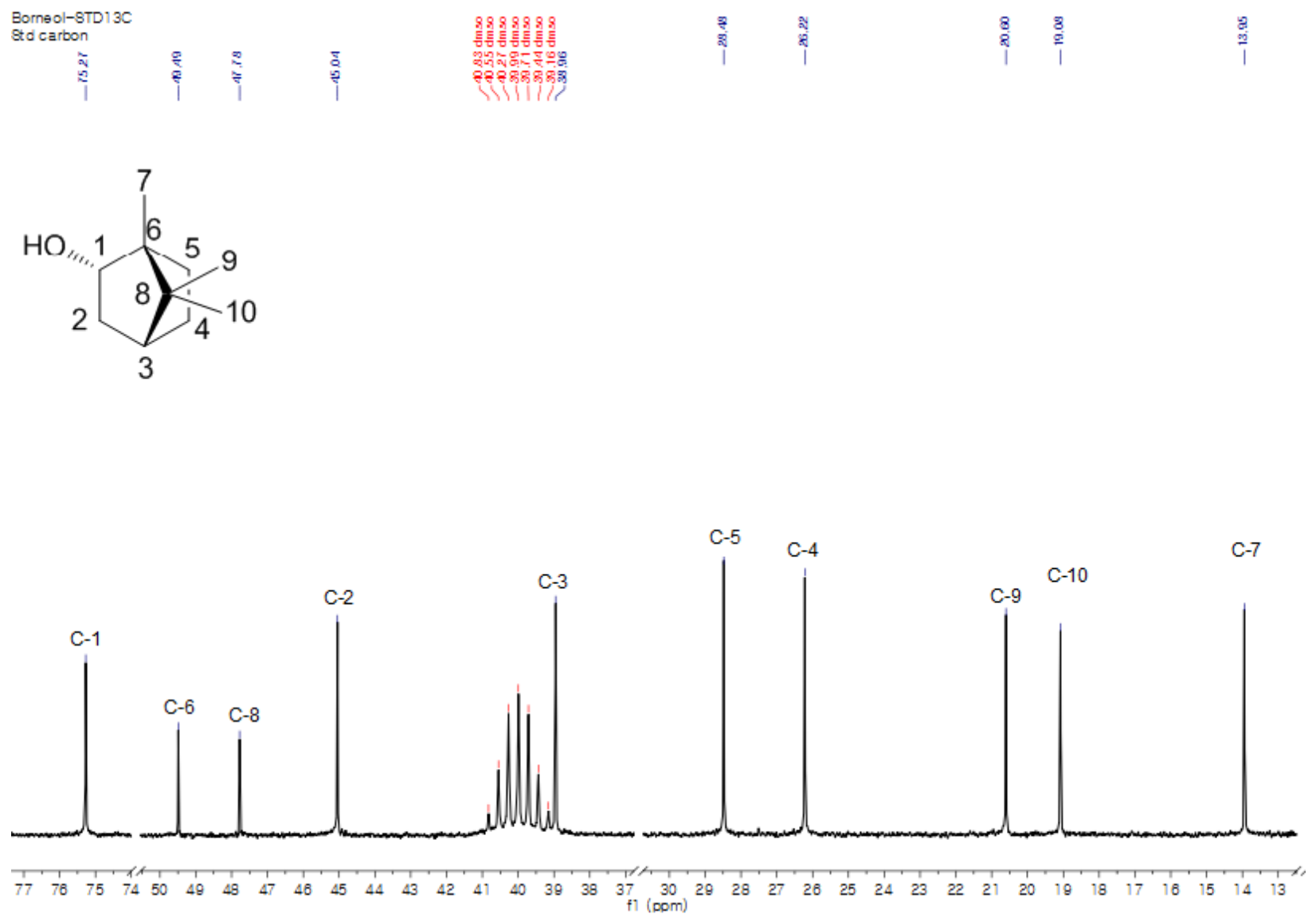
Figure S15c. ${ }^{1} \mathrm{H}-\mathrm{NMR}\left(300 \mathrm{MHz}\right.$, DMSO- $\left.d_{6}\right)$ of $\mathbf{7 a}$.

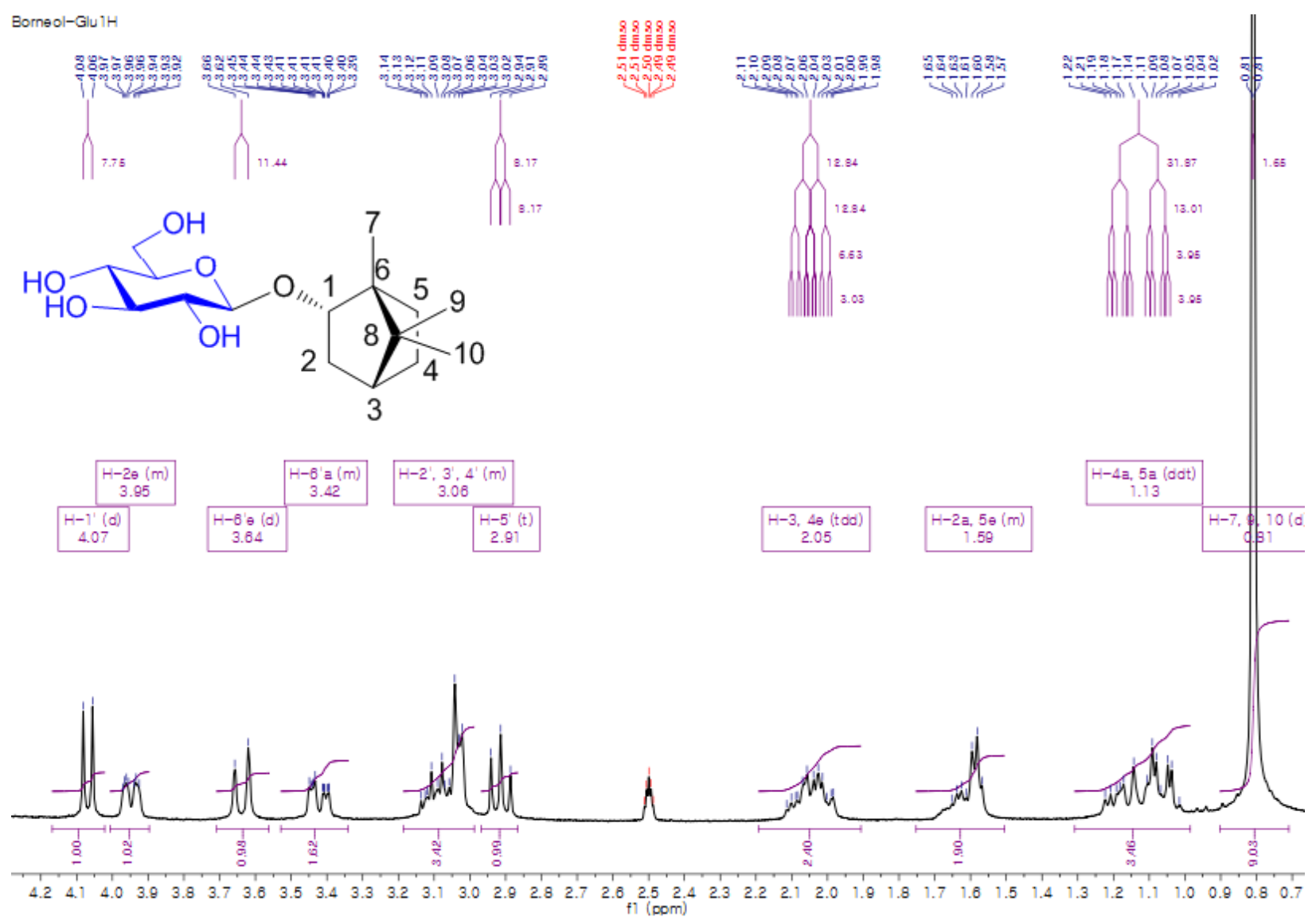


Figure S15d. ${ }^{13} \mathrm{C}-\mathrm{NMR}\left(75 \mathrm{MHz}\right.$, DMSO- $d_{6}$ ) of $7 \mathbf{a}$.
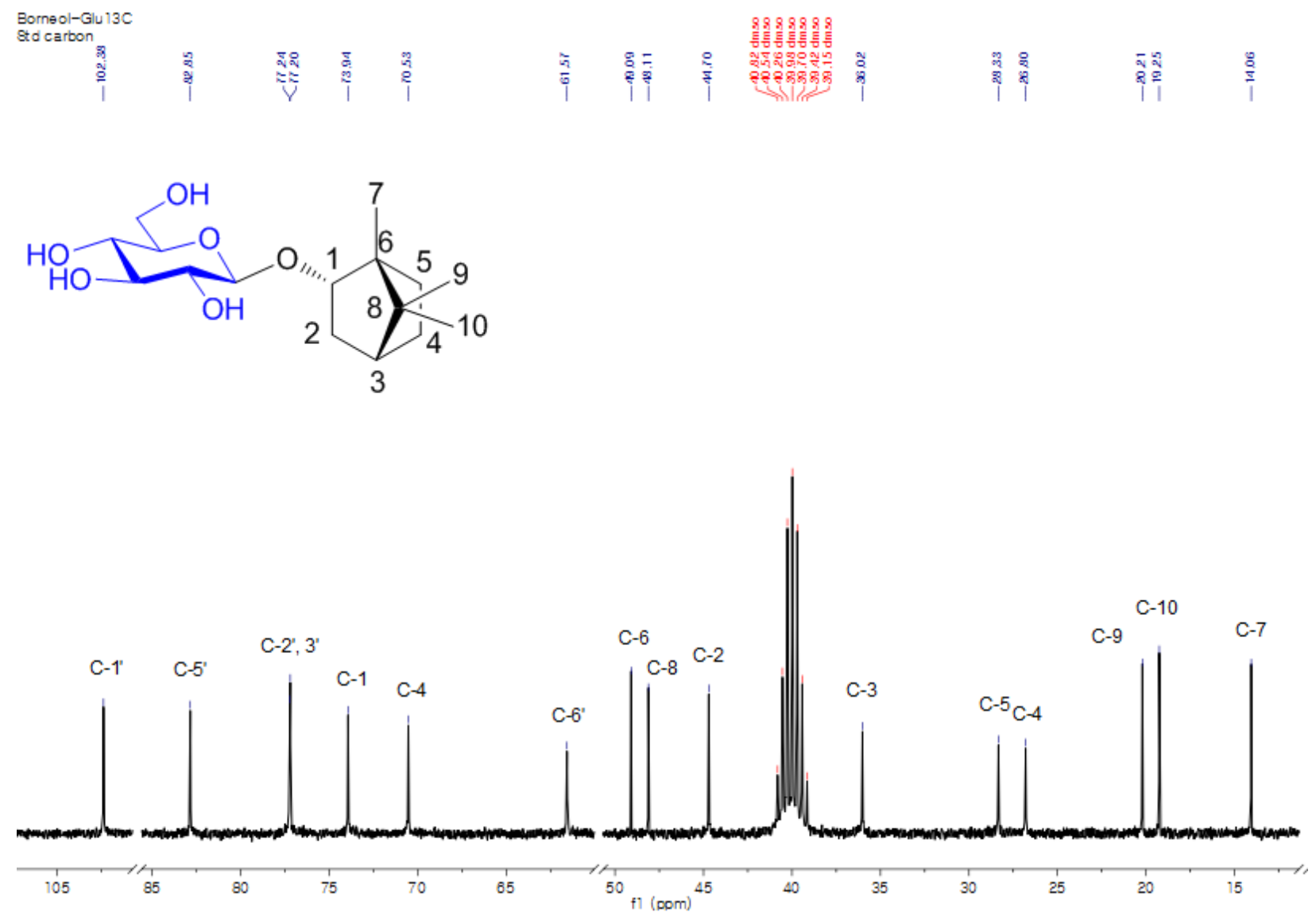


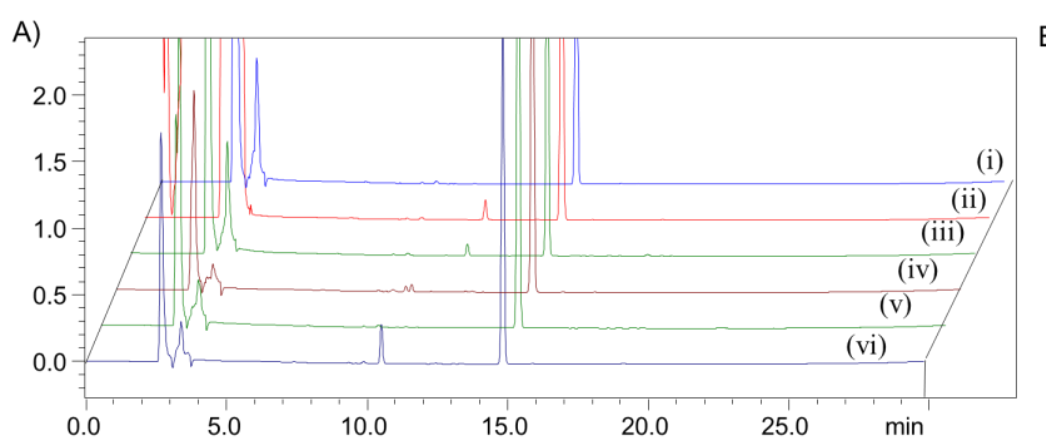

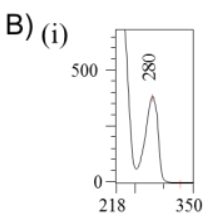

(iv)

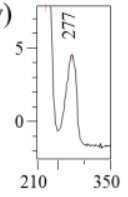

(ii)

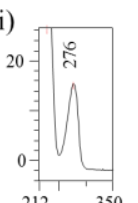

(v) $212 \quad 350$ (vi)

iii)

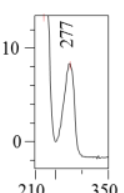

(vi)

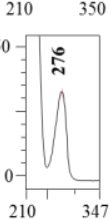

C) (i)

(ii)
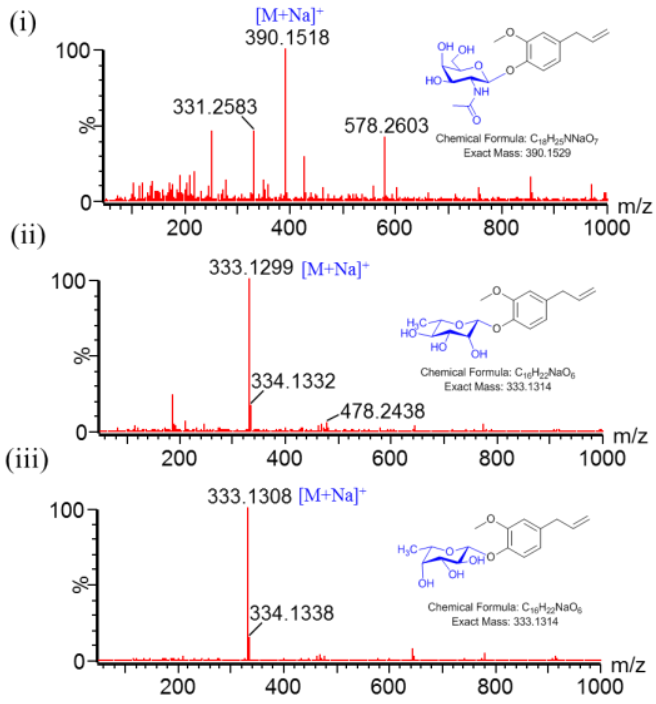

(iv)
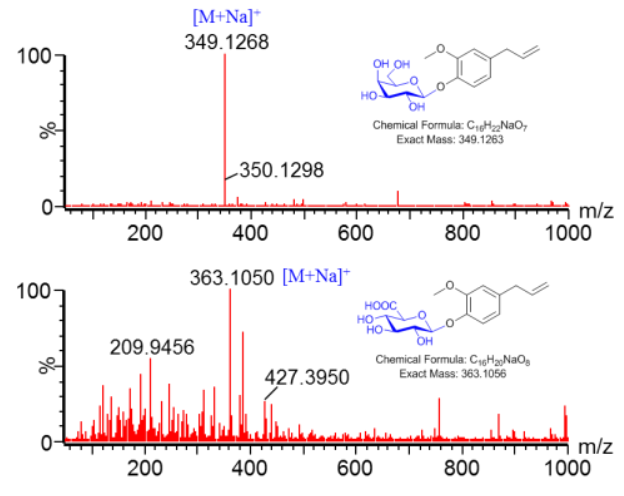

(vi)

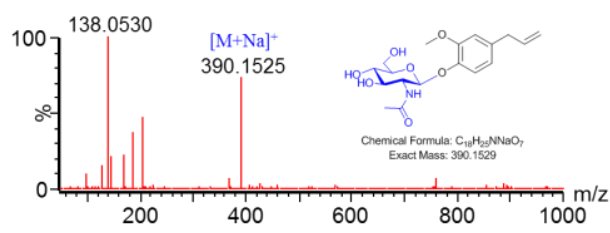

Figure S16. Chromatographic and spectrometric analysis of glycosylation reaction of 1 with different NDP-sugars. A) HPLC-PDA analysis of reaction of 1 with i) UDP- $N$-acetylgalactosamine, ii) TDP-L-rhamnose, iii) GDP-L-fucose, iv) UDP-D-Galactose, v) UDP-Dglucuronic acid, and vi) UDP- $N$-acetyl-glucosamine. B) UV-VIS of i) standard 1, ii) product peak of reaction with TDP-L-rhamnose, iii) product peak of reaction with GDP-L-fucose, iv) product peak of reaction with UDP-D-galactose, v) product peak of reaction with UDP-D-glucuronic acid, and vi) product peak of reaction with UDP- $N$-acetyl-glucosamine. C) HR-QTOF-ESI/MS of product peak of reaction mixture with i) UDP- $N$-acetyl-galactosamine, ii) TDP-L-rhamnose, iii) GDP-L-fucose, iv) UDP-D-galactose, v) UDP-D-glucuronic acid, and vi) UDP- $N$-acetylglucosamine. 


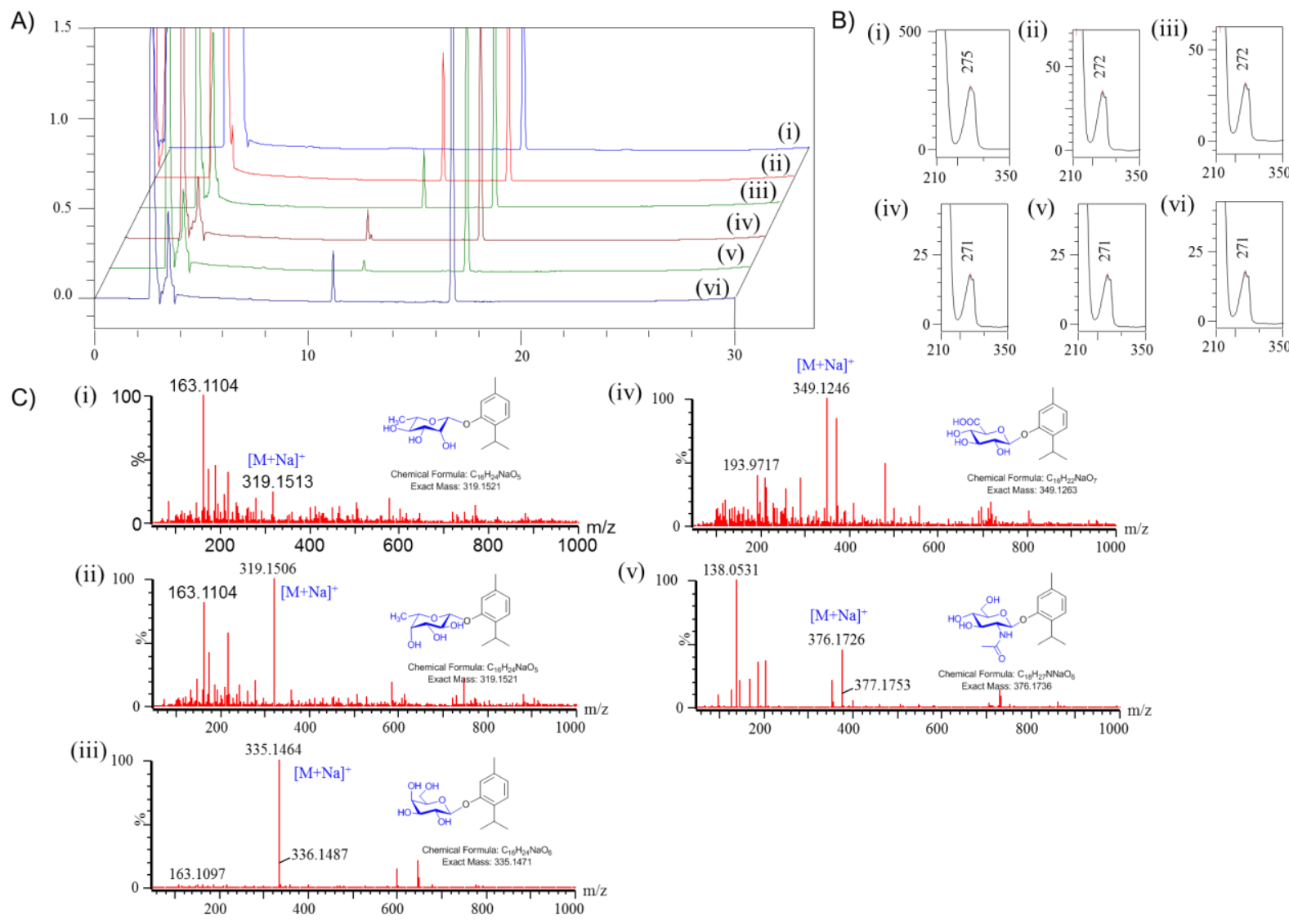

Figure S17. Chromatographic and spectrometric analysis of glycosylation reaction of 2 with different NDP-sugars. A) HPLC-PDA analysis of glycosylation reaction of 2 with i) UDP- $N$ acetyl-galactosamine, ii) TDP-L-rhamnose, iii) GDP-L-fucose, iv) UDP-D-Galactose, v) UDP-Dglucuronic acid, and vi) UDP- $N$-acetyl-glucosamine. B) UV-VIS of i) standard 2, ii) product peak of reaction with TDP-L-rhamnose, iii) product peak of reaction with GDP-L-fucose, iv) product peak of reaction with UDP-D-galactose, v) product peak of reaction with UDP-D-glucuronic acid, and vi) product peak of reaction with UDP-N-acetyl-glucosamine. C) HR-QTOF-ESI/MS of product peak of reaction mixture with i) TDP-L-rhamnose, ii) GDP-L-fucose, iii) UDP-Dgalactose, iv) UDP-D-glucuronic acid, and v) UDP- $N$-acetyl-glucosamine. 
A)

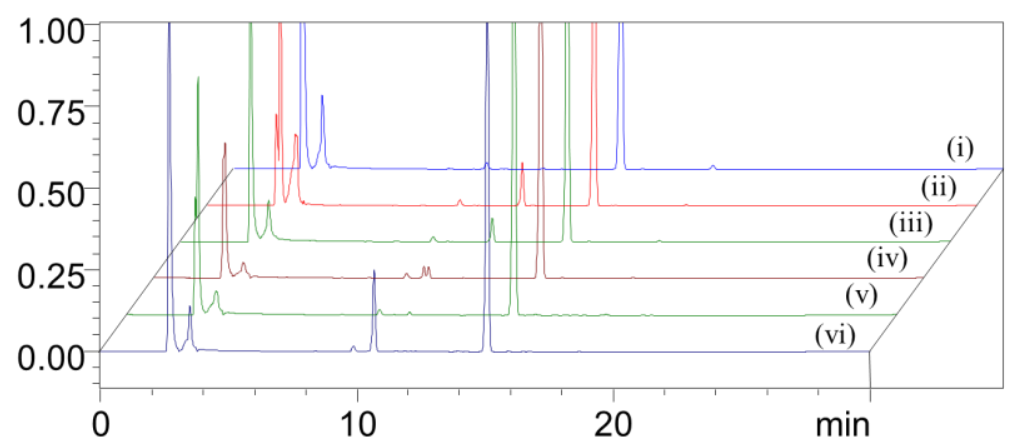

B)

(i) 1

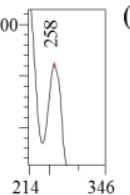

(iv)

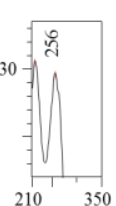

(ii) 150

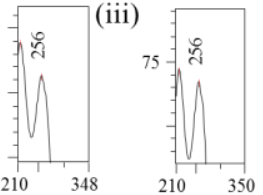

(v)

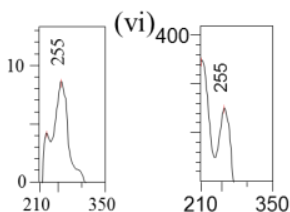

C)

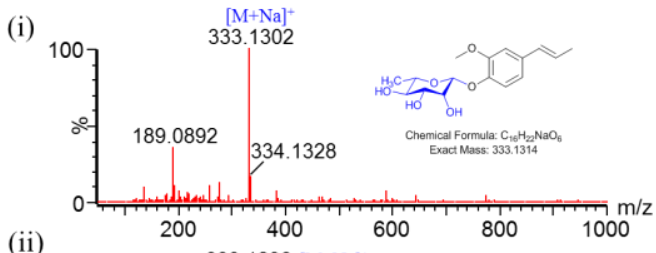

(ii)

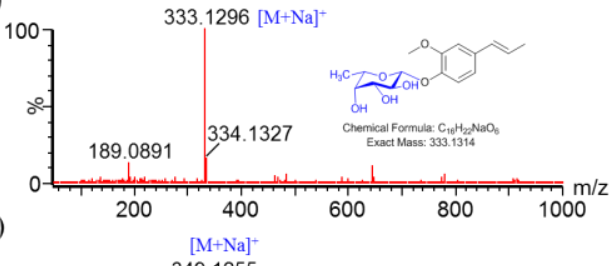

(iv)

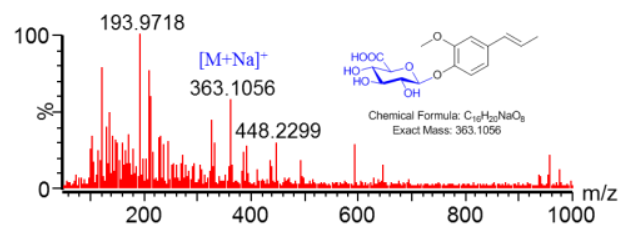

(v)

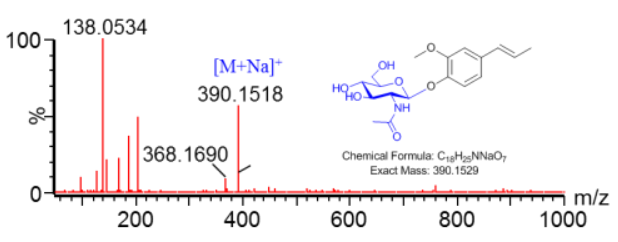

Figure S18. Chromatographic and spectrometric analysis of glycosylation reaction of $\mathbf{3}$ with different NDP-sugars. A) HPLC-PDA analysis of glycosylation reaction of 3 with i) UDP- $N$ acetyl-galactosamine, ii) TDP-L-rhamnose, iii) GDP-L-fucose, iv) UDP-D-Galactose, v) UDP-Dglucuronic acid, and vi) UDP- $N$-acetyl-glucosamine. B) UV-VIS of i) standard 3, ii) product peak of reaction with TDP-L-rhamnose, iii) product peak of reaction with GDP-L-fucose, iv) product peak of reaction with UDP-D-galactose, v) product peak of reaction with UDP-D-glucuronic acid, and vi) product peak of reaction with UDP-N-acetyl-glucosamine. C) HR-QTOF-ESI/MS of product peak of reaction mixture with i) TDP-L-rhamnose, ii) GDP-L-fucose, iii) UDP-Dgalactose, iv) UDP-D-glucuronic acid, and vi) UDP- $N$-acetyl-glucosamine. 
A)

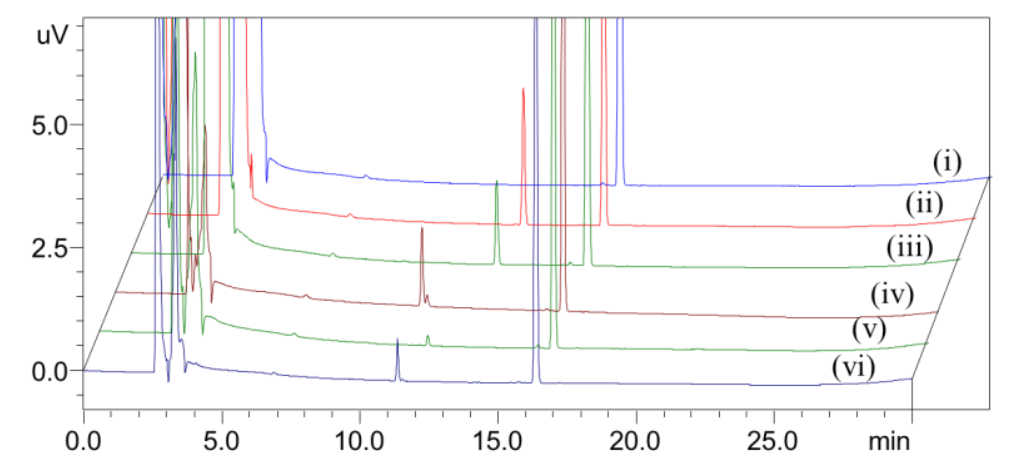

C)

(i)

(ii)

$$
\text { (i) } 100
$$

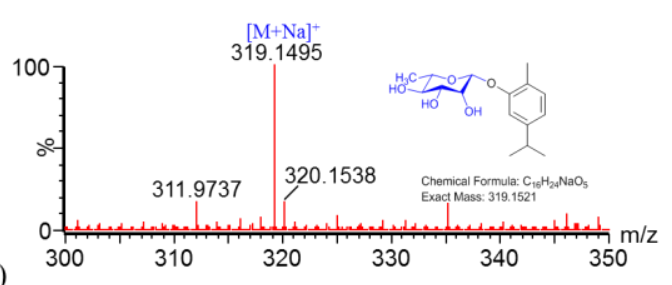

(iv)

(v)

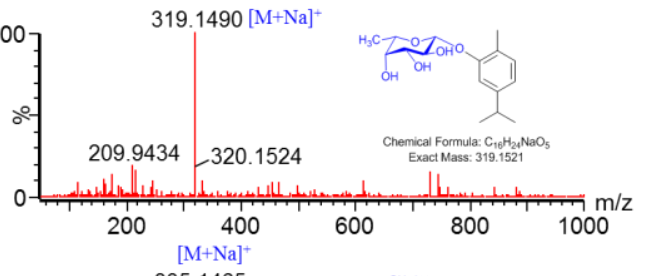

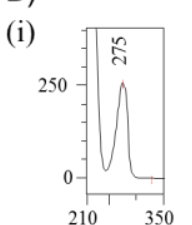

(iv)

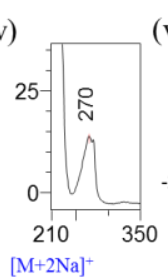

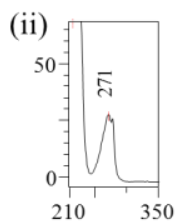

(v)

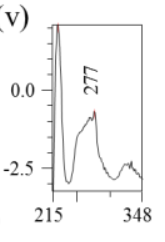

(iii)

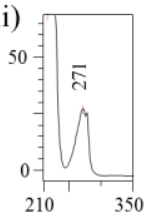

(vi)

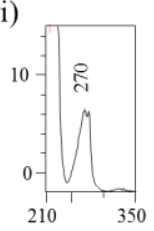

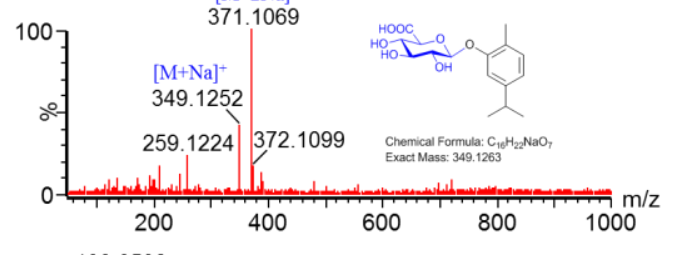
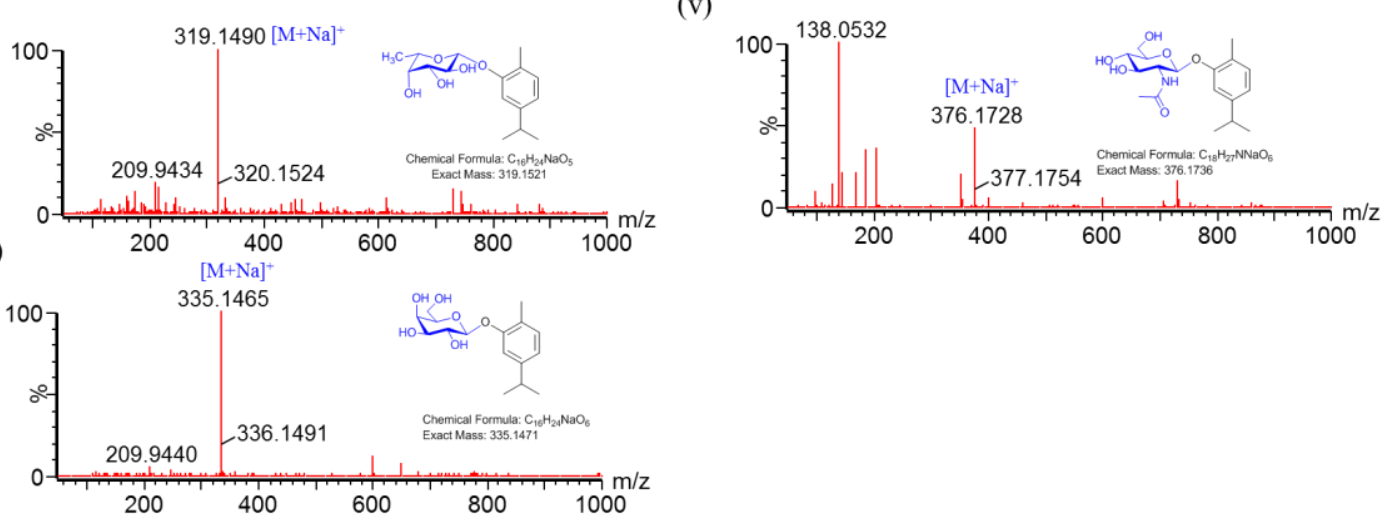

Figure S19. Chromatographic and spectrometric analysis of glycosylation reaction of 4 with different NDP-sugars. A) HPLC-PDA analysis of glycosylation reaction of 4 with i) UDP- $N$ acetyl-galactosamine, ii) TDP-L-rhamnose, iii) GDP-L-fucose, iv) UDP-D-Galactose, v) UDP-Dglucuronic acid, and vi) UDP- $N$-acetyl-glucosamine. B) UV-VIS of i) standard 4, ii) product peak of reaction with TDP-L-rhamnose, iii) product peak of reaction with GDP-L-fucose, iv) product peak of reaction with UDP-D-galactose, v) product peak of reaction with UDP-D-glucuronic acid, and vi) product peak of reaction with UDP-N-acetyl-glucosamine. C) HR-QTOF-ESI/MS of product peak of reaction mixture with i) TDP-L-rhamnose, ii) GDP-L-fucose, iii) UDP-Dgalactose, iv) UDP-D-glucuronic acid, and v) UDP- $N$-acetyl-glucosamine. 
A)

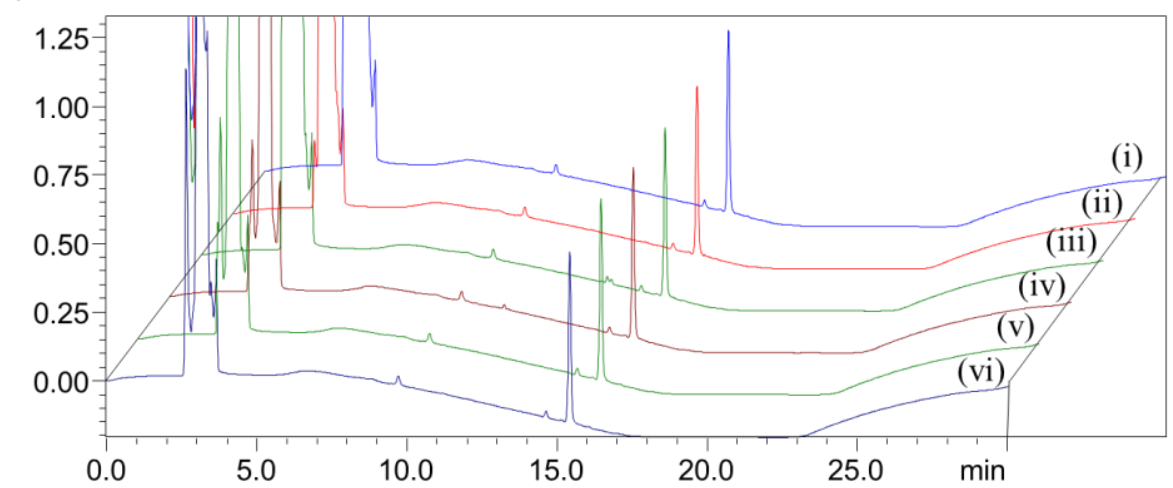

C)

(i)

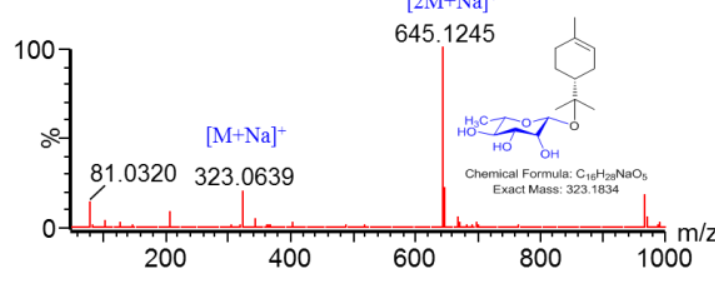

(ii)

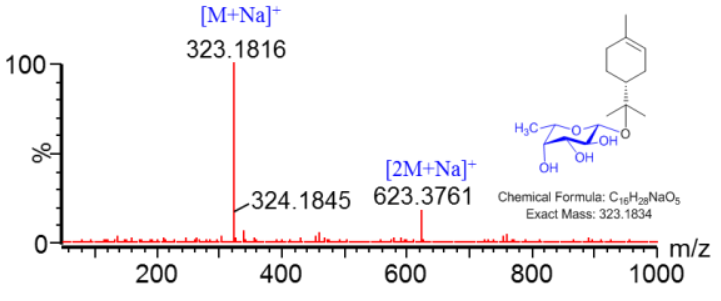

B)

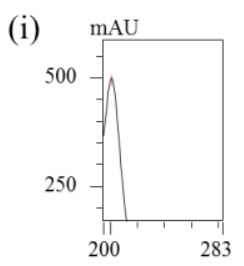

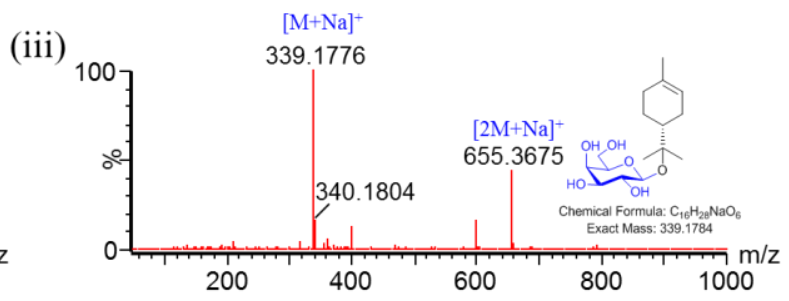

Figure S20. Chromatographic and spectrometric analysis of glycosylation reaction of 5 with different NDP-sugars. A) HPLC-PDA analysis of glycosylation reaction of 5 with i) UDP- $N$ acetyl-galactosamine, ii) TDP-L-rhamnose, iii) GDP-L-fucose, iv) UDP-D-Galactose, v) UDP-Dglucuronic acid, and vi) UDP- $N$-acetyl-glucosamine. B) UV-VIS of i) standard 5 C) HR-QTOF-ESI/MS of product peak of reaction mixture with i) TDP-L-rhamnose, ii) GDP-Lfucose, iii) UDP-D-galactose. 
A)

(i)

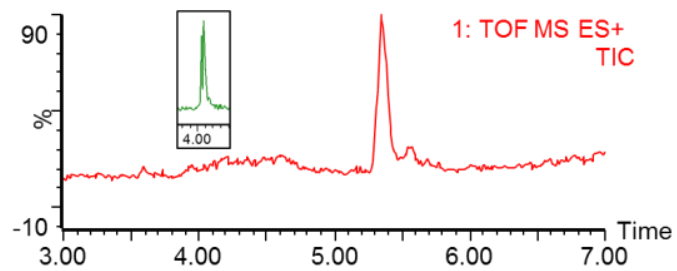

(ii)

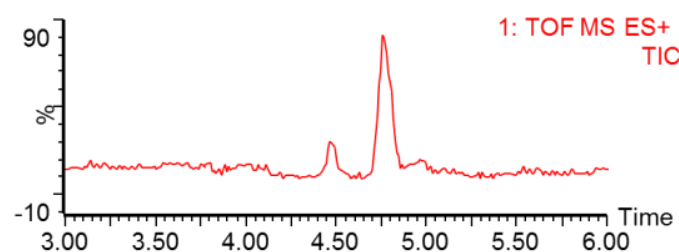

(iii)

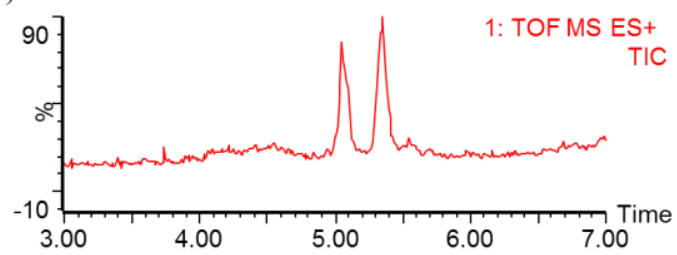

B)

(i)

(ii)
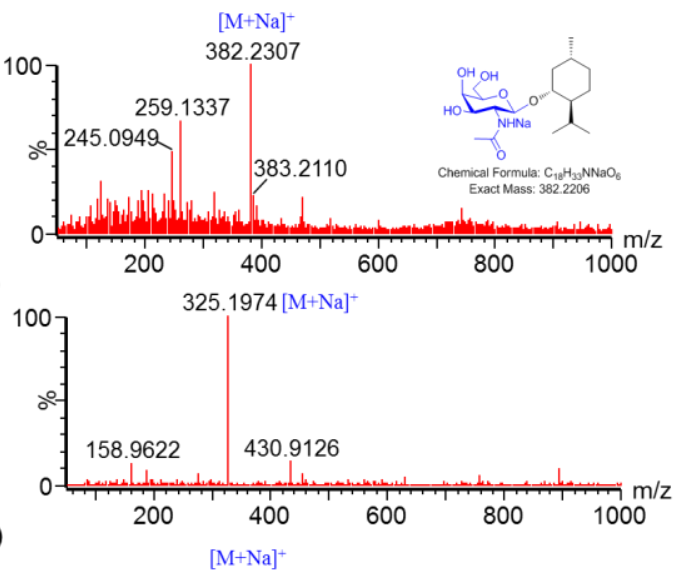

(iii)

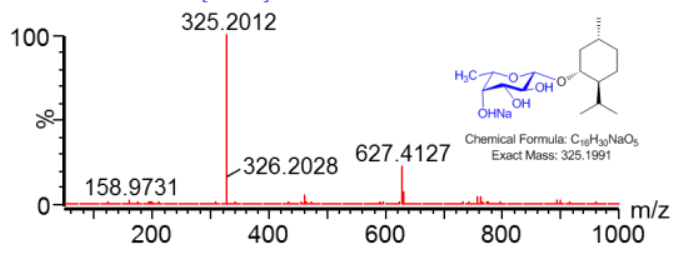

(iv)

(v)
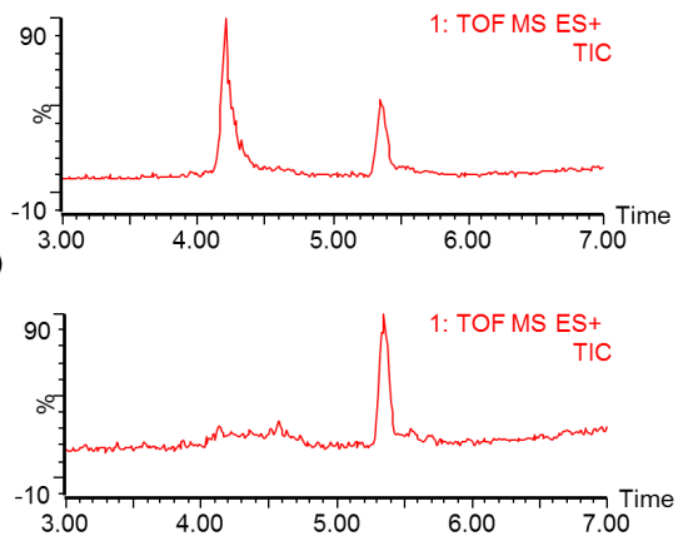

(vi)

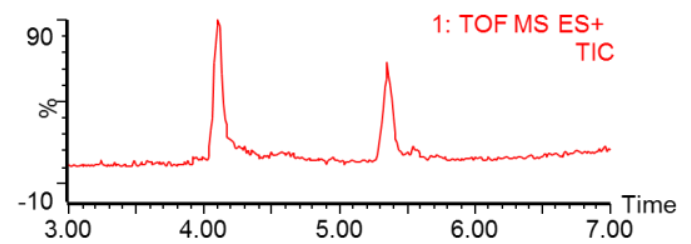

(iv)

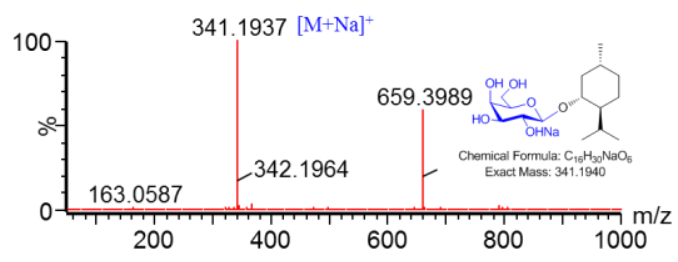

(v)

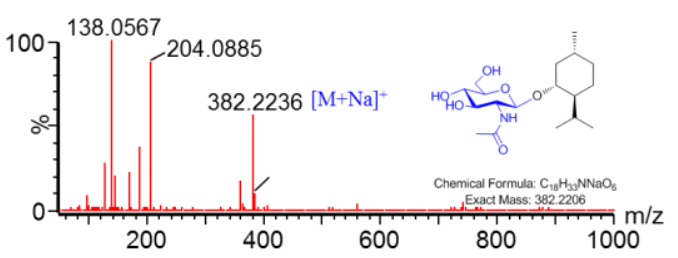

Figure S21. Spectrometric analysis of glycosylation reaction of 6 with different NDP-sugars.

A) ) HR-QTOF-ESI/MS total ion chromatogram (TIC) of glycosylation reaction of 6 with i) UDP$N$-acetyl-galactosamine, ii) TDP-L-rhamnose, iii) GDP-L-fucose, iv) UDP-D-Galactose, v) UDPD-glucuronic acid, and vi) UDP- $N$-acetyl-glucosamine. B) HR-QTOF-ESI/MS of product peak of reaction mixture of $\mathbf{6}$ with i) UDP- $N$-acetyl-galactosamine, ii) TDP-L-rhamnose, iii) GDP-Lfucose, iv) UDP-D-galactose, v) UDP- $N$-acetyl-glucosamine. 
A)

(i)

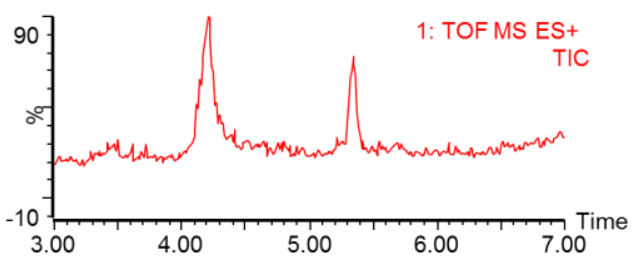

(ii)

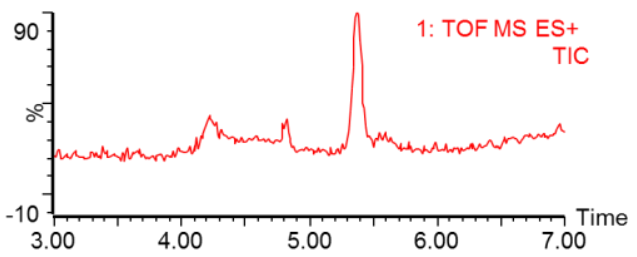

(iii)

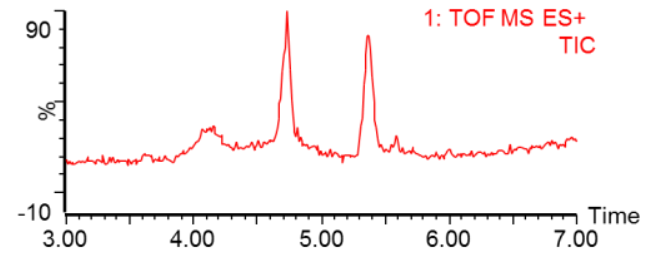

B)

(i)

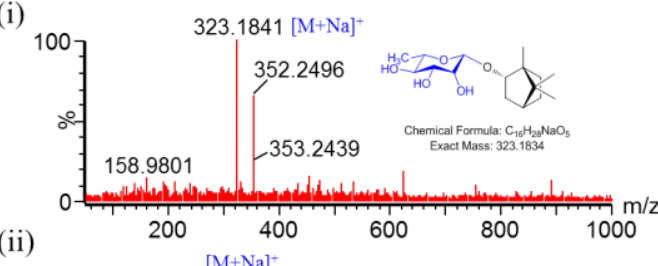

(ii)

(iii)
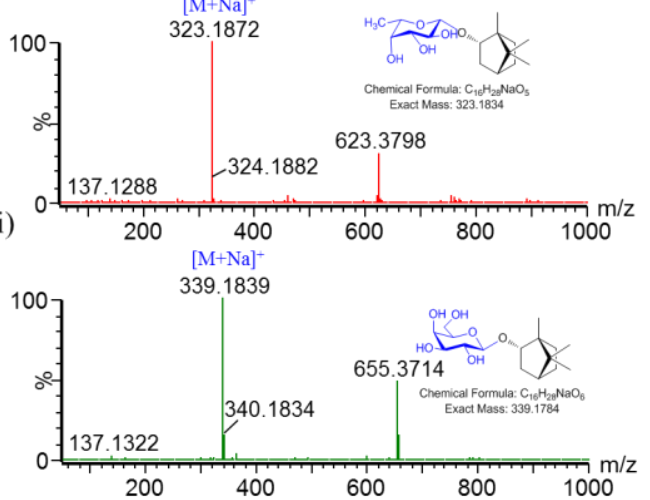

(iv)

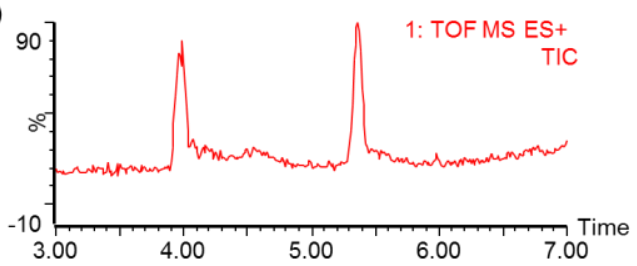

(v)

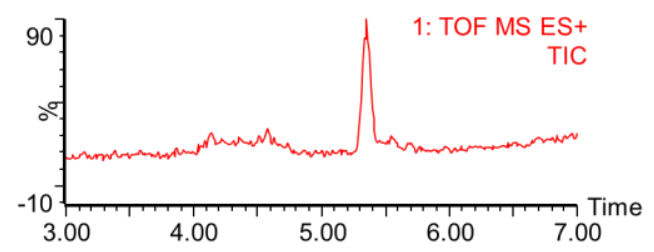

(vi)

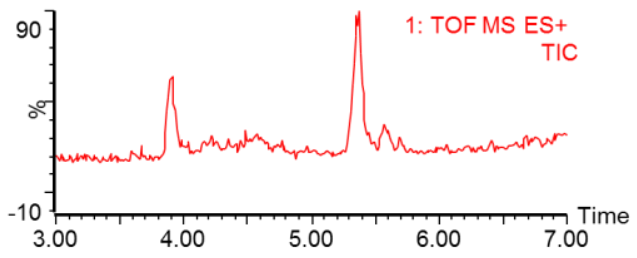

(iv)

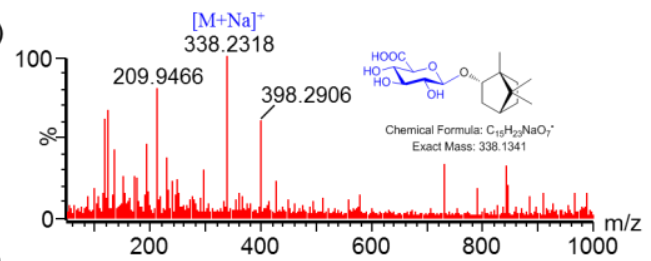

(v)

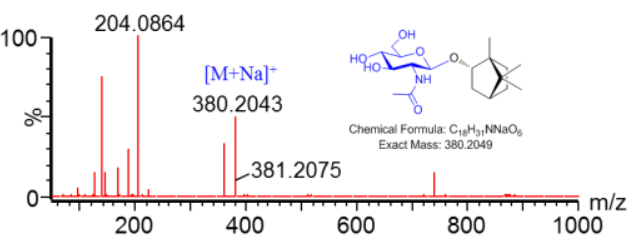

Figure S22. Spectrometric analysis of glycosylation reaction of 7 with different NDP-sugars. A) ) HR-QTOF-ESI/MS total ion chromatogram (TIC) of glycosylation reaction of 7 with i) UDP$N$-acetyl-galactosamine, ii) TDP-L-rhamnose, iii) GDP-L-fucose, iv) UDP-D-Galactose, v) UDPD-glucuronic acid, and vi) UDP- $N$-acetyl-glucosamine. B) HR-QTOF-ESI/MS of product peak of reaction mixture of 7 with i) TDP-L-rhamnose, ii) GDP-L-fucose, iii) UDP-D-galactose, iv) UDP-D-glucuronic acid, and v) UDP- $N$-acetyl-glucosamine. 


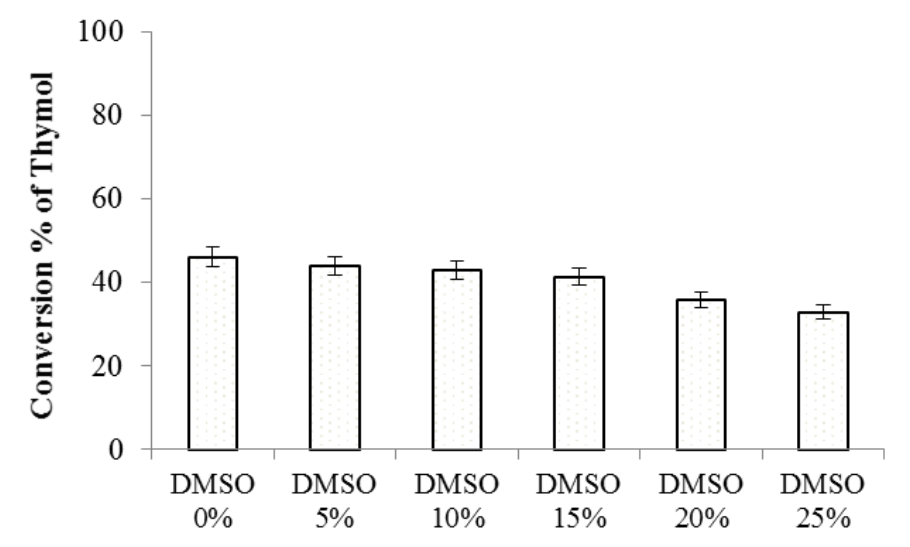

Final DMSO \% in reaction mixture

Figure S23. The enzyme activity for conversion of $\mathbf{2}$ to $\mathbf{2 a}$ was checked in the presence of different concentration of co-solvent such as dimethyl sulfoxide (DMSO).

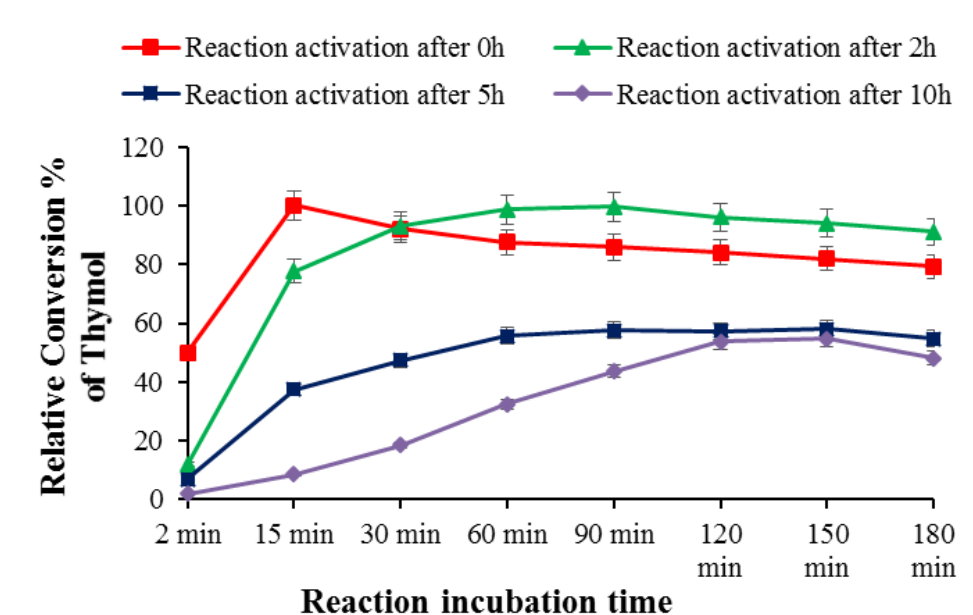

Figure S24. Enzyme stability test. The stability of the enzyme activity under the reaction condition was checked after activating the reaction mixture by adding donor and acceptor substrates at different time interval. After activating the reaction, samples were taken at (2-180) min interval and relative conversion $\%$ of thymol was determined. 


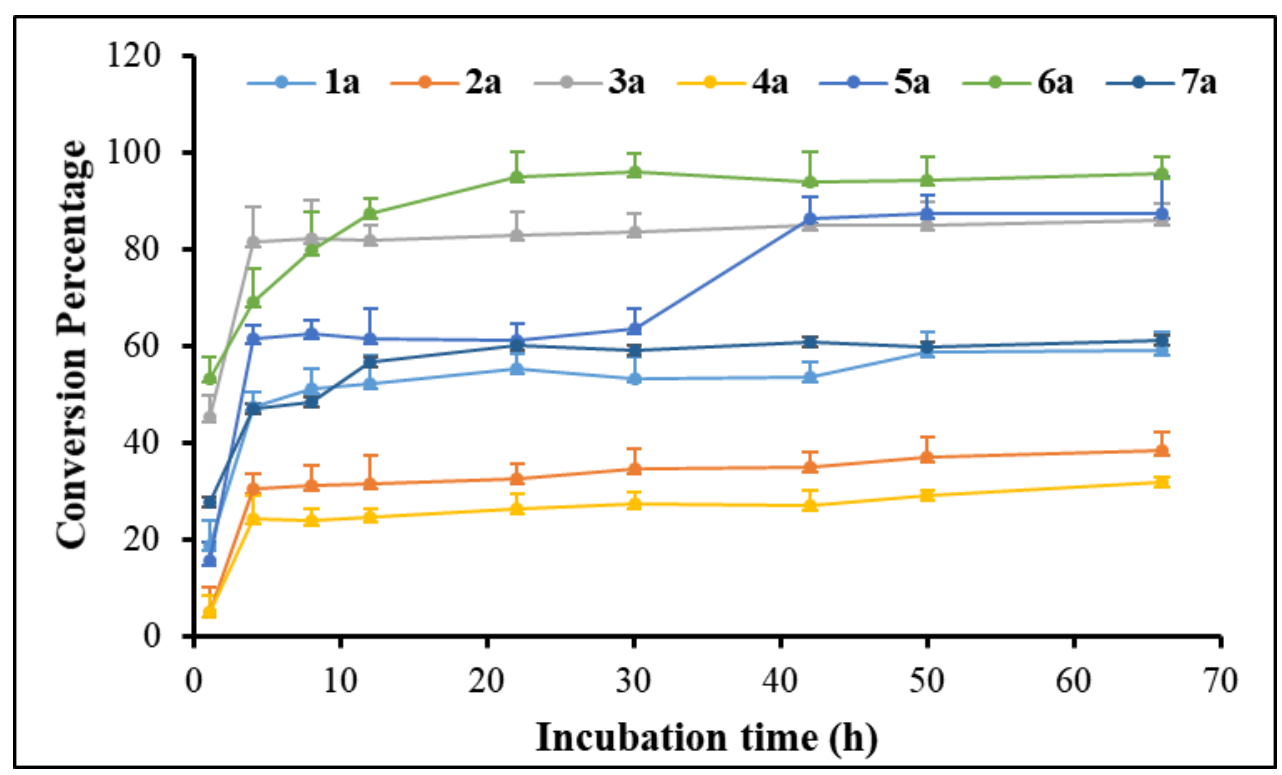

Figure S25. In vivo conversion percentage of monoterpenes into respective glucosides using whole cells of $E$. coli BL21 (DE3) harboring pET28-YjiC at different time interval. The conversion of all monoterpenes was checked at $0.5 \mathrm{mM}$ final concentration. No additional glucose was supplemented into the medium. 

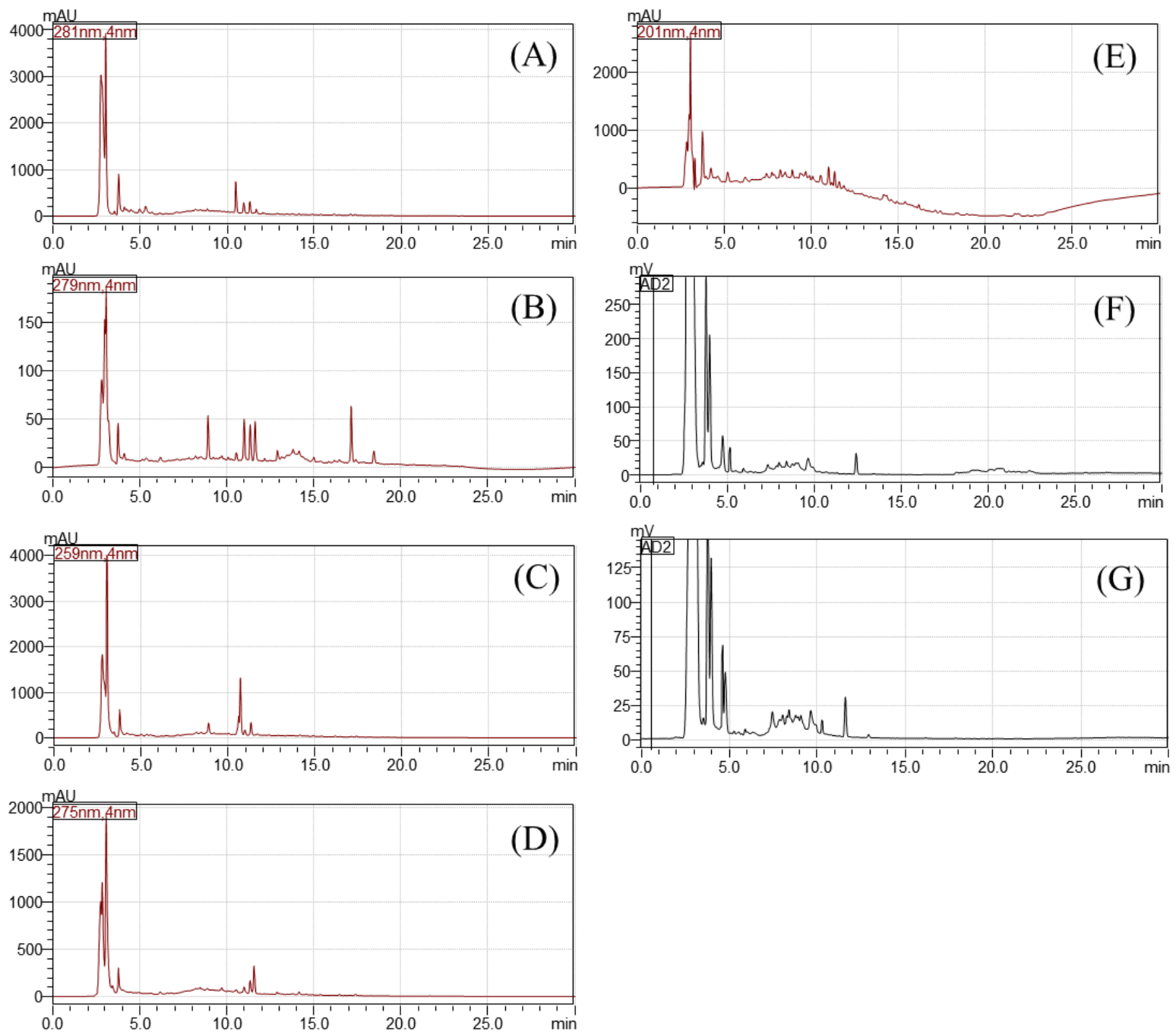

Figure S26. HPLC-PDA (A-E) and HPLC-ELSD (F-G) analysis of cell lysate extracts of in vivo biotransformed cells. A-G) biotransformation of 1-7, respectively. 


\section{References}

1. Pandey, R. P.; Li, T. F.; Kim, E. H.; Yamaguchi, T.; Park, Y. I.; Kim, J. S.; Sohng, J. K. Enzymatic synthesis of novel phloretin glucosides. Appl. Environ. Microbiol. 2013, 79, 3516-3521.

2. Wiegand, I.; Hilpert, K.; Hancock, R. E. W. Agar and broth dilution methods to determine the minimal inhibitory concentration (MIC) of antimicrobial substances. Nat. Protoc. 2008, $3,163-175$. 